\title{
WestVirginiaUniversity
}

THE RESEARCH REPOSITORY @ WVU

Graduate Theses, Dissertations, and Problem Reports

2017

\section{Characterizing the Mechanisms of Insulin Resistance in Dairy Cattle}

Amanda Nicole Davis

Follow this and additional works at: https://researchrepository.wvu.edu/etd

\section{Recommended Citation}

Davis, Amanda Nicole, "Characterizing the Mechanisms of Insulin Resistance in Dairy Cattle" (2017). Graduate Theses, Dissertations, and Problem Reports. 7075.

https://researchrepository.wvu.edu/etd/7075

This Thesis is protected by copyright and/or related rights. It has been brought to you by the The Research Repository @ WVU with permission from the rights-holder(s). You are free to use this Thesis in any way that is permitted by the copyright and related rights legislation that applies to your use. For other uses you must obtain permission from the rights-holder(s) directly, unless additional rights are indicated by a Creative Commons license in the record and/ or on the work itself. This Thesis has been accepted for inclusion in WVU Graduate Theses, Dissertations, and Problem Reports collection by an authorized administrator of The Research Repository @ WVU. For more information, please contact researchrepository@mail.wvu.edu. 


\title{
CHARACTERIZING THE MECHANISMS OF
}

INSULIN RESISTANCE IN DAIRY CATTLE

\author{
AMANDA NICOLE DAVIS, B.S.
}

\section{THESIS}

Submitted

to the Davis College of Agriculture, Natural Resources and Design at West Virginia University

\author{
In partial fulfillment of the requirements for the degree of \\ Master of Science in \\ Animal Physiology \\ Joseph W. McFadden, Ph.D. \\ Scott A. Bowdridge, Ph.D. \\ K. Marie Krause, Ph.D \\ Division of Animal and Nutritional Sciences \\ Morgantown, West Virginia \\ 2017
}

Keywords: dairy cow, insulin sensitivity, ceramides

Copyright 2017 Amanda Davis 


\title{
ABSTRACT
}

\section{CHARACTERIZING THE MECHANISMS OF}

\section{INSULIN RESISTANCE IN DAIRY CATTLE}

\begin{abstract}
Amanda N. Davis
Dairy cows transitioning from gestation to lactation experience insulin resistance as maternal adaptation to partition nutrients toward the mammary gland to support milk production. Insulin resistance causes increased lipolysis and free fatty acid (FFA) release into circulation.

Unfortunately, this metabolic adaptation occurs during a time when energy demands are heightened and cows are already experiencing negative energy balance. As a result, accelerated hepatic FFA influx promotes hepatic triacylglycerol (TAG) accumulation and ketogenesis, which can cause postpartum metabolic disease. In diabetic monogastrics, mechanisms that mediate insulin resistance involve the sphingolipid ceramide. The role of ceramide in insulin signaling in dairy cows transitioning from gestation to lactation has not been previously established. The studies presented in this master of science thesis evaluate the relationship between fatty acid availability, ceramide synthesis, and insulin sensitivity. In the first experiment, we tested the hypothesis that ceramide accumulates in dairy cows experiencing lipolysis and insulin resistance. We show that nutrient restriction (NR) increased serum fatty acids and ceramide levels, and impaired insulin sensitivity; however, infusion with nicotinic acid (NA), a known suppressor of lipolysis, was unable to prevent these responses. We also showed that NR increased hepatic ceramide accumulation, a response that was positively associated with serum ceramide supply. Our data demonstrate that circulating and hepatic 24:0-Cer are inversely associated with systemic insulin tolerance, an effect not observed for the 16:0 moiety. In the second experiment, our objective was to characterize relationship between prepartum adiposity and insulin sensitivity in dairy cows transitioning from gestation to lactation. Our data demonstrate that during the periparturient period, FFA, BHBA, and liver lipid increase, more so for overweight cows. While plasma glucose and serum insulin were not affected by adiposity, serum insulin concentrations decreased postpartum. Using a hyperinsulinemic-euglycemic clamp (HEC) technique to directly measure insulin sensitivity, we show that steady state serum glucose, insulin, and FFA levels were not modified by adiposity. HEC glucose infusion rate was not affected by adiposity, but systemic insulin resistance developed in overweight cows postpartum when accounting for changes in insulin and glucose. Insulin-stimulated phosphorylation of subcutaneous adipose tissue AKT was not modified by adiposity, but AKT phosphorylation significantly decreased from pre- to postpartum. Collectively, these data demonstrate that adiposity does not affect adipose tissue-specific insulin signaling, even though it did impair insulin sensitivity as indicated by the $\mathrm{SI}_{\text {Clamp. }}$.
\end{abstract}


This thesis is dedicated to my mother, father, brother, and family. 


\section{ACKNOWLEDGEMENTS}

I would like to thank Dr. Joseph McFadden for the opportunity to develop independence as a scientific researcher and writer and for encouraging me throughout my graduate program at West Virginia University. I gratefully acknowledge Alice Mathews, William A. Myers III, Zachary Phipps, J. Eduardo Rico, Sina Saed Samii, Yu Zang, Mary Clapham, Mary Coleman, the farm staff from West Virginia University, and the VanGilder family at DoVan Farms for their

participation. This work was supported by Agriculture and Food Research Initiative Competitive Grant no. 2014-67016-21611 and 2016-67015-24582 from the USDA National Institute of Food and Agriculture and the West Virginia University Ruby Distinguished Doctoral Fellows Program. I also thank Vetagro, S.p.A. (Reggio Emilia, Italy) for supplying the NA. 


\section{TABLE OF CONTENTS}

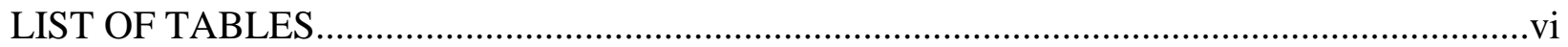

LIST OF FIGURES..........................................................................................................

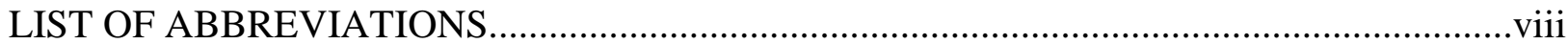

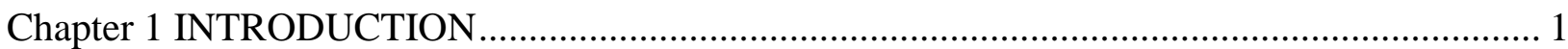

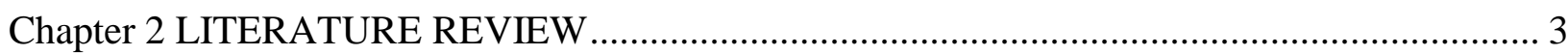

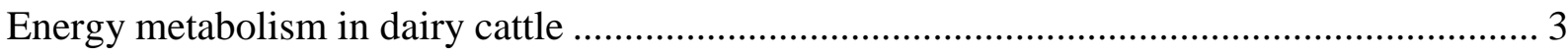

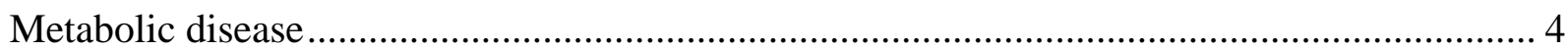

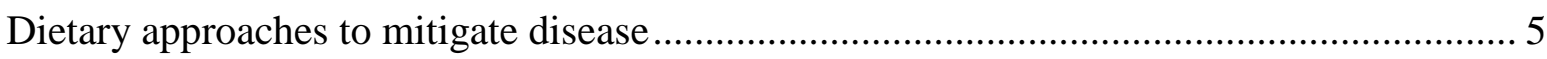

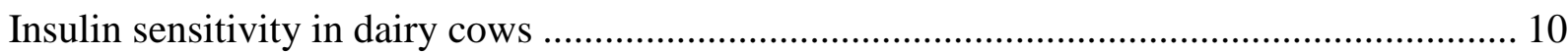

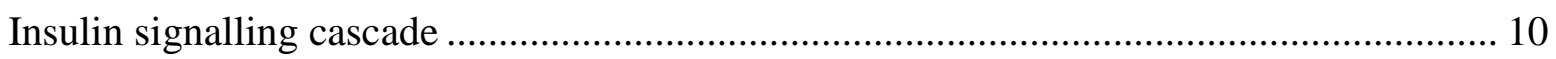

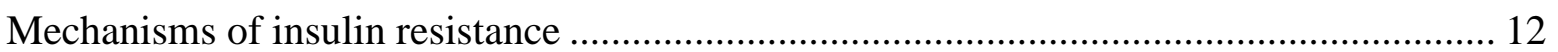

Potential role of ceramide as a mediator of insulin resistance............................................ 14

Chapter 3 NUTRIENT RESTRICTION INCREASES CERAMIDE IN DAIRY COWS .......... 18

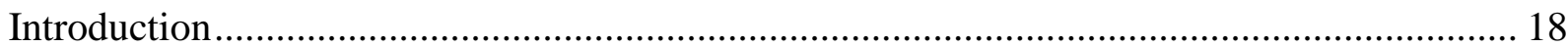

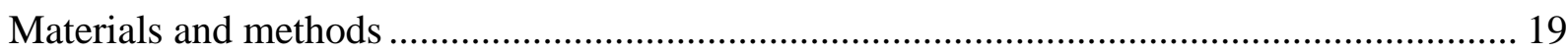

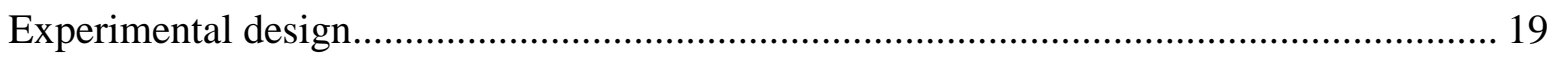

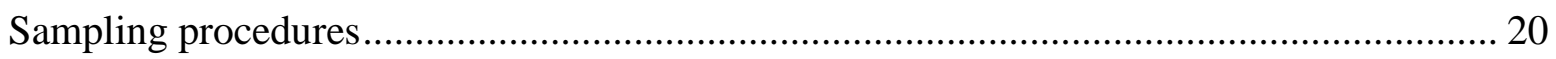

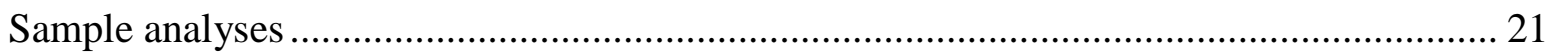

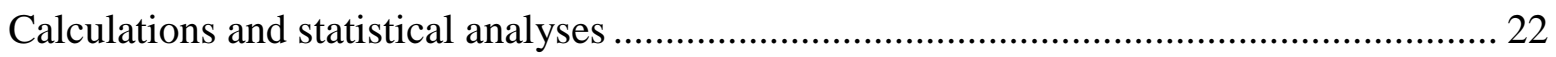

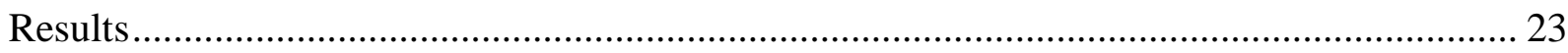

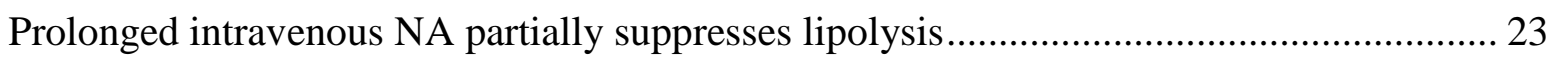

Nutrient restriction increases serum and hepatic ceramide............................................... 24

Ceramides are inversely related to insulin tolerance .......................................................... 24

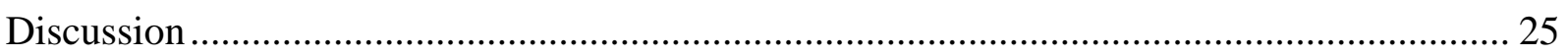

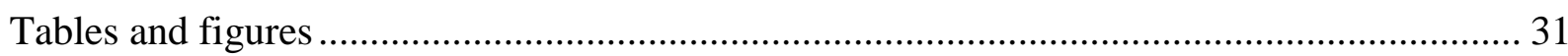

Chapter 4 THE EFFECTS OF PREPARTUM ADIPOSITY IN LOCALIZED AND SYSTEMIC INSULIN SENSITIVITY ON PERIPARTURIENT HOLSTEIN DAIRY COWS ..................... 41

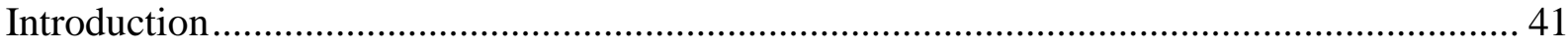

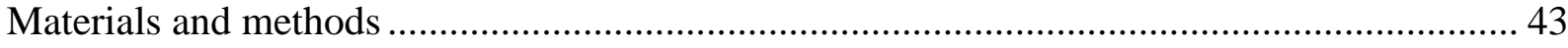

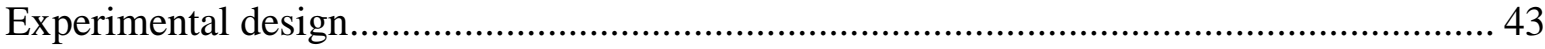

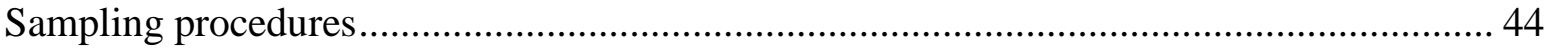

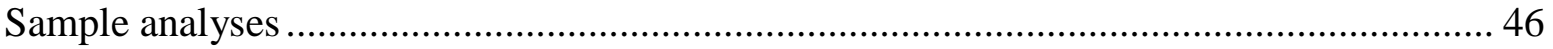

Calculations and statistical analyses ………………….................................................... 47 


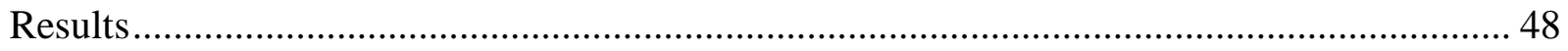

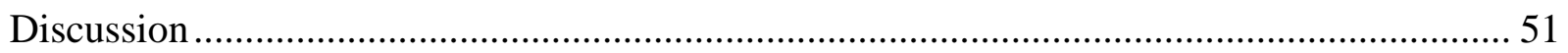

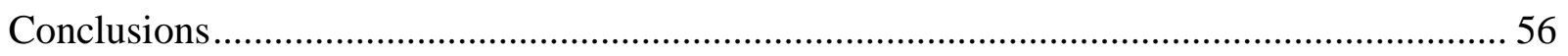

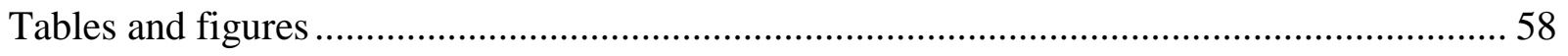

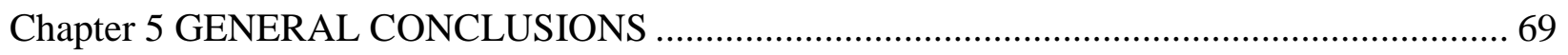

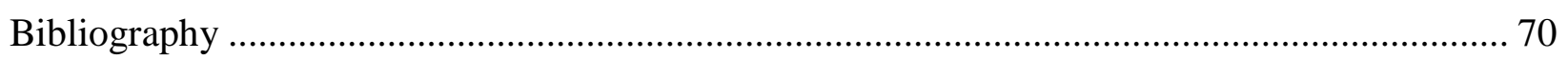




\section{LIST OF TABLES}

Table 3.1. Ingredients and nutrient composition (\% of DM unless otherwise noted) of experimental diet when offered. 31

Table 4.1. Feed ingredients and composition (\% of DM unless otherwise noted) for all cows

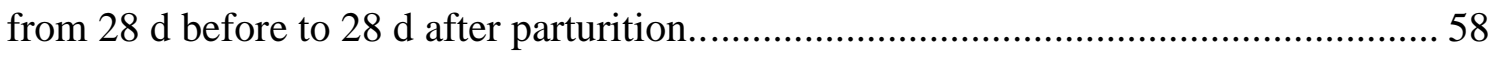

Table 4.2. Metabolic responses to hyperinsulinemic-euglycemic clamp. 59

\section{LIST OF FIGURES}

Figure 3.1. Intravenous infusion of nicotinic acid (NA) partially suppresses lipolysis in nutrientrestricted (NR) dairy cows.. 35

Figure 3.2. Circulating TAG, glucose, and total cholesterol concentrations in dairy cows ad libitum fed, nutrient-restricted (NR), or NR plus nicotinic acid infusion (NR + NA)... 36

Figure 3.3. Nutrient restriction increases circulating ceramide in dairy cows.......................... 37

Figure 3.4. Nutrient restriction increases hepatic ceramide in dairy cows. .............................. 48

Figure 3.5. Nutrient restriction decreases insulin sensitivity in dairy cows. ............................ 39

Figure 3.6. Very long chain ceramides are inversely related to insulin tolerance in dairy cows. 40

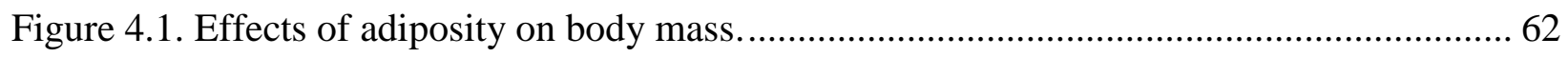

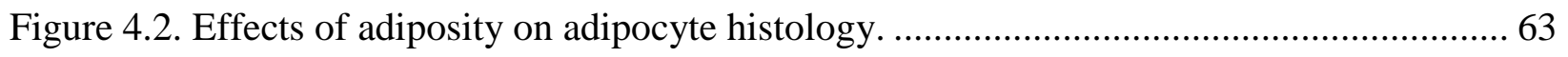

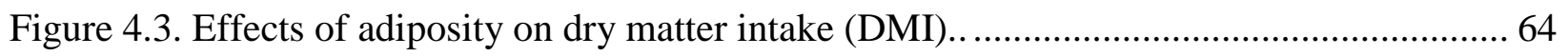

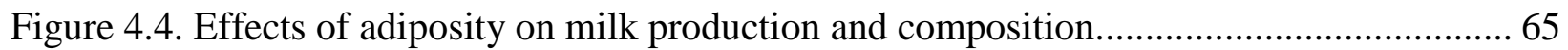

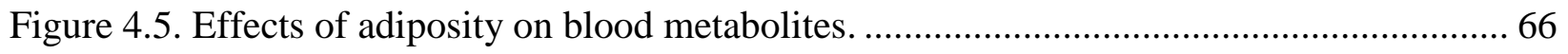

Figure 4.6. Effects of adiposity on (A) liver lipid percentage and (B) plasma BHBA

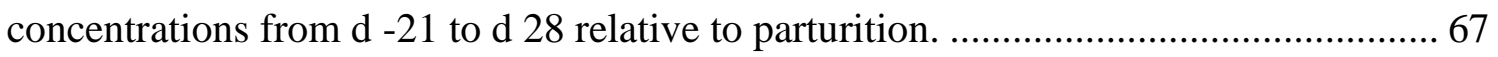

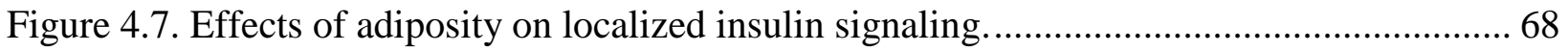




\section{LIST OF ABBREVIATIONS}

\begin{tabular}{|c|c|}
\hline AA & amino acids \\
\hline $\mathrm{AKT}$ & Protein kinase B \\
\hline AUC & area under the curve \\
\hline BCS & Body condition score \\
\hline BHBA & $\beta$-hydroxybutyrate \\
\hline $\mathrm{bST}$ & Bovine somatotropin \\
\hline $\mathrm{BW}$ & body weight \\
\hline $\mathrm{Ca}$ & Calcium \\
\hline cAMP & Cyclic adenosine monophosphate \\
\hline Cer & ceramide \\
\hline $\mathrm{CHO}$ & Carbohydrate \\
\hline $\mathrm{CR}$ & clearance rate \\
\hline DMI & Dry matter intake \\
\hline FA & Fatty acids \\
\hline FFA & Free fatty acids \\
\hline $\mathrm{GH}$ & Growth hormone \\
\hline GLUT4 & Glucose transporter 4 \\
\hline GTT & Glucose tolerance test \\
\hline $\mathrm{HEC}$ & Hyperinsulinemic-euglycemic clamp \\
\hline HSL & Hormone sensitive lipase \\
\hline IGF-1 & Insulin-like growth factor-I \\
\hline IRS & Insulin receptor substrate \\
\hline
\end{tabular}


ITT Insulin tolerance test

NA nicotinic acid

NEB Negative energy balance

$\mathrm{NE}_{\mathrm{L}} \quad$ Net energy of lactation

NFC Non-fiber carbohydrate

NR nutrient-restricted

PDE3B Phosphodiesterase 3B

PGF2 $\alpha \quad$ Prostaglandin $\mathrm{F}_{2 \alpha}$

PI3K Phosphatidylinositol 3-kinase

$\mathrm{PIP}_{2} \quad$ Phosphatidylinositol 4,5-bisphosphate

$\mathrm{PIP}_{3} \quad$ Phosphatidylinositol 3,4,5-triphosphate

pAKT/tAKT Ratio of phosphorylated protein kinase B to total protein kinase B

PKA Protein kinase A

PO Palm oil

SFA Saturated fatty acids

SFL Safflower oil fatty acids

SMase Sphingomyelinase

SO Safflower oil

SPT Serine palmitoyl transferase

SubqAT Subcutaneous adipose tissue

TAG Triacylglycerol

$t$ FA trans-octadecenoic fatty

TMR Total mixed ration 
VLDL Very low density lipoprotein 


\section{Chapter 1}

\section{INTRODUCTION}

Due to intense genetic selection, milk production per cow has risen dramatically over the last century, with cows producing 20,000 $\mathrm{kg}$ of milk per lactation (Oltenacu and Broom, 2010). This dramatic increase in milk production has been accompanied by a decrease in fertility, an increase in the incidence of metabolic disease, and a decrease in longevity of the cow (Oltenacu and Broom, 2010). Specifically, these detrimental consequences can be attributed to the metabolically challenging transition from gestation to lactation. During the peripartum, the dairy cow experiences a coordinated shift in metabolism to divert energy away from maternal utilization, and toward the mammary gland to support copious milk production (Bell and Bauman, 1997). Unfortunately, the periparturient cow cannot meet the energy demands of lactation and in turn the animal relies extensively on catabolism to meet energy requirements (Bauman and Currie, 1980).

The pancreatic hormone insulin plays a fundamental role in regulating metabolic changes that develop during the peripartum. Resistance by peripheral tissues to the insulin signal facilitates partitioning of nutrients (e.g., glucose and fatty acids) to the mammary gland to support milk synthesis (Hart, 1983). Because insulin is an anti-lipolytic hormone, insulin resistance can lead to mobilization of adipose triacylglycerol (TAG) reserves as an adaptation to meet energy demand. Moreover, reduction in glucose uptake by skeletal muscle and adipose tissue spares glucose for mammary lactose synthesis (Bauman and Currie, 1980; Bell, 1995; Bell and Bauman, 1997). The magnitude of insulin resistance may be heightened by adiposity (Zachut et al., 2013). Overconditioned cows experience exacerbated lipolysis during the peripartum, 
which can increase risk of developing a metabolic disease (i.e., fatty liver or ketosis) and negatively impact reproductive success.

Characterizing mechanisms of insulin resistance during energy deficit or in cows with enhanced peripartal adiposity is needed to develop practical nutrition and management practices to control insulin action and maximize cow health. In diabetic monogastrics with non-alcoholic fatty liver disease, mechanisms of insulin resistance involve the sphingolipid ceramide (Holland and Summers, 2008). Ceramide represents a lipid mediator that reduces insulin sensitivity in part by inhibiting activation of protein kinase B (AKT) within the insulin signaling cascade (Powell et al., 2003; Hajduch et al., 2008). Although previous work has demonstrated that hepatic and circulating ceramide increases during the transition from gestation to lactation in cows (Rico et al., 2015; Rico et al., 2016; Mathews et al., 2016), the effects of energy deficit on ceramide accrual remained undefined in dairy cattle; therefore, the hypotheses of these studies were that hepatic and circulating ceramide increases in association with controlled feed-restriction and insulin antagonism and that prepartum adiposity reduces systemic and localized insulin sensitivity via AKT-dependent mechanisms. 


\section{Chapter 2}

\section{LITERATURE REVIEW}

\section{Energy Metabolism in Dairy Cows}

Dairy cows transitioning from gestation to lactation are challenged by increased energy requirements for fetal growth and milk production during a time when energy intake is suppressed. Onset of energy deficit begins three weeks prior to parturition, and as parturition approaches, maternal dry matter intake (DMI) decreases by 10 to $30 \%$ (Bell, 1995). Immediately following parturition, net energy for lactation $\left(\mathrm{NE}_{\mathrm{L}}\right)$ and metabolizable protein required for milk production exceeds intake by 26 and 25\%, respectively (Bell, 1995). Considering that the mammary gland uses 97 and $83 \%$ of the consumed $\mathrm{NE}_{\mathrm{L}}$ and metabolizable protein, respectively (Bell, 1995), energy deficit can have detrimental consequences on milk synthesis. Because the peripartal cow experiences high nutrient demand, a physiological state of negative energy balance (NEB) develops. To meet the heightened demand for energy, the cow will mobilize energy stores including triacylglycerol (TAG), protein, and glycogen. As lactation advances, intake is restored, energy balance improves, and energy stores are repleted.

The onset of lactation is characterized by homeorhetic adaptations that facilitate the partitioning of nutrients away from maternal utilization and toward the mammary gland for milk component synthesis. First, the mammary gland uses glucose for synthesis of lactose, the major osmotic regulator of milk volume. To ensure adequate glucose delivery to the mammary gland, hepatic gluconeogenesis increases (Reynolds et al., 2003) and oxidation of glucose by peripheral tissues decreases (Bennink et al., 1972). Substrates for gluconeogenesis include propionate from microbial fermentation in the rumen, lactate from the Cori cycle, amino acids (AA; e.g. alanine) from protein catabolism, and glycerol mobilized from adipose tissue TAG (Seal and Reynolds, 
1993). The cow relies predominantly on propionate as a substrate for gluconeogenesis; however the contribution from glycerol increases during energy deficit and associated adipose tissue mobilization (Lomax et al., 1983; Aschenbach et al., 2010). Furthermore, peripartal glucose uptake by skeletal muscle and adipose tissue is decreased because of the development of localized insulin resistance, thereby facilitating glucose uptake by the mammary gland in an insulin-independent manner (Bell and Bauman, 1997; De Koster and Opsomer, 2013). Development of insulin resistance also partitions free fatty acids (FFA) to the mammary gland for their re-esterification into milk fat TAG. (McNamara and Hillers, 1986; Zachut et al., 2013). Noticeable increases in milk fat yields and content are observed immediately postpartum, relative to mid or late lactation. Additionally, circulating FFA are used for $\beta$-oxidation in peripheral tissues and hepatic ketogenesis. Beyond peak milk production, insulin sensitivity in peripheral tissues is restored to partition glucose toward skeletal muscle and adipose tissue, and away from the mammary gland (McNamara and Hillers, 1986; Bell and Bauman, 1997). As a consequence, nutrients are diverted towards body tissue accretion and the developing fetus as positive energy balance is reestablished.

\section{Metabolic Disease}

In dairy cows, negative energy balance can promote the development of metabolic disease during the peripartum. A hallmark characteristic of metabolic impairment is accumulation of fat in liver tissue (i.e., fatty liver disease). Although FFA can be oxidized in liver, fatty liver develops because of increased FFA esterification in response to elevated FFA uptake (Pullen et al., 1989; Reynolds et al., 2003). Moreover, hepatic TAG export within very low density lipoprotein (VLDL) is much lower in ruminants compared to nonruminants (Pullen et al., 1990). Therefore, when the rate of hepatic FFA influx exceeds the rate of oxidation and 
export during the peripartum, liver lipid accumulation ensues (Hocquette and Bauchart, 1999).

The low secretion of VLDL from the liver may be due to limited availability of VLDL components (Bauchart et al., 1996). Such components may include apolipoproteins, cholesterol, or phosphatidylcholines (Bernabucci et al., 2004; Loor et al., 2007; Kessler et al., 2014).

In addition to hepatic TAG accumulation, excessive oxidation of fatty acids can contribute to rampant ketogenesis (i.e., the production of acetoacetate, acetone, and $\beta$ hydroxybutyrate (BHBA) from acetyl-CoA). In turn, elevated levels of ketones promote clinical and subclinical ketosis (Esposito et al., 2014). Furthermore, fatty liver disease can interfere with hepatic gluconeogenesis by limiting transformation of propionate to glucose in part by inhibiting the vitamin $\mathrm{B}_{12}$-dependent enzyme methylmalonyl-coA mutase (Piepenbrink and Overton, 2003b; McDowell, 2000; Preynat et al., 2010). Fatty liver disease and ketosis are linked with immunosuppression, which is likely a cause of retained placenta (Ingvartsen et al., 2003) and environmental mastitis (Mallard et al., 1998). Moreover, cows that experience retained placenta often develop metritis and become infertile (Coleman et al., 1985). Other disorders associated with NEB and poor hepatic health include displacement of the abomasum, metritis, and milk fever (Le Blanc et al., 2005a, b). Collectively, the onset of these metabolic diseases can compromise milk production and fertility that can result in enhanced veterinary costs and culling rates (Wathes et al., 2007). Therefore, novel nutritional strategies are needed to improve bovine energy status and hepatic health during the peripartum.

\section{Dietary approaches to mitigate disease}

Pregnant cows fed in nutrient excess are susceptible to body fat accumulation (Morrow, 1976; Roche et al., 2013), which can cause a more severe decrease in DMI around calving thereby contributing to excessive adipose tissue lipolysis (Rico et al., 2015; Holtenius et al., 
2003; Holtenius et al., 2007). Lean cows [body condition score (BCS) of 2-2.5; Wildman et al., 1982] tend to have higher DMI and milk yield postpartum than cows with excessive adiposity (BCS of 3.5 to 4; Garnsworthy and Topps 1982a, 1982b; Treacher et al., 1986; Garnsworthy and Jones, 1987). Moreover, an elevated calving and early lactation BCS are associated with an increased incidence of ketosis (Gillund et al., 2001), milk fever (Roche and Berry, 2006), and fatty liver (Drackley, 1999). Cows that exhibit a greater BCS loss during the early postpartum ( $\geq$ 1.25 points) are half as likely to conceive at first insemination and thus have a longer calving to conception interval (Gillund et al., 2001). Considering this evidence, dairy producers are encouraged to manage cattle to achieve a BCS of 3.0 to 3.25 at dry off ( 40 to $60 \mathrm{~d}$ prepartum; Contreras et al., 2004; Gillund et al., 2001).

Controlling prepartum adiposity can be achieved by limiting dietary energy intake. Douglas and colleagues (2006) fed moderate grain- or fat-supplemented diets (1.50 Mcal of $\mathrm{NE}_{\mathrm{L}} / \mathrm{kg}$ ) from dry off (60 days before expected parturition) to calving at either ad libitum (160\% of $\mathrm{NE}_{\mathrm{L}}$ requirement) or restricted (80\% of $\mathrm{NE}_{\mathrm{L}}$ requirement) intakes. During the first 21 days in milk, cows previously energy-restricted had higher intakes of DMI and NEL. Relative to ad libitum feeding, nutrient restriction reduced plasma concentrations of FFA and BHBA, and liver concentrations of total lipid and TAG postpartum. In support of this work, Dann and coworkers (2006) found similar metabolite responses postpartum when comparing a high plane (150\% of NRC energy requirements) versus a low plane of nutrition ( 80 or $100 \%$ or NRC requirements) during the early dry period (from dry-off to $-25 \mathrm{~d}$ relative to expected parturition). Interestingly, plane of nutrition during the close-up period (three weeks prepartum) did not affect these parameters postpartum (Dann et al., 2006). Moreover, Mann and coworkers (2015) examined the effects of feeding a high fiber, controlled-energy diet for the dry period duration (100\% of 
energy requirements; starting 57 days before expected parturition) versus a high-non-fiber carbohydrate (NFC), high-energy- diet (150\% of energy requirements). A third treatment group received the high energy diet for the first 28 days after dry off followed by an intermediate diet containing $125 \%$ of energy requirements until calving. They found that cows fed a high plane of nutrition had higher circulating BHBA and FFA, and more severe NEB postpartum. The controlled-energy diet improved energy balance as well as lowered the frequency and severity of hyperketonemia postpartum. More so, switching from a high-energy diet to an intermediateenergy diet during the close-up period did not completely ameliorate negative effects of feeding a high-energy diet for the duration of the dry period.

Although restricting energy for the entire dry period appears to benefit cow health and milk production, some evidence supports feeding a higher energy diet for two to three weeks before calving (Mashek and Beede, 2001; Corbett, 2002; Contreras et al., 2004), a response that is likely due to the source of dietary carbohydrate (CHO) fed. Specifically, the concentration of non-fiber $\mathrm{CHO}$ (NFC; e.g., highly digestible sugars and starch) and neutral detergent fiber (NDF; e.g., cellulose, hemicellulose, and lignin) can influence microbial fermentation and volatile fatty acid production. Volatile fatty acids (e.g., propionate, butyrate, and acetate) are essential energy sources derived from rumen microbial fermentation of CHO (Bergman, 1990; Nafikov and Beitz, 2007). Undoubtedly, energy density of the postpartum diet must be increased to meet the demand of lactation. However, a sudden increase in dietary energy density from highly fermentable NFC may lead to subacute ruminal acidosis due to lactate accumulation, which can decrease DMI, contribute to NEB and thus FFA mobilization and hepatic lipid deposition (Ingvartsen et al., 2006; Mulligan and Doherty, 2008). Using close-up diets containing increased levels of starch has been suggested to allow the rumen to adapt to a high-grain diet before the onset of lactation. 
A number of studies have reported positive effects on metabolism postpartum after feeding a higher concentration of NFC prepartum (reviewed by Overton and Waldron, 2004). For example, Minor and coworkers (1998) found that cows fed a high NFC diet for 19 days before calving had higher plasma glucose concentrations and lower FFA and BHBA concentrations, reduced liver lipid accumulation, and higher milk production than cows fed a low NFC diet. However, it is difficult to attribute changes in metabolic health postpartum to dietary $\mathrm{CHO}$ source prepartum because most experiments examining the effects of NFC content of the prepartum diet have confounding effects due to either energy content (Minor et al., 1998; Mashek and Beede, 2000; Holcomb et al., 2001) or fat content (Grum et al., 1996). Smith and coworkers $(2005,2008)$ examined the effects of NFC content in prepartum diets independent of dietary energy or fat content. They offered cows one of two diets from day -21 relative to parturition until calving containing either high NFC ( $40.3 \%$ of dry matter) or low NFC (33.6\% of dry matter). Milk yield and dry matter intake were not affected by prepartum NFC source (Smith et al., 2005). Cows fed the high NFC diet tended to have lower plasma FFA concentrations postpartum. However, cows on this diet also tended to have higher BHBA and lower liver glycogen concentrations (Smith et al., 2008) making interpretation challenging. Collectively, feeding high-energy diets for the entirety of the dry period has negative effects on health and milk production, and feeding a low plane of nutrition for the dry period duration is recommended to minimize the incidence of postpartum metabolic disease; however, more research is needed to determine the balance of NFC and energy necessary during the closeup period to improve metabolic health during the early postpartum.

Dietary fats may also affect metabolism and reproduction during the peripartum, and fat supplementation represents a common practice on dairy farms. Feeding fat supplements that can 
suppress milk fat production during the early postpartum period may help to minimize NEB, reduce adipose tissue mobilization, and improve fertility. For example, Caldari-Torres and colleagues (2011) examined the effects of feeding diets enriched in either saturated fatty acids (SFA), calcium (Ca) salts of trans-octadecenoic fatty acids ( $t \mathrm{FA})$, or Ca salts of safflower oil fatty acids (SFL) starting 28 days before expected parturition on performance, metabolic, and endocrine responses. Cows fed SFL produced less milk fat and entered positive energy balance sooner after parturition than those fed $t$ FA. Furthermore, plasma FFA concentrations were lower in cows fed the SFL diet than in those consuming the $t$ FA diet. Moreover, plasma glucose, insulin-like growth factor-I (IGF-I), and progesterone were greater in animals fed the SFLenriched diet compared with those fed SFA, reflecting improved energy balance and potential corpus luteum development. Altering the ratio of dietary n-6 to n-3 fatty acids (FA) during the peripartum can influence the release of prostaglandin $\mathrm{F}_{2 \alpha}(\mathrm{PGF} 2 \alpha)$, an eicosanoid that controls the lifespan of the corpus luteum and might influence the retention of fetal membranes (Santos et al., 2008). Petit and coworkers (2004) showed that feeding n-6 FA resulted in increased circulating $\mathrm{PGF}_{2 \alpha}$ following an oxytocin challenge early postpartum (Petit et al., 2004), while feeding n-3 FA has been shown to reduce $\mathrm{PGF}_{2 \alpha}$ production after an oestradiol/oxytocin challenge (Mattos et al., 2002). Furthermore, Silvestre and colleagues (2011) examined the effect of feeding Ca-salts of palm oil (PO; low in n-6 and n-3 FA) or safflower oil (SO; high in n-6 FA) from 30 days prepartum to 30 days postpartum, followed by feeding Ca-salts of PO or fish oil (high in n-3 FA) from 30 to 160 days postpartum. They found that supplementation of n-3 FA decreased pregnancy loss from the first artificial insemination and increased second service pregnancy per service. This effect was enhanced when cows were fed n-6-enriched diets during the transition period. The combination of feeding n-6 FA during the transition period followed 
by feeding n-3 FA during the breeding period represented the best combination of FA supplementation. Silvestre and coworkers (2011) suggested that n-3 FA increases the concentrations of eicosapentaenoic and docosahexaenoic acids in the caruncular and endometrial tissues, which competitively inhibit arachidonic acid from producing $\mathrm{PGF}_{2 \alpha}$, thus delaying luteolysis (Mattos et al., 2000; 2003; 2004).

Collectively, current research supports that to maintain postpartum metabolic health and milk production restriction of energy intake during the dry period is recommended to promote DMI and improve energy balance after calving. However, the short-term application of a moderate-starch diet immediately before expected calving can prepare the rumen for high energy early lactation diets. Finally, feeding polyunsaturated fatty acids during the postpartum may represent a method to improve metabolic health if compromised by energy impairments caused by prepartum overnutrition.

\section{Insulin Sensitivity in Dairy Cows}

\section{Insulin signaling cascade}

The insulin signaling transduction pathway has been extensively studied in monogastrics (Chavez and Summers, 2010). In the fed state, insulin stimulates uptake of glucose into insulinsensitive adipose and skeletal muscle tissues, and inhibits lipolysis (Duncan et al., 2007). The cascade of events begins with insulin binding to its receptor. The insulin receptor consists of two $\alpha$-subunits and two $\beta$-subunits linked by disulfide bonds. The $\alpha$-subunits are extracellular and contain an insulin binding site, while the cytosolic $\beta$-subunits are adjacent to the plasma membrane (Hedo and Simpson, 1984). When insulin binds to the $\alpha$-subunit, the $\beta$-subunits become activated by auto-phosphorylation of tyrosine residues (Kasuga et al., 1982; Ward and Lawrence, 2009). The $\beta$-subunit then recruits the insulin receptor substrate (IRS) protein and 
uses its tyrosine kinase activity to phosphorylate IRS on multiple tyrosine residues.

Phosphorylation of IRS signals for the recruitment and activation of phosphatidylinositol 3kinase (PI3K; Sun et al., 1993; Avruch, 1998). Phosphatidylinositol 3-kinase contains Srchomology-2 domains that bind to tyrosine-phosphorylated IRS, which then activates the catalytic subunit of PI3K (Myers et al., 1992; Virkamäki et al., 1999; Shaw, 2011). Activation of PI3K signals recruitment and phosphorylation of phosphatidylinositol 4,5-bisphosphate ( $\left.\mathrm{PIP}_{2}\right)$ to form phosphatidylinositol 3,4,5-triphosphate $\left(\mathrm{PIP}_{3}\right)$ at the plasma membrane. These phosphoinositides then recruit protein kinase B (AKT) to the plasma membrane, where it becomes phosphorylated on specific threonine and serine residues by phosphoinositide-dependent kinase-1 (PDK-1) and PDK-2, respectively (Saltiel and Kahn, 2001; Petersen and Shulman, 2006).

Protein kinase B can then mediate activation of lipogenesis, glycogen synthesis, and glucose uptake via translocation of the only insulin sensitive glucose transporter, GLUT4, to the plasma membrane (Bae et al., 2003), and inhibit gluconeogenesis and glycogenolysis through activation of glycogen synthase kinase-3 (Cross et al., 1995), AKT substrate 160 (Karlsson et al., 2005), and forkhead box protein 01 (Tzivion et al., 2011). Insulin's anti-lipolytic effect is also mediated by AKT. Specifically, insulin signaling activates phosphodiesterase 3B (PDE3B) via AKT-mediated phosphorylation of serine residue 273 (Degerman et al., 1998; Kitamura et al., 1999). When PDE3B is activated, it catalyzes hydrolysis of cyclic adenosine monophosphate (cAMP) to 5'AMP so that protein kinase A (PKA) activity is reduced (Manganiello et al., 1996; Degerman et al., 1997). Reduction in PKA leads to decreased activity of hormone-sensitive lipase and reduction in TAG hydrolysis (Eriksson et al., 1995; Beebe et al., 1985; Degerman et al., 1990). 


\section{Mechanisms of insulin resistance}

Besides insulin, other endocrine hormones such as glucagon, epinephrine, and GH play a role in coordinating the anabolic to catabolic shift in metabolism that accompanies the transition from gestation to lactation. First an increase in gluconeogenesis during lactation is promoted by glucagon and catecholamines. Glucagon enhances the supply of gluconeogenic precursors by mobilizing FFA and glycerol from adipose tissue, and catecholamines stimulate lactate production from muscle (Hart et al., 1983). Moreover, somatotropin (growth hormone, GH) is a known to inhibit insulin-stimulated glucose uptake and lipogenesis in adipose tissue (Bauman and Vernon, 1993). Under normal conditions, GH increases circulating concentrations of insulinlike growth factor I (IGF-I), which inhibits further production of GH by the pituitary gland (Bichell et al., 1992; Le Roith et al., 2001). The GH-IGF-I axis uncouples in the liver during high nutrient demand, as during the transition to lactation (Thissen et al., 1994), resulting in decreased IGF-I and increased GH in circulation (Taylor, 2004). Therefore, researchers hypothesized that GH is responsible for causing insulin resistance during early lactation (Bell and Bauman, 1997). This hypothesis was supported by the observation that chronic treatment of lactating dairy cows with bovine somatotropin (bST) decreased insulin-dependent GLUT4 mRNA expression in omental adipose tissue (Zhao et al., 1996). Moreover, bST administration reduced insulin receptor concentration and tyrosine kinase activity in skeletal muscle of rapidly growing lambs (Wilson et al., 1996), and lowered GLUT4 mRNA expression in lactating dairy cow muscle (Zhao et al., 1996). This hypothesis was further strengthened by the observation that bST administration had no effect on the abundance of GLUT1 mRNA, which is not insulinresponsive, in the mammary gland of lactating cows (Zhao et al., 1996). 
The transition from gestation to lactation is characterized by a dynamic change in metabolic regulation to support fetal growth and milk synthesis, and insulin certainly plays a major role to facilitate glucose partitioning towards the fetus and the mammary gland (Bauman Currie, 1980). The concentration and sensitivity to insulin decreases dramatically as lactation approaches (Bauman and Currie, 1980; Bell, 1995; Bell and Bauman, 1997). A decrease in circulating insulin concentration in part reduces insulin-stimulated glucose uptake. Also, the decrease in circulating insulin concentration is accompanied by a decrease in insulin sensitivity (i.e., increased insulin resistance) as a metabolic adaptation to lactation (Bell and Bauman, 1997; Kerestes et al., 2009). A reduction in insulin sensitivity increases hepatic gluconeogenesis and lipolysis to meet the demands of milk production. Moreover, the relationship between NEB and systemic insulin sensitivity is well established. For example, partial nutrient restriction or fasting decreases insulin-stimulated glucose clearance measured with an insulin tolerance test (ITT; Oikawa and Oetzel, 2006) or glucose tolerance test (GTT; Pires et al., 2007; Schoenberg et al., 2012), and insulin responsiveness is negatively correlated with circulating FFA (Oikawa and Oetzel, 2006). Furthermore, inducing hyperlipidemia in dairy cows by intravenous infusion of tallow emulsion can impair glucose clearance during a GTT or ITT, reflecting lower responsiveness to insulin during elevated hepatic FA influx (Pires et al., 2007a).

In monogastrics, molecular mechanisms of FFA-mediated insulin resistance are wellestablished. For example, administering saturated FFA to muscle cells decreases phosphorylation (i.e., activation) of AKT (Chavez et al., 2003). Additionally, elevation in FFA can result in serine (rather than tyrosine) phosphorylation of IRS-1, leading to disruption of downstream phosphorylation and insulin signal transduction (Le Marchand-Brustel et al., 2003). Also, protein kinase C- $\zeta$ activation serves as a negative regulator for AKT (Konishi et al., 1994; Doornbos et 
al., 1999). While changes in systemic insulin sensitivity during the peripartum is well established in dairy cows, molecular mechanisms contributing to insulin resistance in cows experiencing overnutrition are not well understood. It has been proposed that peripheral-tissue specific insulin resistance develops postpartum in cows prone to high weight loss, as evidenced by lack of phosphorylation of AKT in adipose tissue postpartum compared to prepartum (Zachut et al., 2013). However, recent evidence confounds this hypothesis. For example, Mann and colleagues (2016) measured phosphorylation of AKT and hormone sensitive lipase (HSL) in adipose tissue of cows overfed by $50 \%$ of requirements in the dry period compared to controls, and detected no differences between groups. This can potentially be explained by the fact that the high energy diet did not cause a significant increase in BCS compared to controls. They did observe phosphorylation of HSL is increased postpartum, which is supported by the work of Locher and coworkers (2011). They suggest the reason for an increase in circulating FFA postpartum in cows overfed prepartum is not due to changes in adipose tissue insulin signaling, but rather due to lower circulating concentrations of glucose and insulin postpartum contributing to greater negative energy balance, and due to an increase in total amount of mobilized adipose tissue mass (Mann et al., 2016).

\section{Potential role of ceramide as a mediator of insulin resistance}

In overweight, type 2 diabetic monogastrics, the antagonistic effects of FFA on insulin sensitivity are mediated in part by the sphingolipid ceramide (Holland and Summers, 2008). Ceramides were previously described as merely structural elements of cell membranes; however, recent research implicates ceramides as bioactive lipid mediators that play a role in a number of cellular processes including cell cycle arrest, apoptosis, and stress responses (Hannun, 1996). Ceramide synthesis involves three different pathways including de novo synthesis, 
sphingomyelin hydrolysis, and the salvage pathway. Distinct activation of these pathways may be possible due to compartmentalization of enzymes that contribute to ceramide formation (Kitatani et al., 2008). First, ceramides can be generated de novo by condensation of palmitoylcoA and serine in a reaction catalyzed by serine palmitoyl transferase (SPT) to form 3ketosphinganine (Merrill and Wang, 1986). The keto group is then reduced using 3ketodihydrosphingosine reductase to form sphinganine (Merrill and Wang, 1986; Perry 2002; Menaldino et al., 2003). Dihydroceramide synthase then adds an acyl group, forming a dihydroceramide (Merrill and Wang, 1986; Perry 2002; Menaldino et al., 2003). Different dihydroceramide synthase isoforms exist to produce specific ceramides with unique carbon chain length, which accounts for their diversity (Mizutani et al., 2005; Lahiri et al., 2005; Park and Pewzner-Jung, 2013). Dihydroceramide desaturase then converts dihydroceramide to ceramide, which contains a 4, 5-trans-double bond in the sphingosine group (Merrill and Wang, 1986; Rother et al., 1992, Perry 2002; Menaldino et al., 2003). Following synthesis, ceramide can be glycoslyated to form glucosylceramide, lactosylceramide, and gangliosides (Reynolds et al., 2004). Second, ceramides can also originate from sphingomyelin hydrolysis mediated by sphingomyelinases (SMases) classified as acid-, alkaline-, or neutral-SMase based on their optimal pH (Callahan et al., 1983; Nilsson, 1969; Wu et al. 2010). Third, the salvage pathway involves use of several enzymes including SMases, glucocerebrosidase, ceramidases, and (dihydro) ceramide synthases to breakdown complex sphingolipids into sphingosine and regenerate ceramide (Riboni et al., 1997; Kitatani et al., 2008). Researchers estimate that 50-90\% of sphingolipid biosynthesis comes from recycling of long chain-sphingoid bases (Gillard et al., 1998; Tettamanti et al., 2003), which suggests perhaps sphingolipid breakdown plays an important role in ceramide biosynthesis and signal transduction (Kitatani et al., 2008). 
In obese humans with type 2 diabetes, the severity of insulin resistance is correlated with circulating 18:0-, 20:0-, 24:1-, 24:0- and total ceramide (Cer; Haus et al., 2009). Moreover, the ability of the liver to de novo synthesize ceramide due to an oversupply of FFA has been previously established in humans and rats (Holland et al., 2007; Watt et al., 2012). Specifically, an elevation in SFA (e.g., palmitate) contributes to ceramide production through condensation with SPT in the first step of de novo ceramide synthesis. Ceramide blocks normal insulin signaling by recruiting protein kinase $\mathrm{C}-\zeta$ and inactivating AKT (Powell et al., 2003; Hajduch et al., 2008). Phosphodiesterase 3B is inactivated as a result, leading to accumulation of cAMP and enhanced lipolysis (Mei et al., 2002; Holm 2003). Thus, ceramide appears to work in a vicious cycle whereby NEB leads to mobilization of FFA, elevated FFA concentration leads to ceramide formation, and ceramide accrual further activates lipolysis potentially leading to non-alcoholic fatty liver disease and other metabolic disorders in humans. However, these mechanisms remained to be confirmed in ruminants.

Ceramide's ability to antagonize insulin action may be a function of its acyl moiety (Boon et al., 2013, Raichur et al., 2014; Turpin et al., 2014). Controversy exists about the role of 16:0- vs. 24:0-Cer on insulin resistance (Raichur et al., 2014; Turpin et al., 2014). The most abundant ceramide in human circulation is $24: 0-C e r$, which has been identified in association with type 2 diabetes (Haus et al., 2009). Increases in LDL containing either 16:0- or 24:0-Cer decreases systemic and skeletal muscle glucose uptake in lean mice by inhibiting insulinstimulated AKT phosphorylation (Boon et al., 2013). In contrast, when a high fat diet was administered to ceramide synthase-2 knockout mice displaying lower hepatic 24:0-Cer, 16:0-Cer was increased through overexpression of ceramide synthase 6 , and insulin sensitivity was hindered. Similarly, Turpin and coworkers (2014) found that in adipose tissue of obese humans, 
ceramide synthase 6 gene expression is increased causing an elevation in 16:0-Cer and insulin resistance. However, Meikle and colleagues (2013) found that 16:0-Cer and type 2 diabetes are not related. Therefore, the effect of 16:0- and 24:0-Cer on insulin sensitivity may be due to either intracellular or extracellular compartmentalization of ceramide; however, future research is required.

We have recently demonstrated that greater adiposity is associated with a more extreme loss in body condition during the peripartum and that overweight cows (increased BCS) have elevated plasma glucose, insulin, FFA, and lower estimated insulin sensitivity compared to their lean counterparts (Rico et al., 2015). Additionally, circulating ceramides are elevated in dairy cows during the transition period, are positively correlated with FFA, and are negatively correlated with insulin sensitivity (Rico et al., 2015; Rico et al., 2016; Mathews et al., 2016). Moreover, supplementing cows with palmitatic acid during mid-lactation increases hepatic synthesis and plasma accumulation of ceramide, decreases insulin sensitivity, and improves milk production (Rico et al., 2016); thus demonstrating that ceramide may be able to restore insulin resistance during positive energy balance via ceramide-dependent mechanisms. 


\section{Chapter 3}

\section{NUTRIENT RESTRICTION INCREASES CIRCULATING AND HEPATIC CERAMIDE IN DAIRY COWS DISPLAYING IMPAIRED INSULIN TOLERANCE \\ Introduction}

Development of insulin resistance in dairy cattle represents a homeorhetic adaptation to support milk production (Bell, 1995). Specifically, reduced insulin sensitivity in adipose and skeletal muscle tissue develops during early lactation as a means to partition glucose to the mammary gland (Bell, 1995). Increased energy requirements for lactation coupled with suppressed energy intake promotes accelerated adipose tissue lipolysis and hepatic lipid deposition during the peripartum which represent unfavorable conditions that promote metabolic disease when uncontrolled (e.g., fatty liver and ketosis). As lactation advances beyond peak milk production, insulin sensitivity and metabolic health improves as positive energy balance is restored (Bell, 1995; McNamara and Hillers, 1986). Characterization of the mechanisms that regulate insulin action in dairy cows is necessary to identify approaches to improve cow health and lifelong milk production.

The sphingolipid ceramide mediates the pathophysiology of insulin resistance in diabetic monogastrics (Holland et al., 2007; Chavez and Summers, 2012). Membrane ceramide inhibits insulin signaling by recruiting protein kinase $\mathrm{C}-\zeta$ and inactivating AKT (Powell et al., 2003; Hajduch et al., 2008). As a consequence, PDE3B is inactivated, cAMP accumulates, and the lipolytic release of FFA is enhanced (Mei et al., 2002; Holm, 2003). We have recently established that circulating ceramide (e.g., 24:0-Cer) is elevated in dairy cows transitioning from gestation to lactation (Rico et al., 2015), and lactating cows fed supplemental palmitic acid (Rico et al., 2016). Moreover, we demonstrated that circulating ceramide is positively related to FFA 
supply and inversely associated with insulin sensitivity (Rico et al., 2015; Rico et al., 2016;

Mathews et al., 2016). The central hypothesis of this manuscript is that ceramide may represent a maternal adaptation to support nutrient partitioning and milk production in dairy cattle.

Considering that the relationship between dietary energy intake and ceramide supply has not been investigated in dairy cattle, our objective was to evaluate changes in circulating and hepatic ceramide levels during controlled feed restriction. To assess ceramide responses, a feed restriction protocol was employed to promote lipolysis and insulin resistance, and ceramide levels were quantified using mass spectrometry. The effects of nicotinic acid (NA), a known suppressor of lipolysis (Pires et al., 2007; Pires and Grummer 2007b), was also assessed, although we recognized that chronic NA treatment can antagonize insulin action (Heemskerk et al., 2014; Pires et al., 2016). Herein, it was confirmed that feed restriction increases circulating and hepatic ceramide; however, NA treatment was unable to prevent ceramide accrual or improve insulin sensitivity. In support of our previous work, these data revealed that circulating and hepatic 24:0-Cer are inversely associated with insulin sensitivity.

\section{Experimental Design}

\section{Materials and Methods}

Experimental procedures were approved by the West Virginia University Institutional Animal Care and Use Committee (Morgantown) and were completed at the West Virginia University Animal Science Farm. Nine non-lactating, non-pregnant Holstein cows (2.6 \pm 0.9 parity; $617 \pm 51 \mathrm{~kg}$ body weight $(\mathrm{BW}) ; 3.0 \pm 0.3$ body condition score (Wildman et al., 1982) were housed in a free stall barn and trained to access feed by using Calan gate feeders (American Calan Inc., Norwood, NH). Cows were enrolled $14 \mathrm{~d}$ before treatment and randomly allocated to 1 of 3 groups in a replicated $3 \times 3$ Latin square design. Cows were ad libitum fed, nutrientrestricted (NR), or NR with nicotinic acid (NA; $5 \mathrm{mg}$ of NA/h per $\mathrm{kg} \mathrm{BW}$; delivered i.v.) for 34 
h. When provided access, cows were ad libitum fed (0800 and $1800 \mathrm{~h})$ a mixed ration of grass hay and ground corn to meet or exceed requirements (Table 3.1) (NRC, 2001). Nutrientrestricted cows were provided with vitamins and minerals that were mixed with wheat middlings as a carrier (1 kg/d) to meet requirements (NRC, 2001). Nicotinic acid (99\% purity; Vetagro S.p.A., Reggio Emilia, Italy) was administered to suppress lipolysis, and prepared with equimolar amounts of sodium bicarbonate to facilitate solubilization in saline in accordance with previously established methods (Pires et al., 2007b). Post-treatment, all cows were provided ad libitum access to feed and monitored for an additional $8 \mathrm{~h}$. Two 14-d recovery periods were included. Because fluctuations in circulating progesterone may influence insulin sensitivity (Livingstone and Mary, 2002), an intravaginal progesterone-releasing device (1.38 g; Eazi-Breed CIDR; Zoetis Inc., Florham Park, NJ) was inserted and replaced every $7 \mathrm{~d}$ throughout experimentation. Free access to water was ensured at all times. Body weights and body condition scores were recorded within $36 \mathrm{~h}$ of the initiation of treatment.

\section{Sampling Procedures}

Following established procedures (Mathews et al., 2016; Pires and Grummer, 2007a), cows were fitted with two indwelling jugular catheters (Micro-Renathane implantation tubing; Braintree Scientific, Inc., Braintree, MA) into each jugular vein $36 \mathrm{~h}$ prior to the initiation of treatments. Patency was maintained by flushing with heparinized saline every $12 \mathrm{~h}$ when not in use. Blood $(8 \mathrm{~mL})$ was collected at $-48(0700 \mathrm{~h}),-24,0$, and every $2 \mathrm{~h}$ until $\mathrm{h} 34$, relative to the start of treatment. Post-treatment, blood was collected at $1,2,4,6$, and $8 \mathrm{~h}(35,36,38,40$, and $42 \mathrm{~h}$ relative to the start of treatment, respectively). Blood samples were transferred into a glass test tube and serum was harvested following centrifugation $\left(3,400 \times g\right.$ for 10 min at $\left.4^{\circ} \mathrm{C}\right)$, frozen on dry ice, and stored at $-80^{\circ} \mathrm{C}$ until analyzed. 
Liver biopsies were performed at $\mathrm{h} 32$ relative to the start of treatment using aseptic techniques as previously described with modifications (Rico et al., 2016; Hughes, 1962). Hair was clipped surrounding the $11^{\text {th }}$ intercostal space, and the incision site was sanitized with iodine scrub and anesthetized with lidocaine $\mathrm{HCl}$ (5 to $10 \mathrm{~mL}$; Vedco, Inc., Saint Joseph, MO) delivered subcutaneously. Following tissue collection, the biopsy site was stapled and sprayed with antiseptic. Tissue was snap-frozen in liquid nitrogen and stored at $-80^{\circ} \mathrm{C}$. At $\mathrm{h} 33$ of treatment, an ITT $(0.1 \mathrm{IU} / \mathrm{kg}$ of BW) was performed. Additional blood samples $(8 \mathrm{~mL})$ were collected at $-10,0,10,20,40,50$, and 60 min relative to insulin infusion. Blood samples were processed as described above.

\section{Sample Analyses}

Daily dry matter contents of the mixed ration were determined by drying at $60^{\circ} \mathrm{C}$ until a static weight was observed. Mixed rations were composited and analyzed by near infrared reflectance spectroscopy (Cumberland Valley, Cumberland, MD; AOAC International, 1995; method 989.03). Serum concentrations of FFA, triacylglycerol, glucose, and total cholesterol were determined by enzymatic methods using commercial kits (HR Series NEFA-HR (2), LType TG M, Autokit Glucose, and Cholesterol E, respectively; Wako Chemicals USA, Inc., Richmond, VA). All spectrophotometric measurements were conducted using a SpectraMax Plus 384 Microplate Reader (Molecular Devices, Sunnyvale, CA). Intra- and inter-assay CV were 3.2 and $6.8 \%, 2.8$ and $4.1 \%, 3.6$ and $4.6 \%$, and 3.8 and $14.2 \%$ for FFA, triacylglycerol, glucose, and total cholesterol, respectively.

Ceramides were extracted from serum and liver using a modified Bligh and Dyer procedure including 12:0-Cer as an internal standard (Avanti Polar Lipids, Alabaster, AL; (Haughey et al., 2004; Bandaru et al., 2013). Sample extracts were injected using a LC-20A 
HPLC (Shimadzu Corp., Kyoto, Japan) and separated by gradient elution using a C18 reversephase column (ACE Technologies LTD., Aberdeen, Scotland). Samples were analyzed using an electrospray ionization source operating in positive ion mode that was coupled to a triple quadrupole mass spectrometer (5500 QTRAP, Sciex Inc. Thornhill, ON, Canada). Ion spray voltage was 5,500 at a temperature of $500^{\circ} \mathrm{C}$ and a collision gas setting of 9 psi. The declustering potential, entrance potential, and collision cell exit potential were set at 80,12 , and $10 \mathrm{~V}$, respectively. Individual ceramide species were detected by multiple reaction monitoring of the $[\mathrm{M}+\mathrm{H}]^{+}$molecular ion with transition ion of $264.2 \mathrm{~m} / \mathrm{z}$. A ten-point calibration curve ( 0.5 to 500 $\mathrm{ng} / \mathrm{mL}$ ) was constructed by plotting the area under the curve for 16:0-, 18:0-, 20:0-, 22:0-, and 24:0-Cer (Avanti Polar Lipids). Normalized ceramide concentrations were estimated by curve fitting the identified ceramide species based on acyl-chain length. Spectral data quantitation was performed using Analyst 1.6.3 (Sciex Inc).

\section{Calculations and Statistical Analyses}

The area under the curve (AUC) for serum FFA (duration of treatment; $\mathrm{AUC}_{0-32} \mathrm{~h}$ ) or glucose AUC (duration of ITT; $\mathrm{AUC}_{0-60 \mathrm{~min}}$ ) was calculated using the trapezoidal method as previously described by (Pires and Grummer, 2007b). Glucose clearance rate (\%/min during ITT; $\left.\mathrm{CR}_{40 \mathrm{~min}}\right)=[(\ln )$ glucose level at baseline (average of -10 and $0 \mathrm{~min})-(\mathrm{ln})$ glucose level at time point $40 \mathrm{~min}$ )/40] $\times 100$ (Pires and Grummer, 2007b. Data were analyzed using a mixed model with repeated measures including the random effect of cow and fixed effects of treatment, time, and their interaction in SAS (version 9.3, SAS Institute Inc., Cary, NC). When necessary, data were $\log$ transformed. Outliers were identified (studentized residuals $>3$ or $<-3$ ) and removed from analysis (typically no more than 1 per variable). Parametric Pearson correlations were performed to determine associations between ceramide levels and insulin-stimulated 
glucose disposal during an ITT. All results are expressed as least square means unless otherwise noted. Significance was determined at $P \leq 0.05$ and trends toward significance were considered at $0.05<P \leq 0.10$.

\section{Results}

\section{Prolonged intravenous NA partially suppresses lipolysis}

Daily dry matter intake for all cows was comparable prior to treatment $(19 \pm 0.55 \mathrm{~kg} / \mathrm{d} ; P$ $=0.49)$ and ad libitum fed cows consumed $20 \pm 1.08 \mathrm{~kg} / \mathrm{d}$ during treatment. Relative to feeding, NR increased lipolysis by h 2 (103 vs. $58 \mu \mathrm{M} ; P<0.05)$, a response that progressively increased for the duration of treatment (725 vs. $69 \mu \mathrm{M}$ at h 32; $P<0.001$; Figure 3.1A). In response to NA infusion in NR cows, adipose tissue lipolysis was suppressed $(P<0.001$; Figure 3.1A); however, long-term NA infusion was unable to prevent the gradual rise in FFA caused by feed removal. Collectively, adipose tissue lipolysis was suppressed $55 \%$ in cows infused NA (FFA AUC $0-32 \mathrm{~h}$; Fed, 125,131; NR, 793,641; NR + NA, 423,558 [ $\mu \mathrm{mol} / \mathrm{L} \times 32$ h]; SEM = 43,822; $P<0.001)$. Coinciding with lower hepatic FFA delivery, serum concentrations of triacylglycerol were suppressed in NR + NA treated cows, relative to the ad libitum fed or NR treatment (h 8 or 32; $P$ $<0.05$; Figure 3.2A). During treatment, overall glucose homeostasis was maintained; however, we observed a short-term decline in circulating glucose from h 8 through 14 of NR + NA treatment (Figure. 3.2B). Additionally, NR in the absence or presence of NA infusion increased serum total cholesterol (Figure 3.2C), an effect previously observed (Sävendahl and Underwood, 1999).Following treatment removal, serum FFA surged to $2,911 \mu \mathrm{M}(P<0.01$; Figure 3.1B), and this response was accompanied by an increase in serum triacylglycerol and glucose concentrations (Figure 3.2A-B). 


\section{Nutrient restriction increases serum and hepatic ceramide}

The ability of ceramide to inhibit insulin sensitivity may be influenced by the moiety (Boon et al., 2013; Raichur et al., 2014; Turpin et al., 2014). In our current study, we observed a greater contribution of 16:0-Cer to the total ceramide pool in non-pregnant and non-lactating dairy cows (Figure 3.3A and 3.4A). Consistent with previous observations in peripartal dairy cows experiencing negative energy balance (Rico et al., 2015), we observed a marked increase in circulating ceramide during nutrient restriction, relative to ad libitum feeding (Figure 3.3B-F). For example, NR cows exhibited increased circulating 16:0- and 24:0-Cer (75 and 78\% by h 32, respectively; $P<0.001)$. Moreover, re-feeding for 8 h decreased circulating 16:0- and 24:0-Cer by approximately $23 \%$ ( $P<0.001)$. Similar effects were observed for serum 18:0-, 20:0-, and 22:0-Cer in NR treated cows. Although NA infusion partially suppressed lipolysis, administration of NA was unable to prevent the rise in circulating ceramide caused by nutrient restriction. Most notably, serum 22:0- and 24:0-Cer levels were enhanced by NA infusion. Coinciding with the surge in circulating FA, terminating NA infusion promoted a short-term burst in serum 18:0-Cer levels ( $2 \mathrm{~h}$ post). Although less dramatic, a similar increase post NA infusion was observed for serum 16:0- and 20:0-Cer concentrations.

The ability of liver to synthesize and export ceramide has been previously established (Haus et al., 2009; Watt et al., 2012). Relative to ad libitum feeding, NR with or without NA infusion increased hepatic ceramide (56 to $116 \%$; Figure 3.4B). Moreover, we observed a positive association between serum and hepatic ceramide concentrations (Figure 3.4C).

\section{Ceramides are Inversely Related to Insulin Tolerance}

In order to validate previous data that demonstrates impaired insulin sensitivity during negative energy balance (Pires and Grummer, 2006b; Oikawa and Oetzel, 2006), we assessed 
changes in circulating glucose in response to an insulin challenge. We observed an inhibition of insulin-stimulated glucose disposal following NR treatment (Figure 3.5). Specifically, NR and $\mathrm{NR}+\mathrm{NA}$ decreased $\mathrm{CR}_{40} \min (\mathrm{Fed}, 1.76 ; \mathrm{NR}, 1.36 ; \mathrm{NR}+\mathrm{NA}, 0.88[\% / \mathrm{min}] ; \mathrm{SEM}=0.16 ; P<$ 0.001) and increased glucose $\mathrm{AUC}_{0-60 \min }(\mathrm{Fed}, 2259 ; \mathrm{NR}, 2651 ; \mathrm{NR}+\mathrm{NA}, 2793[\mathrm{mg} / \mathrm{dL} \times 60$ $\min$ ]; $\mathrm{SEM}=169 ; P<0.05)$ relative to ad libitum fed cows. Additionally, serum glucose concentrations rebounded 55\% from min 40 to 60 in cows fed ad libitum, a response not observed for the NR or NR + NA treatment. Administration of NA was unable to restore systemic insulin action during nutrient restriction. To determine whether systemic insulin tolerance is related to circulating or hepatic ceramide supply, we performed a Pearson correlation analysis. We detected an inverse relationship between very long chain ceramide (i.e., serum and hepatic 22:0- and 24:0-Cer) levels and $\mathrm{CR}_{40} \min (r=-0.51$ to $-0.42, P<0.05$; Figure 3.6A), a response not observed for 16:0-, 18:0-, 20:0-Cer, or FFA. We also observed a positive

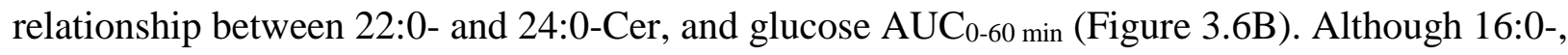
18:0-, and 20:0-Cer were not related to systemic insulin action, our results support an inverse relationship between very long chain ceramides (22:0- and 24:0-Cer) and systemic insulin tolerance.

\section{Discussion}

Development of insulin resistance in dairy cows is mediated in part by the actions of growth hormone and glucocorticoids, and represents a key maternal adaptation to partition energy towards the mammary gland as a means to support milk production for the neonate (Bell, 1995). Onset of insulin resistance will promote glucose sparing, increase lipolysis in adipose tissue, and enhance availability of FFA for oxidation or milk fat synthesis. Unfortunately, the modern early lactation dairy cow depends on insulin antagonism during a stage of lactation 
characterized by decreased intake and increased energy requirements to sustain copious milk production. Hepatic triacylglycerol accumulation may ensue in response to sustained elevations in circulating FFA. These conditions can promote fatty liver disease and ketosis which can compromise the health, fertility, and longevity of the cow. In monogastrics, ceramide is a central mediator of insulin resistance, lipolysis, and hepatic lipid accumulation (Chavez and Summers, 2012; Mei et al., 2002; Xia et al., 2015), and we have observed increased plasma ceramide levels in dairy cows transitioning from gestation to lactation (Rico et al., 2015). In our current study, we validated previous work that demonstrated impaired insulin action in response to energy deficit (Pires et al., 2007; Oikawa and Oetzel, 2006). More importantly, we established that circulating and hepatic ceramide accrual develops in nutrient-restricted dairy cows experiencing impaired insulin tolerance.

Elevations in circulating FFA concentrations can cause insulin resistance in skeletal muscle and adipose tissue of monogastrics (Summers, 2006; Funaki, 2009). Likewise, induction of hyperlipidemia by nutrient restriction or tallow infusion can impair insulin sensitivity in dairy cows (Pires et al., 2007; Pires and Grummer, 2007a). These researchers postulate that establishment of FFA-induced insulin resistance in adipose tissue of peripartal dairy cows may support a vicious cycle in which higher FFA concentrations attenuate insulin signaling and sustain adipose tissue mobilization. Comparable to Pires and colleagues (Pires et al., 2007) our nutrient restriction protocol increased circulating FFA levels and impaired glucose clearance following an insulin challenge; however, intravenous NA infusion was unable to restore insulin sensitivity albeit lipolysis was partially suppressed and circulating triacylglycerol was intermittently lower. Despite reduced FFA supply, others have demonstrated impaired insulin sensitivity following $48 \mathrm{~h}$ NA administration ( $3 \mathrm{mg} / \mathrm{h}$ per $\mathrm{kg}$ of BW; delivered abomassally) in 
cows restricted to $33 \%$ of ad libitum intake (Pires et al., 2016). Moreover, long-term niacin feeding in mice (15 wk dietary supplementation at $0.3 \% \mathrm{wt} / \mathrm{wt}$ ) inhibits systemic insulin sensitivity and blocks insulin-inhibited lipolysis by downregulating PDE3B (Heemskerk et al., 2014). In our investigation, the inability of $32 \mathrm{~h}$ NA infusion to completely suppress FFA mobilization may have involved a similar mechanism. In contrast to our findings and others (Heemskerk et al., 2014; Pires et al., 2016), earlier work (Pires et al., 2007) has revealed that NA administration (6 mg/h per kg of BW delivered abomassally) for a shorter duration (11 h) can enhance insulin-stimulated glucose clearance in feed-restricted dairy cows. Interestingly, we did not observe an increase in 22:0- or 24:0-Cer until h 16; therefore, the insulin-sensitizing effects of short-term ( $<16 \mathrm{~h})$ NA administration at supraphysiological doses may not be accompanied by elevated ceramide. It is clear that the ability of NA to inhibit insulin sensitivity and lipolytic rate are dependent on the duration and dose of the treatment regimen; however, the mechanism of action remains uncertain. Therefore, we explored whether ceramide was related to energy deficit in the absence or presence of $34 \mathrm{~h}$ NA infusion.

Fatty acid oversupply contributes to increased hepatic de novo ceramide synthesis and secretion in humans and rats (Holland et al., 2007; Watt et al., 2012). In turn, lipoprotein ceramide mediates the development of insulin resistance in part by interfering with protein kinase B signaling (Boon et al., 2013; Stratford et al., 2004). Our observed elevations in NRinduced FFA levels developed concurrently with the accumulation of ceramide in liver and serum, a positively correlated relationship suggesting coordinated hepatic synthesis and export. Moreover, following the termination of NA infusion, we observed a FFA surge-dependent increase in 16:0-, 18:0-, and 20:0-Cer thus indicating that rapid ceramide synthesis is possible in cows. This response developed in parallel with a rapid increase in circulating triacylglycerol and 
glucose, likely caused by increased hepatic triacylglycerol export and glycerol-dependent gluconeogenesis (Aschenbach et al., 2010), respectively. Coinciding with improved energy balance, circulating ceramide was lowered by re-feeding. We have previously demonstrated a positive relationship between elevated circulating ceramide and FFA levels in peripartal dairy cows experiencing negative energy balance (Rico et al., 2015). The current study confirms an inverse relationship between circulating ceramide and glucose-stimulated FFA disappearance, thus supporting a role for ceramide as a lipolytic mediator (Rico et al., 2016). Additionally, cellpermeable ceramide decreases PDE3B activity and inhibits insulin-induced anti-lipolysis in 3T3L1 adipocytes (Mei et al., 2002). Collectively, our data supports a lipolytic role for ceramide when cows experience increased energy demand.

Considering that FFA serve as substrate for hepatic de novo ceramide synthesis (Merrill, 2002), we anticipated lower hepatic and circulating ceramide concentrations in response to NA infusion. Contrary to our hypothesis, inhibition of lipolysis by NA was unable to suppress ceramide accumulation in response to feed removal. Unexpectedly, NA infusion selectively enhanced very long chain 22:0- and 24:0-Cer concentrations. The inability of NA to prevent NRinduced ceramide accrual may explain why insulin-stimulated glucose disposal remained unchanged, relative to NR cows. Accumulation of ceramide during suppressed lipolysis suggests that alternative mechanisms independent of substrate supply for serine SPT and ceramide synthase within the de novo synthesis pathway are responsible. For instance, NA may have directly activated SPT. In support, Tanno and coworkers (2000) demonstrated that nicotinamide increases ceramide levels in human keratinocytes by enhancing SPT transcription and activity, and pyridoxal-5'-phosphate (vitamin B $_{6}$ ) is a known cofactor for SPT (Wadsworth et al., 2013). Alternatively, NA infusion may have upregulated other ceramide generating pathways including 
sphingomyelin hydrolysis or salvage synthesis (Hirabayashi et al., 2006). Considering that NA may upregulate ceramide synthesis during a catabolic state and a comparison of 14 studies indicated that niacin lowered FFA once (NRC, 2001), we contemplate whether supplementing NA at practical feeding levels during early lactation may inadvertently exacerbate insulin resistance.

The ability of ceramide to inhibit insulin sensitivity may be dependent upon the acyl moiety of the sphingolipid (Boon et al., 2013; Raichur et al., 2014; Turpin et al., 2014). In our investigation, NR increased serum 16:0-, 18:0-, 20:0-, 22:0- and 24:0-Cer; however, the observed inverse relationship between ceramide and insulin sensitivity (i.e., $\mathrm{CR}_{40}$ min or $\mathrm{AUC}_{0-60}$ min) was reserved for the 22:0 and 24:0 moiety. We have made similar observations in peripartal and mid-lactation dairy cows displaying enhanced total ceramide supply (Rico et al., 2015; Rico et al., 2016). Whereas we have previously established that $24: 0$-Cer is the most abundant ceramide in lactating dairy cows, our current study demonstrated that 16:0-Cer was the predominant ceramide in non-pregnant, non-lactating dairy cows. Considering that the contribution of very long chain ceramides to the total ceramide pool increases as cows transition from gestation to lactation and decline beyond peak milk yield (Rico et al., 2015; Rico et al., 2016), relative to 16:0-Cer, our observed difference in hepatic and serum sphingolipid profiles likely reflect the physiological state of the animal. In support of the role of 24:0-Cer as an insulin antagonist, Boon and coworkers (2013) demonstrated that rodents infused with low density lipoproteins enriched with 24:0-Cer display impaired insulin-stimulated glucose uptake and protein kinase B activation. Additionally, Meikle et al. (2013) found that circulating 16:0-Cer elevation and the development of type 2 diabetes were not related. In contrast, others have proposed that skeletal muscle 16:0-Cer is a proapoptotic mediator of insulin resistance in 
response to high-fat feeding, and 24:0-Cer confers antiapoptotic and proliferative functions (Raichur et al., 2014; Turpin et al., 2014). With these uncertainties recognized, the ability of specific ceramides to inhibit insulin action may be influenced by their compartmental origin.

Our work represents the first investigation to explore the relationship between controlled nutrient restriction, ceramide supply, and systemic insulin sensitivity in dairy cows. We demonstrated that hepatic and serum ceramide levels increase in response to rising circulating FFA levels and insulin resistance caused by nutrient restriction. Moreover, we established that improving the energy status of the cow can lower ceramide concentrations. In support of our previous findings in peripartal and mid-lactation dairy cows, we confirm that the inverse relationship between ceramide levels and insulin sensitivity is specific for ceramides with a 22:0 or 24:0 moiety. We also demonstrated that long-term NA administration does not prevent the rise in ceramide or insulin antagonism caused by nutrient restriction. Our data suggest that ceramides are fundamentally involved in the adaptive metabolic changes associated with the onset of a catabolic state in dairy cows. 
TABLES AND FIGURES

Table 3.1. Ingredients and nutrient composition (\% of dry matter unless otherwise noted) of experimental diet when offered.

Ingredient $^{1}$

Grass hay

Corn grain $\operatorname{mix}^{2}$

Dairy pellets ${ }^{3}$

29.0

Nutrient composition

Dry matter, \%

Crude protein

19.3

Neutral detergent fiber

37.8

Acid detergent fiber

24.6

Starch

15.6

Crude fat

Ash

7.8

Net energy for lactation, Mcal/kg of dry matter

1.5

\footnotetext{
${ }^{1}$ Ingredients were composited weekly.

${ }^{2}$ Corn grain mix contained (as fed) $39.9 \%$ ground corn grain, $46.5 \%$ soybean meal, $1.7 \%$ magnesium sulfate, $0.9 \%$ trace mineral salt, $0.3 \%$ Sel-Plex 600 (Alltech, Nicholasville, KY), 0.6\% Zinpro Availa-Plus (Zinpro Corp., Eden Prairie, MN), 8.5\% Zar-Min (ZEO Inc., McKinney, TX), $0.4 \%$ vitamin premix ADE, and $1.2 \%$ vitamin premix $\mathrm{E}$.

${ }^{3}$ Dairy pellets contained (as fed) $33.1 \%$ soy hulls, $38.2 \%$ corn, $25.2 \%$ soy meal, $1.1 \%$ urea, $0.9 \%$ limestone, $0.4 \%$ calcium phosphate, $0.2 \%$ magnesium oxide, $0.5 \%$ trace mineral salt, and $0.4 \%$ vitamin premix ADE.
} 
Figure 3.1. Intravenous infusion of nicotinic acid (NA) partially suppresses lipolysis in nutrientrestricted (NR) dairy cows. Serum fatty acid concentrations (A) during and (B) following treatment in cows ad libitum fed, NR, or NR plus NA infusion (NR + NA). Intravenous infusion of NA was delivered at $5 \mathrm{mg}$ of NA/h per $\mathrm{kg} \mathrm{BW}$. Data are represented as least squares means and their standard errors

Figure 3.2. Circulating triacylglycerol, glucose, and total cholesterol concentrations in dairy cows ad libitum fed, nutrient-restricted (NR), or NR plus nicotinic acid infusion (NR + NA). Serum (A) triacylglycerol, (B) glucose, and (C) total cholesterol concentrations during or following treatment. Vertical dashed line reflects termination of saline or NA (delivered at $5 \mathrm{mg}$ of NA/h per kg BW) infusion. Data are represented as least squares means and their standard errors

Figure 3.3. Nutrient restriction increases circulating ceramide in dairy cows. Serum ceramide (Cer) (A) composition and (B-F) concentrations in dairy cows ad libitum fed, nutrient-restricted (NR), or NR plus nicotinic acid infusion (NR + NA). Composition of serum ceramides was evaluated at h 32 . Vertical dashed line reflects termination of saline or NA (delivered at $5 \mathrm{mg}$ of $\mathrm{NA} / \mathrm{h}$ per kg BW) infusion. Data are represented as least squares means and their standard errors. Differing superscripts reflect statistical differences between treatments within a time point, $P<$ 0.05

Figure 3.4. Nutrient restriction increases hepatic ceramide in dairy cows. Liver ceramide (Cer) (A) composition and (B) concentrations in dairy cows ad libitum fed, nutrient-restricted (NR), or 
NR plus nicotinic acid infusion (NR + NA). (C) Random regression analysis between serum and hepatic total ceramide concentrations at $\mathrm{h} 32$. Intravenous infusion of NA was delivered at $5 \mathrm{mg}$ of NA/h per $\mathrm{kg} \mathrm{BW}$. Concentrations for individual ceramide moieties are represented as least squares means and their standard errors. Coefficient of determination $\left(\mathrm{R}^{2}\right)$ represents the association between observed and model predicted values when accounting for the random effect of cow. Differing superscripts reflect statistical differences between treatments within a time point, $P<0.05$

Figure 3.5. Nutrient restriction decreases insulin sensitivity in dairy cows. Serum glucose response to an insulin tolerance test in dairy cows ad libitum fed, nutrient-restricted (NR), or NR plus nicotinic acid infusion (NR + NA). Insulin was administered at $0.1 \mathrm{IU} / \mathrm{kg}$ of BW. Intravenous infusion of NA was delivered at $5 \mathrm{mg}$ of NA/h per $\mathrm{kg} \mathrm{BW}$. The tolerance test was performed at $\mathrm{h} 33$ of treatment. Baseline values are represented as the average of -10 and 0 min, relative to start of insulin challenge. Data are represented as least squares means and their standard errors

Figure. 3.6 Very long chain ceramides are inversely related to insulin tolerance in dairy cows. Relationship between ceramide (Cer) supply and insulin tolerance in dairy cows ad libitum fed, nutrient-restricted (NR), or NR plus nicotinic acid infusion (NR + NA). Intravenous infusion of NA was delivered at $5 \mathrm{mg}$ of NA/h per $\mathrm{kg} \mathrm{BW}$. Measurements of insulin tolerance include glucose clearance rate ( $\mathrm{CR}_{40} \mathrm{~min} ; 40 \mathrm{~min}$ following insulin administration) and glucose area under 
the curve $\left(\mathrm{AUC}_{0-60 \text { min }}\right.$; duration of test). Data reflect serum and liver samples collected at $\mathrm{h} 32$ of treatment. $* * P<0.01, * P<0.05, \uparrow P<0.10$ 

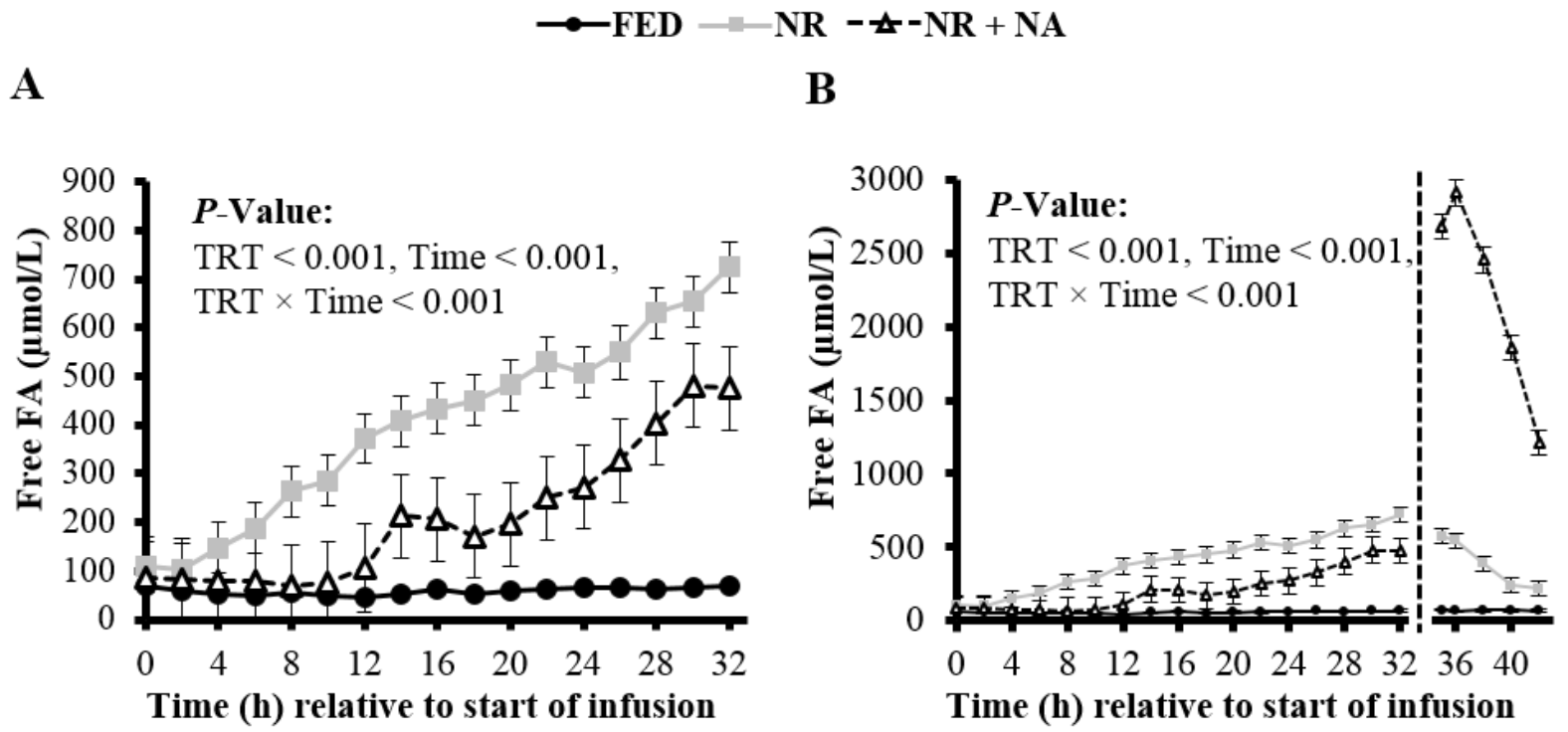

Figure 3.1 


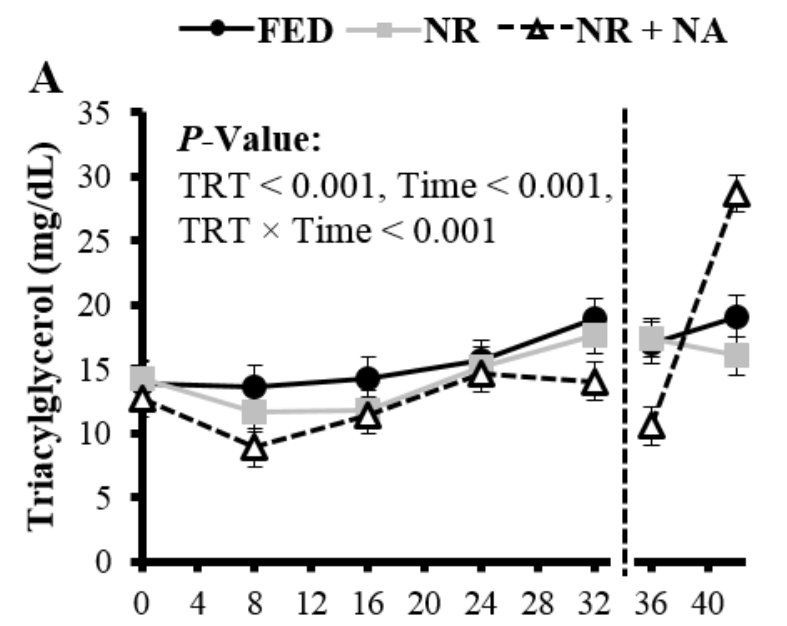

B Time (h) relative to start of infusion

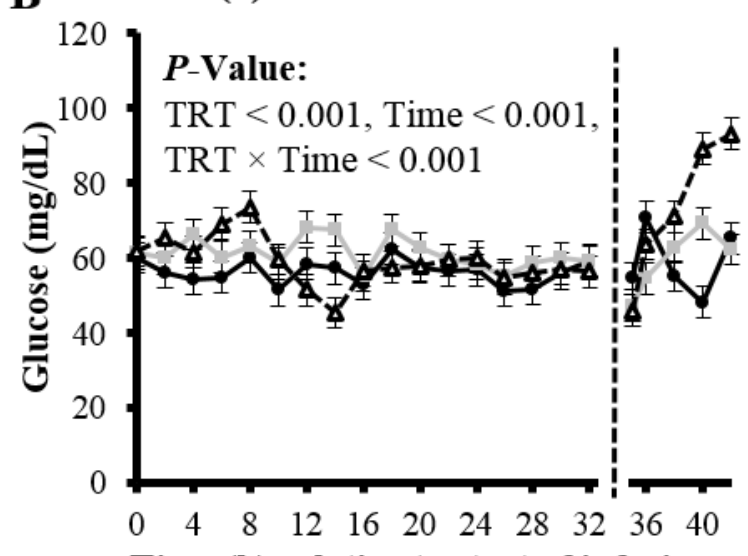

C Time (h) relative to start of infusion

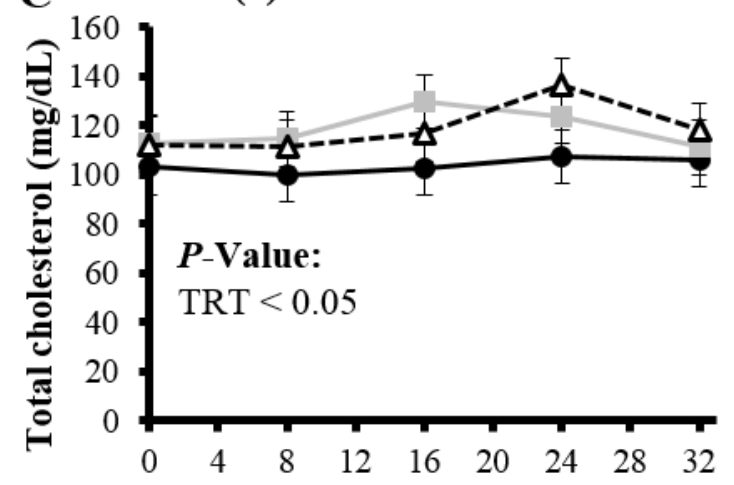

Time (h) relative to start of infusion

Figure 3.2 
- FED $\square$ NR INR + NA

A

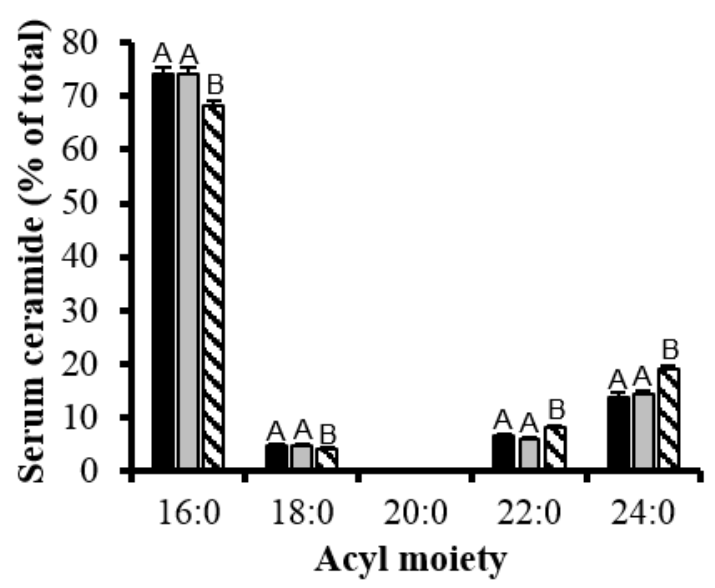

C

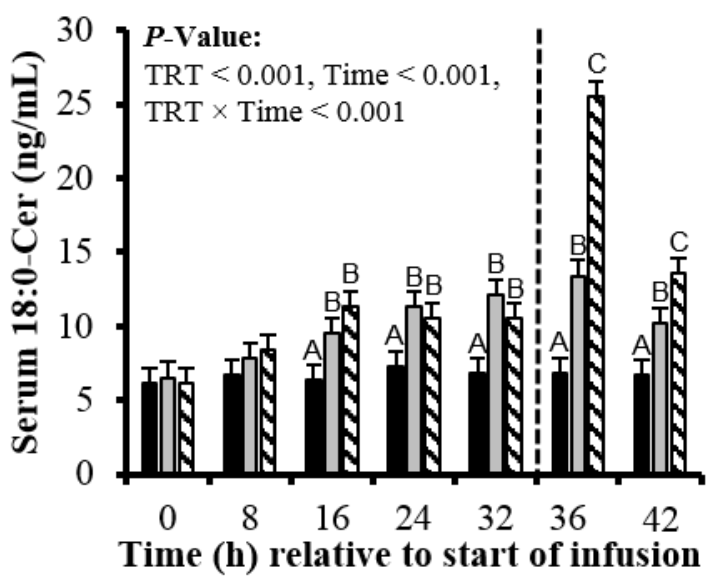

$\mathbf{E}$

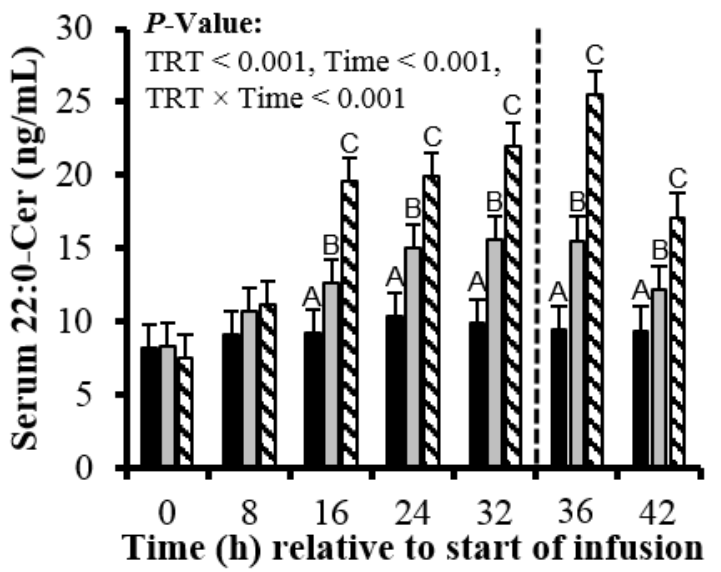

B

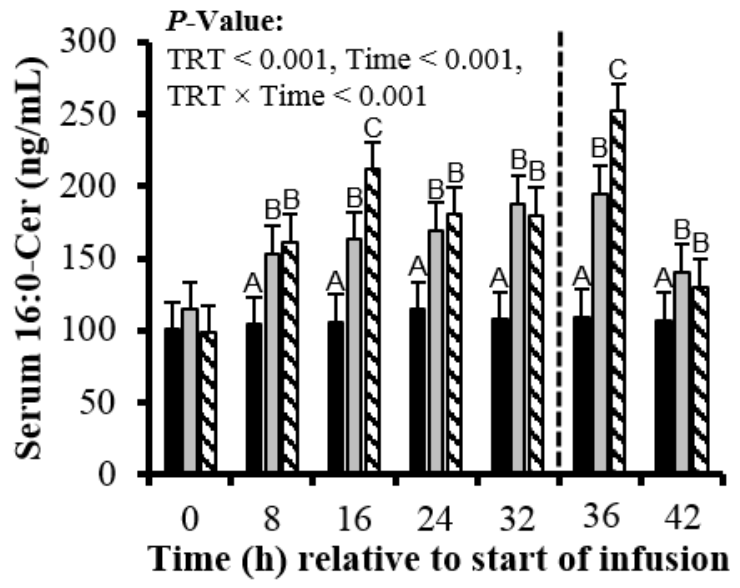

D

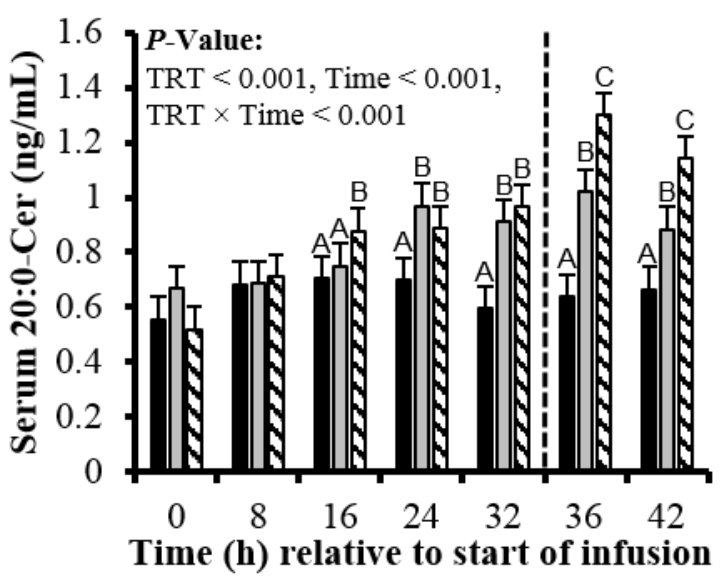

F

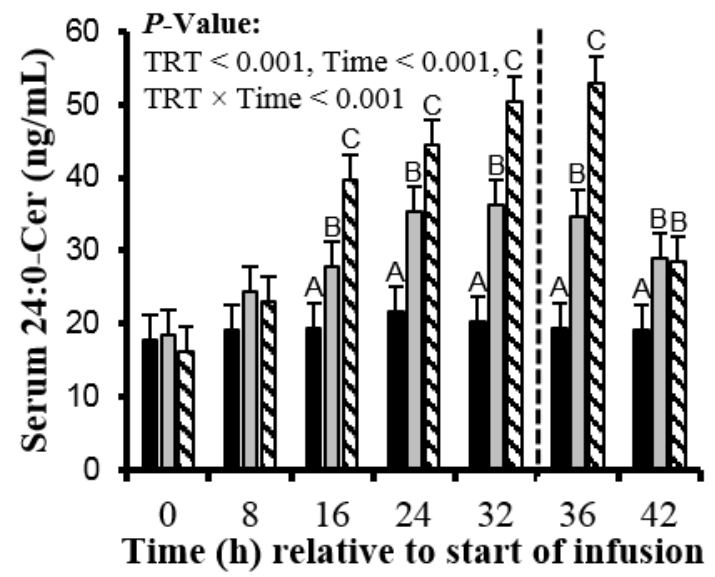

Figure 3.3 

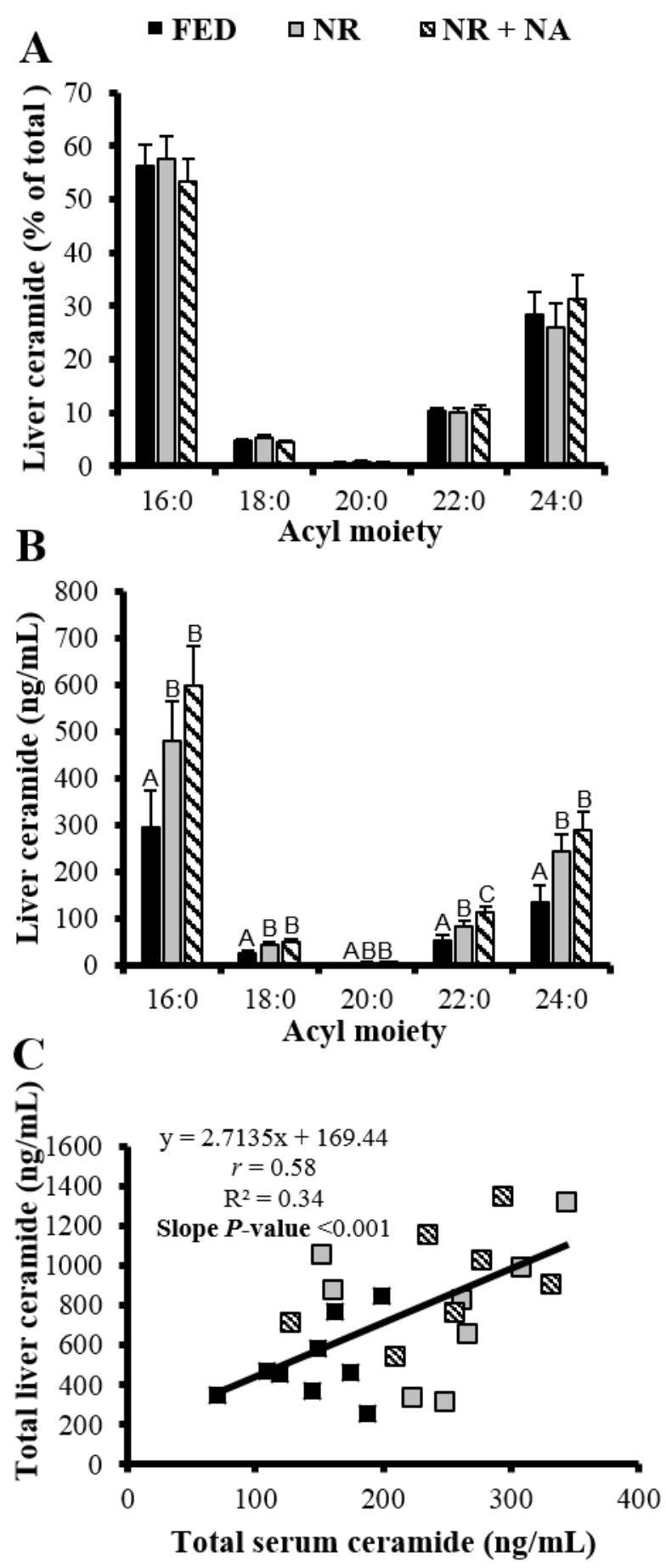

Figure 3.4 


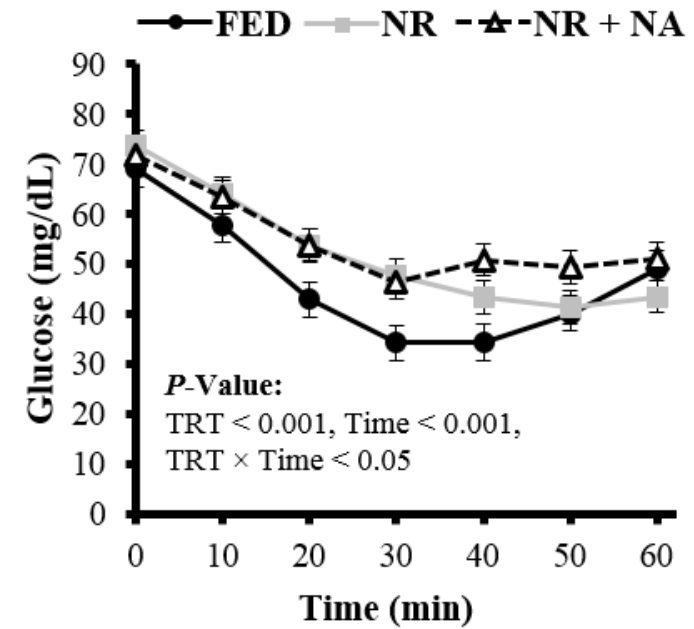

Figure 3.5 

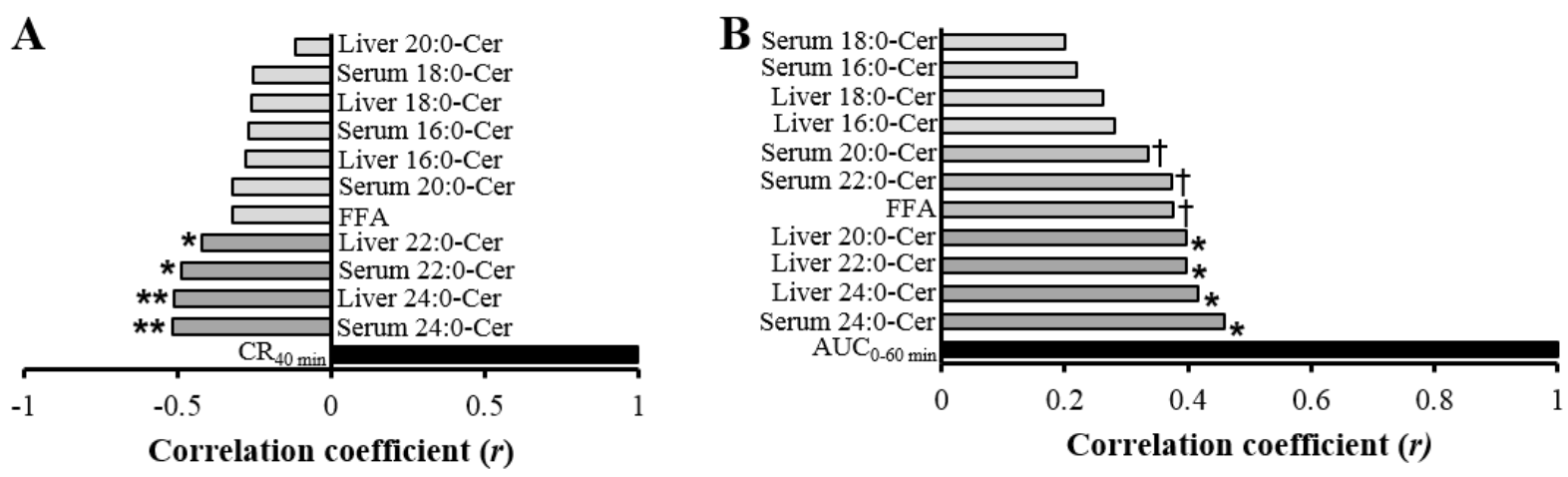

Figure 3.6 


\section{Chapter 4}

\section{EFFECTS OF PREPARTUM ADIPOSITY ON PERIPARTAL SYSTEMIC AND LOCALIZED INSULIN SENSITIVITY IN DAIRY COWS}

\section{Introduction}

During the gestation to lactation transition, the peripartal dairy cow exhibits a high glucose requirement to support the growing fetus and the increased demand for milk production. First, dramatic requirements for glucose by the placenta are increased 4-fold during late gestation, and glucose requirements can increase 7-fold at the onset of lactation to support mammary lactose synthesis (Bell and Bauman, 1997). Due to this dramatic increase in glucose requirement coupled with suppressed energy intake and amplified energy expenditure, peripartal dairy cows develop insulin resistance in adipose and muscle tissues as a metabolic adaptation to support lactation (Bell and Bauman, 1997). Because insulin is an anti-lipolytic hormone, insulin resistance promotes accelerated adipose tissue lipolysis and increases circulating FFA. As a detrimental consequence, hepatic influx of FFA can be re-esterified to form triacylglycerol (TAG). Excessive deposition of TAG in liver can increase ketogensis and compromise gluconeogenesis (Rukkwamsuk et al., 1999; Rukkwamsuk et al., 2000). If not resolved, these hepatic impairments can promote the development of postpartum metabolic diseases including fatty liver disease, ketosis, retained placenta, and mastitis (Holtenius et al., 2003; Bobe et al., 2004; Ospina et al., 2010). Onset of a metabolic disease can comprise cow longevity and decrease producer profits. Understanding the mechanisms of metabolic disease will support development of novel approaches to improve cow health and performance during the transition from gestation to lactation.

Pregnant dairy cows with enhanced adiposity during late gestation are subjected to a 
greater loss in body weight and adiposity during the transition period. Moreover, overweight dairy cows experience greater lipolytic rates and increased circulating FFA concentrations relative to lean cows (Janovick et al., 2011; Rukkwamsuk et al., 2000). Increased hepatic lipid deposition, ketogenesis, systemic inflammation, and oxidative stress all contribute to increased disease risk in overweight dairy cows (Bobe et al., 2004; Bernabucci et al., 2005; Duffield et al., 2009; Lacetera et al., 2005). Current recommendations are to minimize body fat gain during late gestation (Overton and Waldron, 2004); however, modern dairy farms manage cows within heterogenous groups (i.e. cows can have varying adiposity). One potential mechanism that may explain why overweight dairy cows experience increased body fat loss during the peripartum may involve reduced sensitivity to the pancreatic hormone insulin.

In overweight monogastrics, development of insulin resistance involves a reduction in insulin-stimulated glucose uptake in adipocytes via mechanisms involving protein kinase B (AKT) inactivation (i.e. dephosphorylation; Summers et al., 1998). In turn, AKT inactivation suppresses translocation of glucose transporter-4 (GLUT4) to the plasma membrane in skeletal muscle, cardiac, and adipose tissues (Zhao and Keating, 2007). Because insulin is an antilipolytic hormone, insulin resistance can promote adipose tissue lipolysis by activating hormonesensitive lipase (Sumner and McNamara, 2007). In the ruminant dairy cow, early evidence has demonstrated the inactivation of AKT postpartum (Zachut et al., 2013); however, the ability of adiposity to influence adipose tissue AKT phosphorylation status in response to insulin is uncertain.

Development of adipose tissue insulin resistance offers a potential explanation for why overweight cows exhibit a higher concentration of circulating FFA and a greater tendency to develop metabolic disease. By employing several measurements of insulin sensitivity, our 
objective was to examine changes in systemic and localized insulin sensitivity in lean and overweight peripartal dairy cows. Specifically, we utilized the hyperinsulinemic-euglycemic (HEC; Kim, 2009) clamp method to measure glucose infusion rate in cows experiencing sustained elevations in blood insulin concentrations. We also measured phosphorylation status of AKT in subcutaneous adipose tissue (SubqAT), as well as circulating levels of several related markers including insulin, FFA, and glucose. We hypothesized that enhanced adiposity in periparturient dairy cows is associated with reduced glucose infusion during the HEC, increased fat loss, and lower localized insulin sensitivity.

\section{Experimental Design}

\section{Materials and Methods}

Experimental procedures were approved by the West Virginia University Institutional Animal Care and Use Committee (Morgantown). The experiment was completed at Dovan Farms, WVU Agricultural Research and Education Partner, and a 700-Holstein cow commercial dairy farm (located in Berlin, PA). Twenty-five pregnant, multiparous (3.6 \pm 1.60 lactations) Holstein dairy cows were enrolled into the study $28 \mathrm{~d}$ before expected parturition. Five cows were removed from the study and replaced for health reasons ( 2 displaced abomasum, 1 severe mastitis, and 2 complete cessation of eating). Cows were randomly selected and immediately allocated into one of two treatment groups per their prepartum adiposity, using a 1 to 5 body condition score (BCS; overweight (i.e. overconditioned), 3.9 \pm 0.30 BCS or lean, $3.0 \pm 0.16$ BCS; Wildman et al., 1982) and back fat thickness (BFT; overweight, $15.2 \pm 0.86 \mathrm{~mm}$ or lean, $10.2 \pm 0.80 \mathrm{~mm})$. Cows had free access to water while fed twice daily ( $0700 \mathrm{~h}$ and $1700 \mathrm{~h})$ for ad libitum intake to meet or exceed nutrient recommendations during pregnancy and lactation. Cows were milked twice daily (0600 and 2030 h) using a portable milking unit from parturition 
through $\mathrm{d} 12$, then milked three times per day with the main herd. Body weight (BW) was

recorded weekly. Four trained examiners independently recorded BCS for individual cows. Body condition score data for each cow was averaged weekly from d -28 to d 28 relative to parturition. Back fat thickness was measured weekly using an ultrasound according to the methods of Schröder and Staufenbiel (2006).

\section{Sampling Collection}

Prior to morning feeding, blood samples $(10 \mathrm{~mL})$ were collected via coccygeal venipuncture weekly starting at enrollment until $\mathrm{d}-7$, then daily until to $\mathrm{d} 8$, followed by $\mathrm{d} 10$, $12,14,21$, and 28 , relative to calving. Blood samples were placed on ice for 30 min until centrifugation at $3,400 \times g$ for $10 \mathrm{~min}$. Plasma was then removed after centrifugation and snapfrozen in liquid nitrogen. Samples were then stored for analysis at $-20^{\circ} \mathrm{C}$ for no longer than two weeks then moved to $-80^{\circ} \mathrm{C}$ for long-term storage. Total mixed ration (TMR) samples were collected once every two weeks, and composited monthly for analysis. Milk samples were collected at each milking on d 1, 3, 5, 7, 10, 12, 14, 21, and 28 relative to parturition. Samples were kept at $4^{\circ} \mathrm{C}$ and preserved using Bronopol tablets (D\&F Control Systems, San Ramon, CA) for milk composition analysis.

Liver and adipose biopsies were performed on $\mathrm{d}-12$ and 10 relative to calving. For liver biopsies, the incision site was located with the $11^{\text {th }}$ intercostal space by making an incision 0.5 $\mathrm{cm}$ through the skin. Using a custom trocar, $1 \mathrm{~g}$ of liver tissue was collected (Hughes, 1962) and snap-frozen in liquid nitrogen. Within $48 \mathrm{~h}$, biopsy samples were removed from liquid nitrogen and stored at $-80^{\circ} \mathrm{C}$. To evaluate adipose tissue AKT activation (i.e. phosphorylation), 50-100 mg of adipose tissue was removed from the cow and incubated in DMEM medium containing $1 \% \mathrm{BSA}, 1 \mathrm{M}$ acetate, and $5 \mathrm{mM}$ glucose for $10 \mathrm{~min}$ at $39^{\circ} \mathrm{C}$ to reflect physiological conditions. 
The tissue was then spiked with $1 \mathrm{mM}$ insulin. After incubation at $39^{\circ} \mathrm{C}$ for $15 \mathrm{~min}$, the tissue was removed from the solution and snap-frozen in liquid nitrogen. Additionally, an adipose explant was harvested, placed in a cassette, and stored in formalin for histology analyses. After tissue collection, biopsy sites were cleaned with hydrogen peroxide, stapled, and sprayed with antiseptic (Blu-Kote; H.W. Naylor Co. INC; Morris, NY).

The HEC procedure was performed at $\mathrm{d}-10$ and 12 relative to calving. Three jugular catheters (Micro-Renathane Implantation tubing, $2.03 \mathrm{~mm}$ outside diameter $\times 1.02 \mathrm{~mm}$ inside diameter; Braintree Scientific Inc., Braintree, MA; Schoenberg et al., 2012) were inserted the evening prior to the HEC and flushed with heparinized saline every $7 \mathrm{~h}$ to maintain patency. One catheter was used for blood sampling, and the other, in the opposite jugular vein, was used for insulin and glucose infusion. Infusion lines were attached to the same catheter using an anti-y port (Millpledge North America Inc, CA). The insulin solution was prepared using bovine insulin stock solution ( $1 \mathrm{mg} / \mathrm{mL}$; Humulin R; Lilly and Co., Indianapolis, IN), sterile saline, and harvested plasma for insulin infusates (2.5\% of total solution volume; DeFronzo et al., 1979). In order to calculate insulin dose, body weight was recorded once daily for two days before the HEC and averaged. Feed was removed two hours prior to the start of the HEC which occurred prior to the morning feeding. An insulin priming dose was introduced intravenously to raise blood insulin levels (DeFronzo et al., 1979). Subsequently, infusion lines were attached and insulin ( $1 \mu \mathrm{g} / \mathrm{kg}$ of BW, $27 \mathrm{IU} / \mathrm{mg}$, at $9.0 \mathrm{~mL} / \mathrm{h})$ was administered using a syringe pump (New Era Pump Systems Inc., Farmingdale, NY). Concurrently, glucose (50\% dextrose solution) was infused using a Macro XL Plum Pump (Abbott Laboratories, North Chicago, IL) at $9 \mathrm{~mL}$ per h until insulin noticeably dropped blood glucose levels measured by a hand-held glucometer (Precision Xtra, Abbott Diabetes Care Inc., Alameda, CA). Glucose infusion rate was adjusted 
variably to reach and maintain a steady state euglycemia for $30 \mathrm{~min}$ minimum. The target steady state range was considered to be the average of five basal glucose concentrations immediately prior to HEC. The steady state range extended $\pm 10 \%$ beyond this basal average. The resulting steady-state glucose infusion needed to maintain euglycemia was a reflection of insulin action.

\section{Sample Analyses}

Total mixed ration dry matter (DM) contents were determined by drying at $60^{\circ} \mathrm{C}$ until a static weight was achieved. Additional TMR samples were submitted to a commercial laboratory for nutrient composition by near-infrared spectroscopy (Cumberland Valley, Cumberland, MD; AOAC International, 1995; method 989.03). Milk samples were individually sampled and analyzed for true protein, lactose, and fat concentrations within 1 wk of collection. Samples were also analyzed for MUN using mid-infrared spectroscopy and SCC by flow cytometry (Dairy One, Hagerstown, MD; AOAC, 1990; method 972.160).

Plasma glucose, FFA, and BHBA concentrations were measured using enzymatic kits (Autokit Glucose, HR Series NEFA-HR (2), Autokit 3-HB, respectively; Wako Chemicals USA, Inc., Richmond, VA). Serum insulin concentrations were determined using ELISA (Mercodia Bovine Insulin ELISA; Mercodia AB, Uppsala, Sweden). All spectrophotometric measurements were conducted using a SpectraMax Plus 384 Microplate Reader (Molecular Devices, Sunnyvale, CA). Intra- and inter-assay CV were 4.0 and 4.2\%, 3.1 and 11.9\%, 2.4 and 9.1\%, and 4.8 and $16.5 \%$ for glucose, FFA, BHBA, and insulin, respectively. Liver lipid was extracted and quantified using previously described methods (Hara and Radin, 1978; Piepenbrink and Overton, 2003b).

For analysis of AKT phosphorylation, basal and insulin-stimulated SubqAT samples ( 50 $\mathrm{mg}$ of tissue) were pulverized in a bead blender, and ice-cold lysis buffer ( $20 \mathrm{mM}$ tris base, 50 
$\mathrm{mM} \mathrm{NaCl}, 50 \mathrm{mM} \mathrm{NaF}, 5 \mathrm{mM} \mathrm{Na} \mathrm{O}_{7} \mathrm{P}_{2}, 250 \mathrm{mM}$ sucrose, $1 \%$ (v/v) Triton $\mathrm{X}-100,500 \mathrm{mM}$ dithiothreitol, and protease inhibitor; $14 \mu \mathrm{l} / \mathrm{mg}$ of tissue) was added. Samples were centrifuged at $4^{\circ} \mathrm{C}$ at $14,000 \times \mathrm{g}$ for $15 \mathrm{~min}$. Tissue lysates were stored at $-80^{\circ} \mathrm{C}$ until further analysis. Loading dye with denaturing agent was added to samples which were subsequently heated to $70^{\circ} \mathrm{C}$ for 10 min and then cooled on ice. Samples were loaded on the gel at $50 \mu \mathrm{g}$ of protein per lane. The gel was run at $150 \mathrm{~V}$ for $1.5 \mathrm{~h}$. The protein was transferred to a nitrocellulose membrane. The transfer tank was submerged in ice at $120 \mathrm{~V}$ for $2 \mathrm{~h}$. The membrane was blocked for $30 \mathrm{~min}$ under agitation using a 5\% TBST in non-fat dry milk solution. The membranes were rinsed with TBST and incubated overnight with primary antibodies, phosphorylated AKT (pAKT; Ser473; 1:1000) or total AKT (tAKT; 1:1000; Cell signaling, Technology, Danvers, MA) under agitation. Membranes were washed with 1X TBST and incubated with secondary antibody (1:2000; Alexafluor 680, Life Technologies Corporation, Eugene, OR) for $60 \mathrm{~min}$ with agitation at room temperature. After incubation, the membrane was washed with TBST for 5 min, repeatedly washed 3X. Blots were scanned using a NIR fluoresce system (Odyssey imager, LICOR Biosciences, Lincoln, NE) and densitometry was performed using Odyssey Infrared Imaging software (V. 3.0.29).

The adipose tissue stored in formalin were processed by a trained pathologist using a tissue processor. The tissue was embedded using molten paraffin and allowed to harden on a cryo console. The tissue was then removed from the mold and placed in the refrigerator until it was sliced. Before staining, the slides were deparaffinized using xylene, and the nucleus and cytoplasm were stained with hematoxylin and eosin, respectively. Once the slides were fixed, adipocyte volume and counts were recorded using Image J software (NIH Image J; NIH, Bethesda, MD). 


\section{Calculations and Statistical Analyses}

Plasma and serum data were analyzed using a mixed model with repeated measures in SAS (V 9.3, SAS Institute Inc., Cary, NC). The model included the random effect of cow, and the fixed effects of treatment, day relative to parturition, and their interaction. The SLICE effect was utilized to analyze treatment differences by time. Studentized residuals $<-3$ or $>3$ were considered outliers and were removed from the dataset (typically no more than 2 per analysis). When necessary, data were transformed and presented in the original scale. Parametric Pearson correlations were performed to determine associations between measures of insulin sensitivity (GIR, SS glucose, pAKT) and adiposity, basal FFA, glucose, and BHBA. The significance level was set at $P \leq 0.05$, and trends toward significance were considered at $0.05<P \leq 0.10$. The insulin sensitivity index was calculated as follows: SI $_{\text {Clamp }}=$ glucose infusion rate/ [(steady state glucose $) \times($ steady state insulin - basal insulin)], (Muniyappa et al., 2007).

\section{Results}

Body condition scores at enrollment were significantly different between lean $(3.0 \pm 0.16)$ and overweight $(3.9 \pm 0.30)$ cows $(P<0.001)$. For all cows, adiposity declined during the transition from gestation to lactation (Figure 4.1), more so for cows with enhanced prepartum adiposity. Specifically, overweight cows experienced a $29 \%$ decrease in BCS $(P<0.001$; Figure $4.1 \mathrm{~A}$ and 4.1D), a $15 \%$ decrease in BW $(P<0.001$; Figure 4.1B and 4.1E), and a $37 \%$ decrease in BFT (Figure 4.1C and 4.F), relative to lean cows. Moreover, prepartum adipocyte volume was significantly augmented for overweight cows (Figure 4.2A; $P<0.01$ ), a response that was negated by the transition from gestation to lactation. Although adipocyte number was not affected by gestational adiposity, adipocyte volume decreased $14 \%$ from pre- to postpartum (Figure $4.2 ; P<$ 
0.01). Changes in adiposity loss were not due to changes in DMI, a response variable that declined as parturition approached but was comparable for lean and overweight dairy cows (Figure 4.3).

Overweight cows tended to exhibit increased milk yields compared to lean cows (Figure 4.4A; $P=0.08$ ), which may be attributed to more severe negative energy balance and thus weight loss. Notably, milk yield declined briefly following the HEC procedure on d 12 postpartum (Figure 4.4A; $P<0.01$ ), a response that can be attributed to the reduction in intake observed the previous day (Figure 4.3). Regarding milk composition, milk fat yield and percentage was greater in cows with enhanced prepartum adiposity (Figure 4.4B-C; $P<0.05$ ). Milk protein yield (Figure 4.4D; $P=0.11$ ) and milk protein percentage were not affected by adiposity, but milk protein percentage decreased over time as milk yield increased (Figure 4.4E; $P<0.001)$. Milk lactose yield and content increased with time $(P<0.001$; Figure $4.4 \mathrm{~F}$ and 4.4G), a variable that was not influenced by adiposity.

Prepartum adiposity did not modify plasma glucose concentrations (Figure 4.5A); however circulating glucose concentrations spiked by $20 \%$ at parturition $(P<0.001)$. Overweight cows displayed elevated circulating FFA concentrations throughout the peripartum (Figure 4.5B and Table 4.2; $P<0.001$ ). Noticeably, overweight cows experienced a 74\% increase in FFA concentration at parturition relative to lean cows. The increase in circulating FFA postpartum was accompanied by a reduction in circulating insulin (Table $4.2 ; P<0.05$ ). As expected, elevated postpartum plasma FFA levels were accompanied by increased liver lipid accumulation in overweight cows (Figure 4.6A; $P<0.05$ ). Furthermore, hepatic lipid deposition developed concomitantly with increased circulating BHBA levels (Figure 4.6B; $P<0.001$ ), more so in overweight cows. 
Measurements of systemic insulin sensitivity following the HEC are described within Table 4.2. At the time of prepartum and postpartum HEC, BCS was significantly higher for overweight cows compared to lean cows $(P<0.001)$. Prepartum, basal serum FFA and glucose concentrations were comparable; however, postpartum basal serum FFA levels were moderately elevated in overweight cows $(P<0.05)$, while plasma glucose remained stable. Additionally, circulating basal insulin levels were not affected by adiposity $(P=0.13)$. During the HEC, steady state (SS) insulin increased $332 \%$, relative to basal insulin levels; a response that was not modified by adiposity group. Demonstrating the effectiveness of the HEC, euglycemia was maintained as demonstrated by SS glucose levels that were comparable to basal glucose levels. Additionally, the HEC lowered circulating FFA levels during SS. As a direct measure of insulin sensitivity, peripartal glucose infusion rate (GIR) was not affected by adiposity, albeit GIR increased $63 \%$ postpartum $(P<0.01)$. Accounting for changes in glucose and insulin, $\mathrm{SI}_{\text {Clamp }}$ values were lower for overweight cows postpartum $(P<0.05)$.

Under normal physiological conditions protein kinase B is phosphorylated in response to insulin and causes GLUT4 to translocate to the plasma membrane to support glucose uptake (Summers et al., 1998). In the present study, the ratio of basal phosphorylated AKT to total AKT (pAKT/tAKT) in SubqAT was not affected by adiposity; however, SubqAT pAKT/tAKT decreased from pre- to postpartum (Figure 4.7A; $P<0.05$ ). Similarly, adiposity did not modify pAKT/tAKT in insulin-stimulated SubqAT, but pAKT/tAKT decreased during the transition from gestation to lactation (Figure 4.7B; $P<0.01$ ).

Pearson correlation analysis was performed between BCS at the time of HEC (BCS $\mathrm{BEC}_{\text {), }}$ BCS loss, pAKT/tAKT in basal and insulin-stimulated SubqAT, and HEC variables (basal and SS FFA, glucose, insulin; GIR; and $\mathrm{SI}_{\mathrm{Clamp}}$ ) both pre- and postpartum. Prepartum, BCS $\mathrm{HEC}_{\mathrm{H}}$ 
tended to be positively correlated with basal insulin concentration $(r=0.38 ; P=0.09)$.

Postpartum, we detected a positive correlation between $\mathrm{BCS}_{\mathrm{HEC}}$ and basal FFA $(r=0.39 ; P=$ $0.05)$, basal insulin $(r=0.51 ; P<0.05)$, and SS insulin $(r=0.43 ; P<0.05)$, and a tendency for a positive correlation between BCS $\mathrm{HEC}_{\mathrm{H}}$ and SS FFA $(r=0.39 ; P<0.09)$. We also detected a negative correlation between BCS loss and $\mathrm{SI}_{\text {Clamp }}$ postpartum $(r=-0.48 ; P<0.05)$. We detected a negative association between prepartum basal SubqAT pAKT/tAKT and basal glucose concentration $(r=-0.50 ; P<0.05)$, However, we were not able to detect any other correlations between SubqAT pAKT/tAKT and HEC variables.

\section{Discussion}

Periparturient dairy cows experience a dynamic shift in adipose tissue metabolism from energy storage at the end of lactation to rapid mobilization to meet the energy demands associated with lactation (McNamara, 1991). During the transition from gestation to lactation, adipocytes become insulin resistant, and basal and catecholamine-stimulated lipolysis is enhanced, representing a homeorhetic adaptation to partition nutrients to the mammary gland and support milk production (Bauman and Currie, 1980; McNamara, 1991; Vernon, 2005). Since overweight cows display greater FFA mobilization, we hypothesized that overweight cows would experience a greater reduction in systemic and adipose tissue specific insulin sensitivity compared to lean cows during the peripartal period.

Reaffirming the adequacy of our experimental design, overweight cows had greater prepartum BCS, BW, BFT, and adipocyte volume relative to their lean counterparts. While all cows experienced a significant reduction in adiposity measurements during the experimental period, overweight cows experienced a greater reduction relative to lean cows. All cows exhibited a surge in plasma FFA and BHBA at calving, followed by sustained elevations for 
these metabolites postpartum, leading to higher hepatic lipid deposition relative to prepartum. Further supporting the observation of greater adipose tissue mobilization, overweight cows had higher circulating FFA levels, exhibited greater hepatic lipid deposition, and as a consequence displayed elevated plasma BHBA levels compared to their lean counterparts. Consistent with these observations, DeKoster and coworkers (2016) found that adipocyte size increases with increasing BCS and that larger fat cells have higher basal and isoproterenol (an isopropyl analog of epinephrine)-stimulated lipolytic activity. Moreover, changes in peripartal overnutrition may mediate these responses. For example, Mann and coworkers (2016) overfed cows energy (150\% of predicted requirements) during the dry period and these cows displayed increased circulating FFA and BHBA concentrations postpartum whereas cows that were fed a diet to meet requirements benefited from improved metabolic health. However, Mann et al. (2016) did not observe changes in adipose tissue hormone sensitive lipase activity in response to overfeeding, indicating that the rate of lipolysis was similar between cows fed at different energy levels.

As expected, dry matter intake declined around parturition. This can partially be explained by reduced rumen volume due to a growing fetus. Additionally, ketones can suppress appetite (Allen et al., 2014), and potentially the characteristic reduction in leptin around parturition may inactivate orexigenic hypothalamic signals (Liefers et al., 2003). While we did not observe a difference in DMI between lean and overweight cows, the effects of adiposity on DMI in previous studies are inconclusive (Kokkonen et al., 2005; Samii et al., 2015). Both lean and overweight cows increased milk production over time, which can be explained by a reduction in insulin and insulin sensitivity postpartum to facilitate glucose sparing for lactose production. In the present study, overweight cows tended to produce more milk than lean cows. This increase in milk yield for overweight cows is in contrast to the work of Zachut and 
coworkers (2013), who observed that cows experiencing high weight loss produced less milk than cows experiencing low weight loss. However, it is important to note that animals diagnosed with a clinical metabolic disease will have a reduction in milk yield (Deluyker et al., 1991; Lean et al., 1994), and animals that are more insulin resistant will produce more milk (De Koster and Opsomer, 2013). Therefore, a possible explanation for the increased milk yield in our overweight cows is that they were not diagnosed with a metabolic disease. In support, other researchers have reported elevated milk yield in cows with greater BCS when they were metabolically healthy (Roche et al., 2006; Roche et al., 2007; McCarthy et al., 2007). Furthermore, the increased milk yield in overweight animals suggests they were experiencing greater negative energy balance, insulin resistance, and partitioning of nutrients to the mammary gland. In support of greater nutrient partitioning, overweight cows displayed increased milk fat concentrations and percentage due to elevated lipolysis and FFA availability. Lactose concentration increased over time with increasing milk production since lactose is the major osmotic regulator of milk volume.

Changes in circulating FFA are often related to pancreatic insulin secretion (Crespin et al., 1969; Crespin et al., 1973). In monogastrics, insulin resistance is characterized by elevated levels of blood insulin (Reaven et al., 1988; Thévenod, 2008), whereas ruminants experience insulin resistance during a characteristic decline in insulin concentration postpartum (Bauman and Currie, 1980; Bell, 1995; Bell and Bauman, 1997). We observed that independent of adiposity, basal insulin concentrations decreased postpartum, which is supported by Zachut and coworkers (2013). This reduction in insulin can contribute to the glucose sparing effect characteristic of early lactation. This is demonstrated by the reduction in circulating glucose observed postpartum, a response that can be exacerbated by reduced hepatic glucose synthesis 
due to lipid deposition (Piepenbrink and Overton, 2003b). Whereas we observed no effect of adiposity on insulin concentration pre- or postpartum, Rico and colleagues (2015), observed that overweight cows had higher circulating insulin concentrations than lean cows both pre- and postpartum; however, their investigation did not include an evaluation of DMI which may explain their insulin response (Drackley et al., 2005). Moreover, we found that adiposity did not affect plasma glucose concentrations prepartum. Overfeeding dietary energy has been demonstrated to increase circulating glucose during late gestation (Mann et al., 2016); however, in our study DMI was comparable for lean and overweight cows; therefore, propionate supply for hepatic gluconeogenesis was likely comparable.

We have previously observed that overweight cows have impaired systemic insulin sensitivity during the transition from gestation to lactation as estimated using the revised quantitative insulin sensitivity check index (RQUICKI; Holtenius and Holtenius, 2007; Rico et al., 2015). However, we now contemplate the validity of using estimates of insulin sensitivity since they rely heavily on FFA concentrations and have been demonstrated not to be correlated with direct measurements of insulin sensitivity in periparturient dairy cows (Schoenberg et al., 2012; Samii et al., 2015). Additionally, overconditioned ewes experienced a reduction on insulin sensitivity as indicated by an HEC (Bergman et al., 1989). Therefore, we decided to use the gold standard HEC approach for measuring insulin sensitivity and also determine if changes in systemic insulin sensitivity are due to local changes in adipose tissue.

From the pre- to postpartum HEC, both groups experienced an increase in basal and SS FFA. Furthermore, SS insulin was reduced. Other than elevated basal FFA and numerically higher basal insulin postpartum, overweight cows displayed no differences in HEC blood metabolite parameters. While GIR increased for both groups from pre- to postpartum due to 
increase glucose requirements for milk synthesis, we did not detect an effect of adiposity on GIR. However, when accounting for changes in glucose and insulin, we demonstrated decreased systemic insulin sensitivity in overweight cows postpartum using the SI Clamp. We have previously observed no effect of adiposity in response to an ITT or GTT (Samii et al., 2015). However, Samii et al. (2015) did not measure circulating insulin during the tolerance tests and therefore insulin maybe have been higher in overweight cows even though plasma glucose concentrations remained stable. Furthermore, the doses of insulin and glucose given previously were supraphysiological (insulin: $0.1 \mathrm{IU} / \mathrm{kg} \mathrm{BW}$; glucose: $0.3 \mathrm{~g} / \mathrm{kg} \mathrm{BW}$ ) and therefore may not be practical for determining insulin sensitivity (Samii et al., 2015). Lastly, these tests were given in the afternoon following morning feeding, whereas the HEC in the present study was performed before feeding. In support of our findings, we have also observed that glucose-stimulated reduction of plasma fatty acids following a GTT decreased from pre- to postpartum and was lower for overweight cows (Samii et al., 2015; Rico et al., 2017). When considering simultaneous changes in glucose and insulin, our work suggests that overweight cows experience a reduction in systemic insulin sensitivity compared to lean cows.

In the present study the ratio of pAKT/tAKT decreased from pre- to postpartum as expected. However, we were unable to detect an effect of adiposity or adiposity loss on pAKT/tAKT pre- and postpartum. This result is consistent with the results of Mann and coworkers (2016) in cows previously fed a high plane of nutrition during the dry period; however, we note that their cows had markedly lower BFT measurements than the cows in our study, and the difference between their treatment groups was not as dramatic. It has been hypothesized that the reason overweight cows exhibit higher concentrations of FFA is either due to specific changes in the lipolytic activity of adipose tissue or due to the greater amount of fat to 
mobilize (Rukkwamsuk et al., 1998; Herdt, 2000). While we did not observe any changes in adipose tissue insulin signaling in overweight cows via AKT, Zachut and coworkers (2013) measured AKT phosphorylation in SubqAT before and after a GTT and found decreased pAKT/tAKT only in the cows who experienced high weight loss, suggesting adipose tissuespecific insulin resistance in these cows. DeKoster and coworkers (2016) observed that larger adipocytes tend to be more resistant to the maximal antilipolytic effect of insulin. Therefore, perhaps insulin signaling in adipose tissue could be affected via alternative mechanisms besides AKT phosphorylation. For example, Choi and coworkers (2010) found that insulin regulates adipocyte lipolysis through an AKT-independent, PI3K-dependent signaling pathway, which leads to selective PKA phosphorylation of perilipin, while HSL activation remains AKTdependent. We also suggest that adipose tissue depots in distinct locations may respond differently to changes during the periparturient period. For example, Locher and colleagues (2011) suggest that retroperitoneal adipose tissue is more sensitive to periparturient changes in HSL phosphorylation than SubqAT. In contrast to this hypothesis, De Koster and coworkers (2016) found that independently of the location of the adipose tissue (Subq or omental), lipolytic activity increased with adipocyte volume. Lastly, insulin-stimulated phosphorylation of AKT is impaired in humans with insulin resistance and type 2 diabetes (Karlsson et al., 2005). We note that it is possible that changes in systemic insulin sensitivity could be due to insulin antagonism in skeletal muscle, rather than in adipose tissue of overweight dairy cows. Further research is needed to investigate this possibility in dairy cows.

\section{Conclusion}

In the present study all cows experienced elevated FFA, liver lipid, and BHBA concentrations during the transition from gestation to lactation, and these responses were more 
severe for overweight cows. While we did observe a decrease in SubqAT pAKT/tAKT indicating reduced adipose-tissue specific insulin signaling postpartum, the elevations in FFA, liver lipid, and BHBA in overweight cows were not due to changes in SubqAT AKT phosphorylation. More severe systemic insulin resistance developed in overweight cows postpartum when accounting for changes in insulin and glucose. This result is potentially due to numerically higher insulin concentrations in overweight cows with no change in glucose concentrations. Further research is needed to determine if overweight cows mobilize a greater amount of adipose tissue due to specific changes in adipose tissue signaling leading to greater lipolysis or simply because of a greater amount of adipose tissue mass. Additionally, future work should investigate insulin sensitivity changes in different adipose depots, as well as skeletal muscle, and investigate AKTindependent pathways. 


\section{TABLES AND FIGURES}

Table 4.1. Feed ingredients and composition (\% of DM unless otherwise noted) for all cows from $28 \mathrm{~d}$ before to $28 \mathrm{~d}$ after parturition.

\begin{tabular}{lcc}
\hline & & Diet \\
\cline { 2 - 3 } Item & $\mathrm{d}-28$ to parturition & Parturition to d 28 \\
\hline Ingredient & 29.0 & 33.2 \\
Corn silage & 21.7 & 8.61 \\
Mixed grass haylage & 25.0 & 1.95 \\
Mixed grass hay & 2.72 & 20.8 \\
Dry ground corn & 12.8 & - \\
Prepartum mix ${ }^{2}$ & - & 17.8 \\
Lactation mix A & 5.72 \\
Aminoplus & 5.82 & 4.35 \\
Cottonseed with lint & - & 3.40 \\
Sugar cane syrup & - & 4.19 \\
Lactation mix B & - & - \\
Close-up supplement & & \\
Nutrient composition & 3.01 & 51.7 \\
DM, \% & & 31.1 \\
NDF & 51.3 & 19.8 \\
ADF & 47.9 & 15.5 \\
CP & 30.5 & 4.80 \\
Crude Fat & 13.4 & 7.90 \\
Ash & 3.30 & 1.70 \\
NEL Mcal/kg DM & 8.30 & . \\
\hline
\end{tabular}

${ }^{1}$ Mix contained 27\% commercial dry cow mix with Animate (Phibro Animal Health Corp., Teaneck, NJ), $17.3 \%$ ground corn, $17.3 \%$ crimped oats, $13 \%$ corn distillers, $12.9 \%$ soybean meal, $4.3 \%$ calcium carbonate, $4.3 \%$ calcium sulfate, 2.6\% Omnigen AF (Phibro Animal Health Corp.), 1.1 Monocalcium phosphate, and < $1 \%$ of each of the following: Sel-plex 600 (Alltech Biotechnology, Nicholasville, KY) and vitamin $\mathrm{E}$.

${ }^{2}$ Mix contained $33.6 \%$ citrus pulp, $19 \%$ soybean meal. $15.6 \%$ canola meal, $14 \%$ soybean hulls, $4.5 \%$ calcium carbonate, $4.5 \%$ sodium bicarbonate, $2.8 \%$ urea, $2.7 \%$ fat, $2.4 \%$ sodium chloride, and $<1 \%$ from each of the following: Monocalcium phosphate, biotin, and Rumensin 90 (Elanco Animal Health, Greenfield, IN).

${ }^{3}$ Mix contained $43.6 \%$ Fermenten (Church and Dwight Co., Princeton, NJ), 21.8\% calcium carbonate, $10.8 \%$ soybean hulls, 7.8\% Mintrex blend (Novus International Inc., St. Charles, MO), 5.2\% blood meal, $3.5 \%$ mag- nesium oxide, 2.6\% Celmanax (Vi-COR, Mason City, IA), 2.6\% Omnigen (Phibro Animal Health Corp.), and $<1 \%$ of each of the following: vitamin E, selenium selenite, and selenium yeast 600 .

${ }^{4}$ Mix contained $74.5 \%$ ground oats, $15.3 \%$ commercial amino acid, $8 \%$ Reashure (Balchem Encapsulates, Slate Hill, NY), and $<1 \%$ of each of the following: vitamin E and Niashure (Balchem Corporation, New Hampton. 
Table 4.2. Metabolic responses to hyperinsulinemic-euglycemic clamp.

\begin{tabular}{|c|c|c|c|c|c|c|c|c|c|}
\hline \multirow[b]{3}{*}{ Item } & \multicolumn{6}{|c|}{$\mathrm{BCS}^{1}$} & \multirow{2}{*}{\multicolumn{3}{|c|}{$\frac{P \text {-value }}{\text { Main Effects }^{3}}$}} \\
\hline & \multicolumn{3}{|c|}{ Prepartum } & \multicolumn{3}{|c|}{ Postpartum } & & & \\
\hline & Lean & Over & $\mathrm{SEM}^{2}$ & Lean & Over & SEM & $\mathrm{BCS}$ & Stage & $\begin{array}{l}\text { BCS } \times \\
\text { Stage }\end{array}$ \\
\hline BCS at time of HEC & 2.97 & $3.92 *$ & 0.05 & 2.58 & $3.33^{*}$ & 0.05 & $<0.01$ & $<0.01$ & 0.10 \\
\hline Basal FFA (mmol/L) & 715 & 784 & 91.70 & 1020 & $1300 *$ & 85.4 & 0.10 & $<0.01$ & 0.14 \\
\hline SS FFA (mmol/L) & 182 & 220 & 28.14 & 319 & 437 & 56.9 & 0.11 & $<0.01$ & 0.65 \\
\hline Basal Glucose (mg/dL) & 63.4 & 60.3 & 3.84 & 57.9 & 61.3 & 3.65 & 0.98 & 0.53 & 0.37 \\
\hline SS Glucose (mg/dL) & 66.2 & 65.2 & 3.70 & 63.4 & 69.4 & 3.88 & 0.54 & 0.84 & 0.33 \\
\hline Basal Insulin $(\mu \mathrm{U} / \mathrm{mL})$ & 7.72 & 11.1 & 2.13 & 3.71 & 8.4 & 2.09 & 0.13 & 0.04 & 0.65 \\
\hline SS Insulin $(\mu \mathrm{U} / \mathrm{mL})$ & 42.8 & 41.3 & 3.02 & 22.6 & 28.0 & 2.94 & 0.52 & $<0.01$ & 0.25 \\
\hline $\mathrm{GIR}^{4}(\mu \mathrm{mol} / \mathrm{min} / \mathrm{kg})$ & 11.8 & 11.9 & 1.43 & 21.4 & $17.4^{*}$ & 1.42 & 0.18 & $<0.01$ & 0.16 \\
\hline $\mathrm{SI}_{\text {clamp }} 5$ & 0.15 & 0.17 & 0.03 & 0.51 & $0.26^{*}$ & 0.03 & $<0.01$ & $<0.01$ & $<0.01$ \\
\hline
\end{tabular}

${ }^{1}$ Treatment were overweight cows during prepartum and postpartum.

${ }^{2} \mathrm{SEM}$ is the average between lean and overweight standard errors.

${ }^{3}$ Main effects across prepartum and postpartum, $\mathrm{d}-10$ and +12 respectively, during treatment. Data are presented as LS Means \pm SEM. $* P<0.05$, Lean vs. Overweight.

${ }^{4}$ Glucose infusion rate.

${ }^{5}$ Insulin sensitivity index $=($ GIR $/[$ SS Glucose $\times($ SS Insulin - Basal Insulin $)$ 
Figure 4.1. Effects of adiposity on body fat mass. (A) BCS, (B) BW, and (C) BFT records during the transition from gestation to lactation; (D) changes in BCS, (E) BW, and (F) between d -21 and 28 d relative to parturition. Data are presented as least square means and their standard errors. $* P<0.001$.

Figure 4.2. Effects of adiposity on adipocyte histology. (A) Adipocyte volume and (B) adipocyte count per $743.8 \times 557.9 \mu \mathrm{m}$ reading frame measured in SubqAT at $12 \mathrm{~d}$ before and $10 \mathrm{~d}$ after parturition. Data are presented as least square means and their standard errors. ${ }^{*} P<0.001$.

Figure 4.3. Effects of adiposity on dry matter intake (DMI). DMI between d -21 and d 28 relative to parturition. Data are presented as least square means and their standard errors.

Figure 4.4. Effects of adiposity on milk production and composition. (A) Milk yield from d 0 until d 28 relative to parturition; (B) fat yield, (C) fat percent, (D) protein yield, (E) protein percent, (F) lactose yield, and (E) lactose percent in milk on d 1, 3, 5, 7, 10, 12, 14, 21, and 28 relative to parturition. Data are presented as least square means and their standard errors.

Figure 4.5. Effects of adiposity on blood metabolites. (A) plasma glucose and (B) free fatty acid (FFA) concentrations from d -21 to $\mathrm{d} 28$ relative to parturition. Data are presented as least square means and their standard errors.

Figure 4.6. Effects of adiposity on (A) liver lipid percentage and (B) plasma BHBA concentrations from d -21 to $\mathrm{d} 28$ relative to parturition. Data are presented as least square means and their standard errors. 
Figure 4.7. Effects of adiposity on localized insulin signaling. Ratio of phosphorylated to total protein kinase B (AKT) in (A) basal and (B) insulin-stimulated subcutaneous adipose tissue explants (SubqAT) on d -12 and d 10 relative to parturition. Data are presented as least square means and their standard errors. 

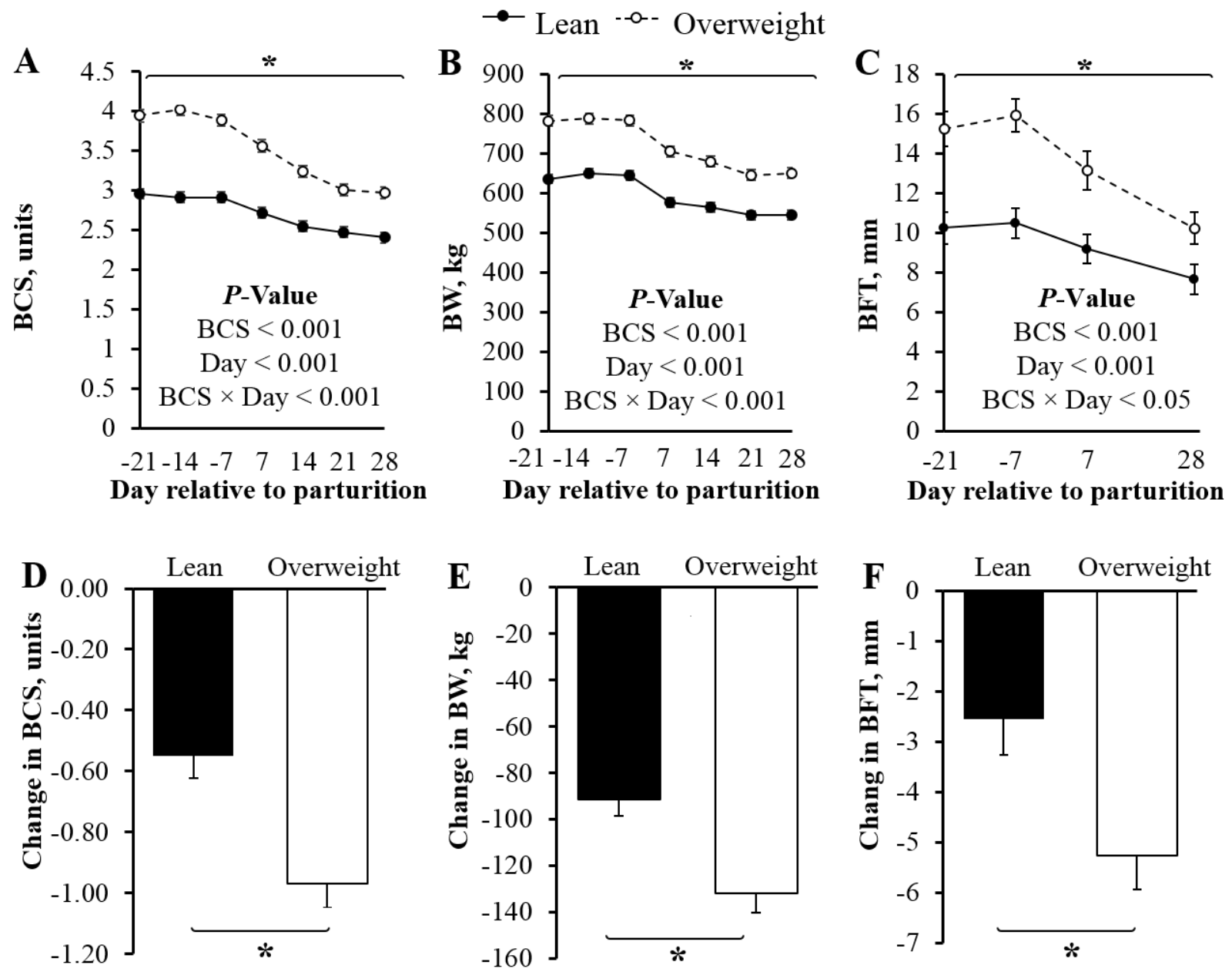

Figure 4.1 
- Lean $\square$ Overweight
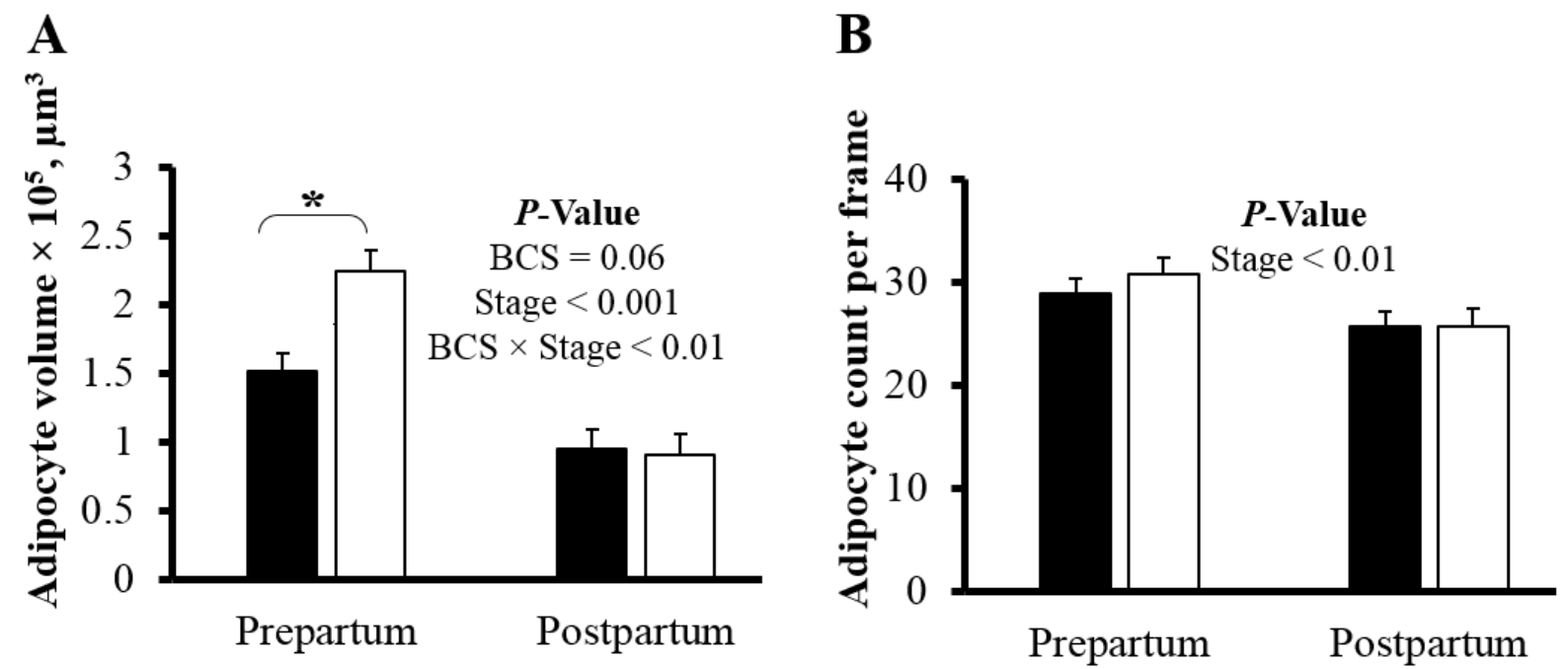

Figure 4.2 


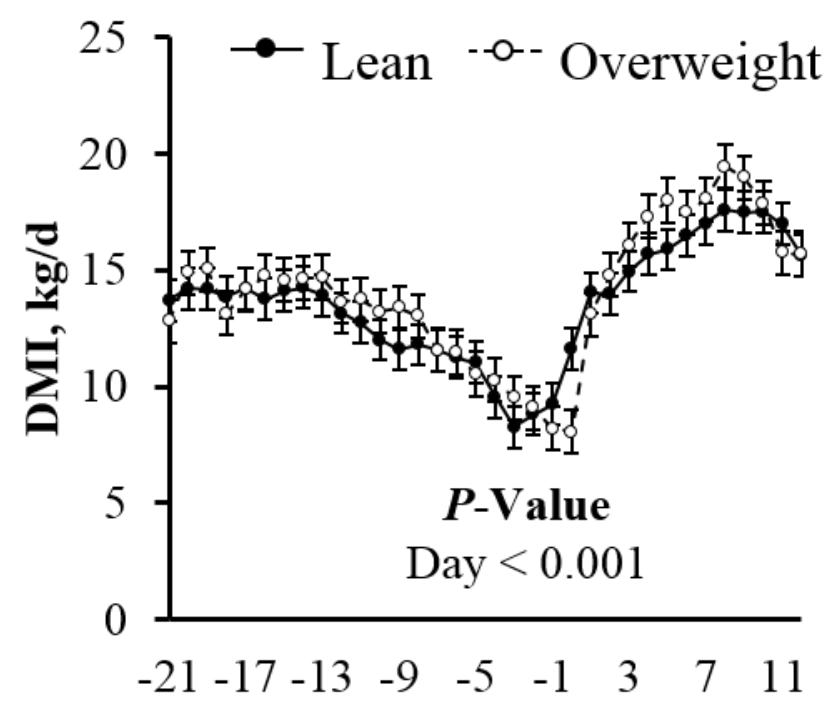

Day relative to parturition

Figure 4.3 

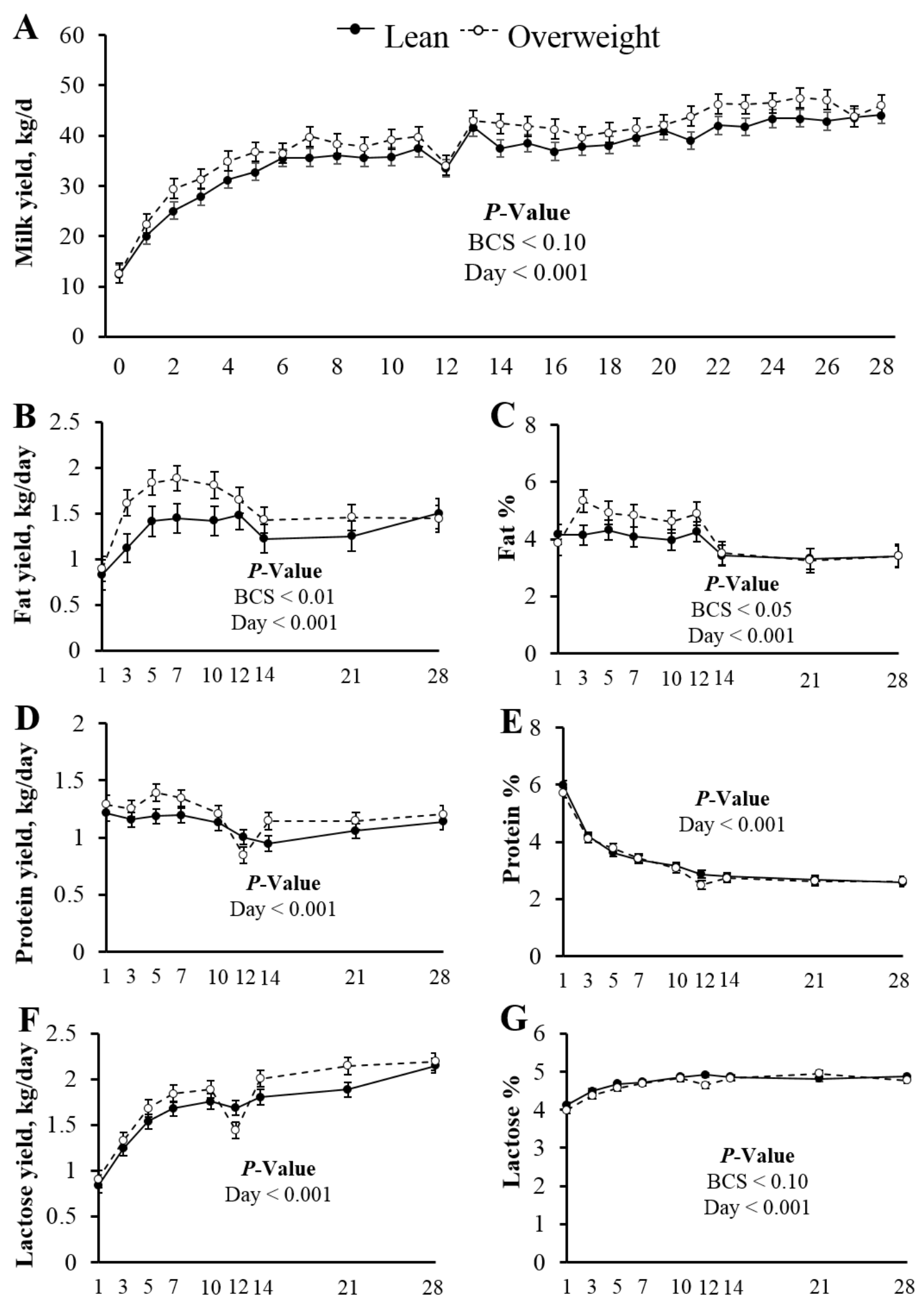

Day relative to parturition

Figure 4.4 
$\rightarrow$ Lean -a- Overweight
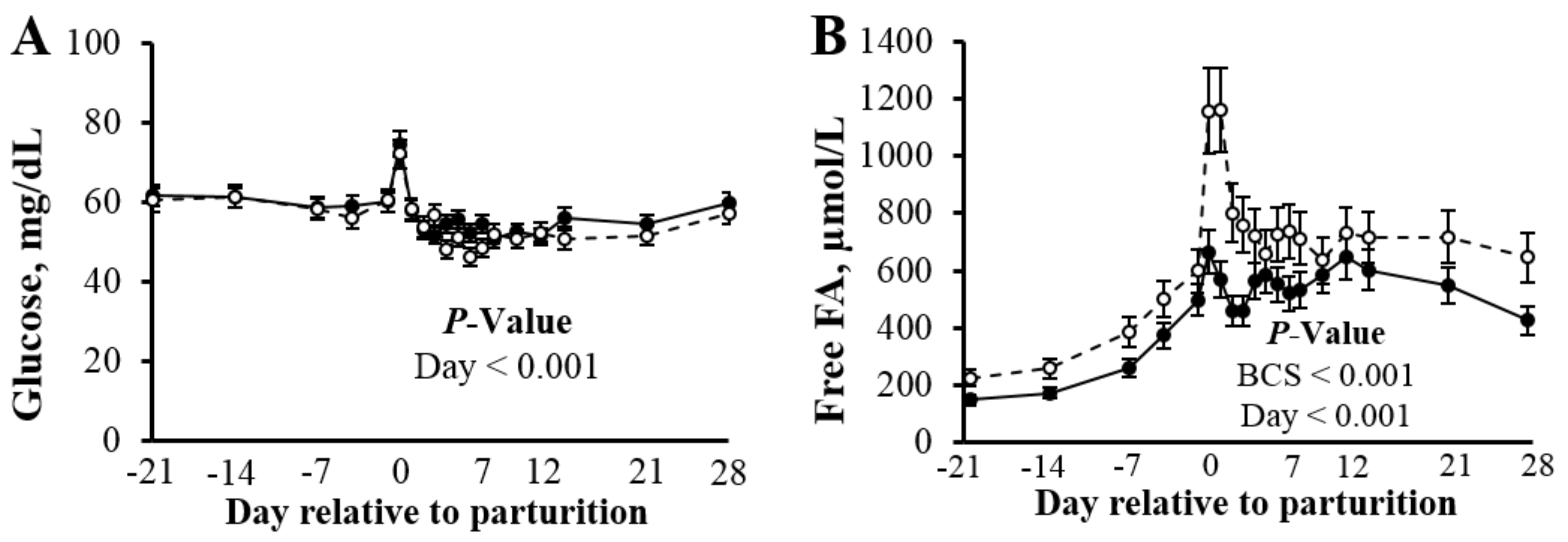

Fig. 4.5 
- Lean $\square$ Overweight
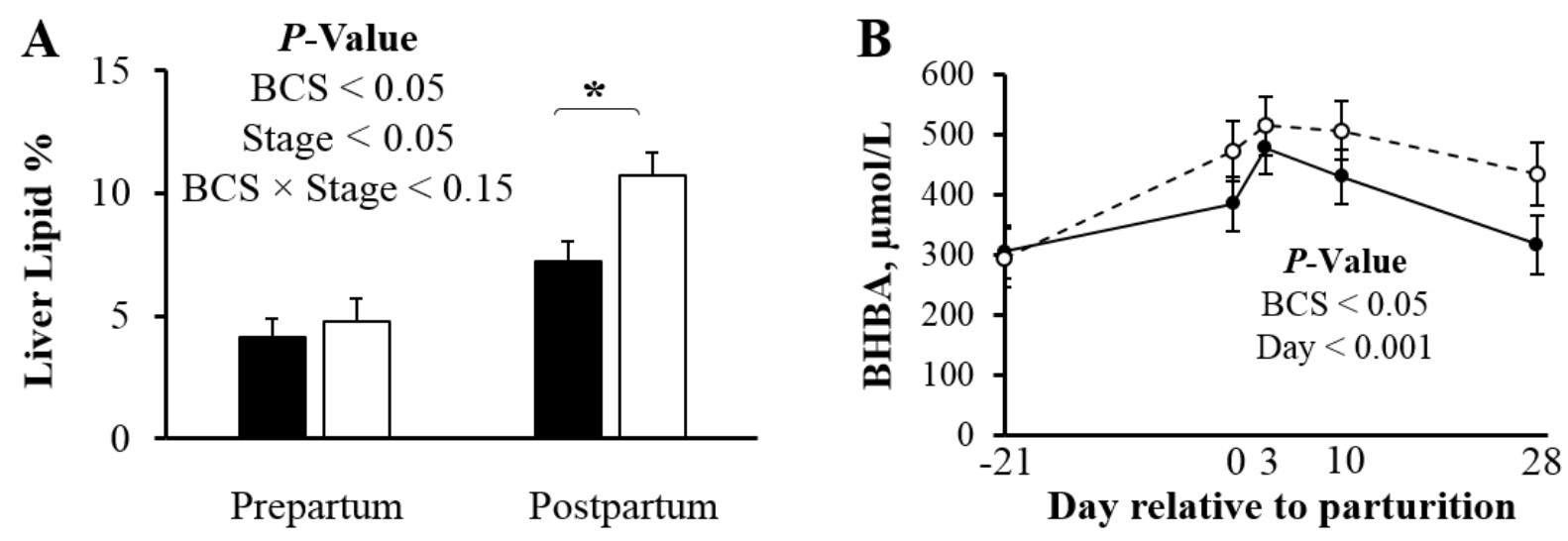

Fig. 4.6 
- Lean $\square$ Overweight
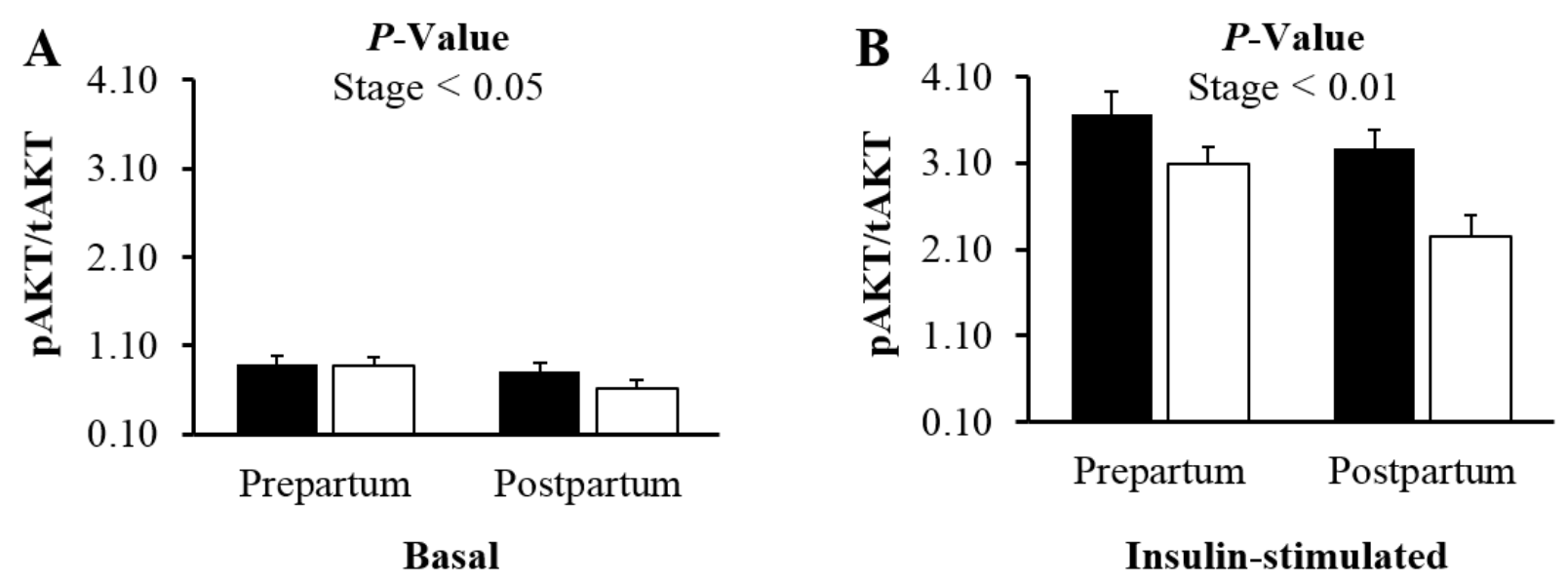

Figure 4.7 


\section{Chapter 5}

\section{GENERAL CONCLUSIONS}

With the experiments presented in this thesis, we have evaluated the relationship between free fatty acid supply, ceramide, and insulin sensitivity in dairy cows. We used a mass spectrometry to quantify ceramide in serum and in the liver. We also determined that nutrient restriction causes elevations in FFA, circulating ceramide, and hepatic ceramide and that long chain ceramide is negatively associated with insulin sensitivity. Additionally, we used the goldstandard approach for directly measuring systemic insulin sensitivity in lean and overweight cows and found that prepartum adiposity reduced systemic insulin sensitivity when taking into account basal glucose and insulin concentrations. Contrary to our original hypothesis prepartum adiposity did not impair localized insulin sensitivity via AKT-dependent mechanisms. Overall, we show that elevations in FFA either through nutrient restriction or due to enhanced prepartum adiposity and lipolysis can impair systemic insulin sensitivity. Our results suggest that ceramide accrual represents a metabolic adaptation to nutrient restriction and impaired insulin action in dairy cows.

Future research should determine the compartmental origin of circulating ceramide, demonstrate that ceramides are a causal inhibitor of insulin action, develop novel nutritional interventions to prevent ceramide accumulation, and determine the efficacy of using 24:0ceramide as a biomarker for metabolic disease. Coming work should also consider whether the cause of elevated circulating FFA in overweight cows is due to specific changes in signaling in distinct adipose tissue depots or due to greater fat mass to mobilize. Collectively, these approaches have the potential to delineate the coordinated shift in metabolism that occurs during the periparturient period in order to improve dairy cow health. 


\section{BIBLIOGRAPHY}

Allen, M. S., B. J. Bradford, and M. Oba. 2009. The hepatic oxidation theory of the control of feed intake and its application to ruminants. Amer. Soc. Anim. Sci. 87:3317-3334.

Aschenbach, J. R., N. B. Kristensen, S. S. Donkin, H. M. Hammon, and G. B. Penner. 2010. Gluconeogenesis in dairy cows: The secret of making sweet milk from sour dough. Life 62:869-877.

Avruch, J. 1998. Insulin signal transduction through protein kinase cascades. Mol. Cell Biochem. 182:31-48.

Bae, S. S., H. Cho, J. Mu, and M. J. Birnbaum. 2003. Isoform-specific regulation of insulindependent glucose uptake by Akt/protein kinase B. J Biol. Chem. 278: 49530-49536.

Bandaru, V. V, M. M. Mielke, N. Sacktor, J. C. McArthur, I. Grant, S. Letendre, L. Chang, V. Wojna, C. Pardo, P. Calabresi, S. Munsaka, N. J. Haughey. 2013. A lipid storage-like disorder contributes to cognitive decline in HIV-infected subjects. Neurol. 81:1492-1499.

Bauchart, D., D. Gruffat, and D. Durand. 1996. Lipid absorption and hepatic metabolism in ruminants. Proc. Nutr. Soc. 55:39-47.

Bauman, D. E. and R. G. Vernon. 1993. Effects of exogneous bovine somatotropin on lactation. Annu. Rev. Nutr. 13:437-461.

Bauman, D. E. and W. B. Currie. 1980. Partitioning of nutrients during pregnancy and lactation: A review of mechanisms involving homeostasis and homeorhesis. J. Dairy Sci. 63:15141529.

Beebe, S. J., J. B. Redmon, P. F. Blackmore, and J. D. Corbin. 1985. Discriminative insulin antagonism of stimulatory effects of various cAMP analogs on adipocyte lipolysis and hepatocyte glycogenolysis. J. Biol. Chem. 260:15781-15788. 
Bell, A. W. 1995. Regulation of organic nutrient metabolism during the transition from late pregnancy to early lactation. J. Anim. Sci. 73:2804-2819.

Bell, A. W. and D. E. Bauman. 1997. Adaptations of glucose metabolism during pregnancy and lactation. J. Mammary Gland Biol. Neoplasia 2:265-278.

Bennink, M. R., R.W. Mellenberger, R.A. Frobish, and D.E. Bauman. 1972. Glucose oxidation and entry rate as affected by the initiation of lactation. J. Dairy Sci., 55:712 (Abstr.).

Bergman, E. N. 1990. Energy contributions of volatile fatty acids from the gastrointestinal tract in various species. Physiological Reviews 70:567-590.

Bergman, E. N., S. S. Reulein, and R. E. Corlett. 1989. Effects of obesity on insulin sensitivity and responsiveness in sheep. Am. J. Phys. 257:E772-E781.

Bernabucci, U., B. Ronchi, L. Basiricò, D. Pirazzi, F. Rueca, N. Lacetera, and A. Nardone. 2004. Abundance of mRNA of apolipoprotein B100, apolipoprotein E, and microsomal triglyceride transfer protein in liver from periparturient dairy cows. J. Dairy Sci. 87:28812888.

Bernabucci, U., B. Ronchi, N. Lacetera, and A. Nardone. 2005. Influence of body condition score on relationships between metabolic status and oxidative stress in periparturient dairy cows. J. Dairy Sci. 88:2017-2026.

Bichell, D. P., K. Kikuchi, and P. Rotwein. 1992. Growth hormone rapidly activates insulin-like growth factor I gene transcription in vivo. Mol. Endocrinol. 6:1899-1908.

Bobe, G., J. W. Young, and D. C. Beitz. 2004. Invited review: pathology, etiology, prevention, and treatment of fatty liver in dairy cows. J. Dairy Sci. 87:3105-3124.

Boon, J., A. J. Hoy, R. Stark, R. D. Brown, R. C. Meex, D. C. Henstridge, S. Schenk, P. J. Meikle, J. F. Horowitz, B. A. Kingwell, C. R. Bruce, and M. J. Watt. 2013. Ceramides 
contained in LDL are elevated in type 2 diabetes and promote inflammation and skeletal muscle insulin resistance. Diabetes 62:401-410.

Caldari-Torres, C., A. L. Lock, C. R. Staples, and L. Badinga. 2011. Performance, metabolic, and endocrine responses of periparturient Holstein cows fed 3 sources of fat. J. Dairy Sci. 94:1500-1510.

Callahan, J. W., C. S. Jones, D. J. Davidson, and P. Shankaran. 1983. The active site of lysosomal sphingomyelinase: evidence for the involvement of hydrophobic and ionic groups. J. Neurosci. Res. 10:151-163.

Chavez, J. A. and S. A. Summers. 2010. Lipid oversupply, selective insulin resistance, and lipotoxicity: Molecular mechanisms. Biochim Biophys Acta. 1801:252-265.

Chavez, J. A. and S. A. Summers. 2012. A ceramide-centric view of insulin resistance. Cell Metab. 15:585-594.

Chavez, J. A., T. A. Knotts, L. P. Wang, G. Li, R. T. Dobrowsky, G. L. Florant, and S. A. Summers. 2003. A role for ceramide, but not diacylglycerol, in the antagonism of insulin signal transduction by saturated fatty acids. J. Biol. Chem. 278:10297-10303.

Choi, S. M., D. F. Tucker, D. N. Gross, R. M. Easton, L. M. DiPilato, A. S. Dean, B. R. Monks, and M. J. Birnbaum. 2010. Insulin regulates adipocyte lipolysis via an AKT-independent signaling pathway. Mol. Cell. Biol. 30:5009-5020.

Coleman, D. A., W. V. Thane, R. A. Dailey. 1985. Factors affecting reproductive performance of dairy cows. J. Dairy Sci. 68:1793-1803.

Contreras, L. L., C. M. Ryan, and T. R. Overton. 2004. Effects of dry cow grouping strategy and prepartum body condition score on performance and health of transition dairy cows. J. Dairy Sci. 87:517-523. 
Corbett, R. B. 2002. Influence of days fed a close-up dry cow ration and heat stress on subsequent milk production in western dairy herds. J. Dairy Sci. 85(Suppl. 1):191-192. (Abstr.)

Crespin, S. R., W. B. Greenough III., D. Steinberg. 1969. Stimulation of insulin secretion by infusion of free fatty acids. J. Clin. Invest. 48:1934-1943.

Crespin, S. R., W. B. Greenough III., D. Steinberg. 1973. Stimulation of insulin secretion by long chain free fatty acids. A direct pancreatic effect. J. Clin. Invest. 52:1979-1984.

Cross, D. A. E., D. R. Alessi, P. Cohen, M. Andjelkovich, and B. A. Hemmings. 1995. Inhibition of glycogen synthase kinase-3 by insulin mediated by protein kinase B. Nature 378:6559.

Dan, H. C., A. Ebbs, M. Pasparakis, T. V. Dyke, D. S. Basseres, and A. S. Baldwin. 2014. Aktdependent activation of mTORC1 complex involves phosphorylation of mTOR (mammalian target of rapamycin) by IкB kinase $\alpha$ (IKK $\alpha$ ). J. Biol. Chem. 289:2522725240.

Dann, H. M., N. B. Litherland, J. P. Underwood, M. Bionaz, A. D’Angelo, J. W. McFadden, and J. K. Drackley. 2006. Diets during far-off and close-up dry periods affect periparturient metabolism and lactation in multiparous cows. J. Dairy Sci. 89:3563-3577.

De Koster, J. D. and G. Opsomer. 2013. Insulin resistance in dairy cows. Vet. Clin. N. Am-Food A. 29:299-322.

De Koster, J., W. Van Den Broeck, L. Hulpio, E. Claeys, M. Van Eetvelde, K. Hermans, and G. Opsomer. 2016. Influence of adipocyte size and adipose depot on the in vitro lipolytic activity and insulin sensitivity of adipose tissue in dairy cows at the end of the dry period. J. Dairy Sci. 99:2319-2328. 
Degerman, E., C. J. Smith, H. Tornqvist, V. Vasta, V. C. Manganiello, and P. Belfrage. 1990. Evidence that insulin and isoprenaline activate the cGMP-inhibited low-Km cAMP phosphodiesterase in rat fat cells by phosphorylation. Proc. Natl. Acad. Sci. USA 87:53337.

Degerman, E., P. Belfrage, and V. C. Manganiello. 1997. Structure, localization, and regulation of cGMP-inhibited phosphodiesterase (PDE3). J. Biol. Chem. 272:6823-6826.

Degerman, E., T. R. Landstrom, J. Wijkander, L. S. Holst, F. Ahmad, P. Belfrage, and V. Manganiello. 1998. Phosphorylation and activation of hormone-sensitive adipocyte phosphodiesterase type 3B. Methods 14:43-53.

DeKoster, J. D. and G. Opsomer. 2013. Insulin resistance in dairy cows. Vet. Clinics North America: Food Anim Practice. 29:299-322.

Deluyker, H. A., J. M. Gay, L. D. Weaver, A. S. Azari. 1991. Change of milk yield with clinical diseases for a high producing dairy herd. J. Dairy Sci. 74:436-445.

Doornbos, R. P., M. Theelen, P. C. J. van der Hoeven, W. J. van Blitterswijk, A. J. Verkleij, and P. M. P. van Bergen en Henegouwen. 1999. Protein kinase $C \zeta$ is a negative regulator of protein kinase B activity. J. Biol. Chem. 274:8589-8596.

Douglas, G. N., T. R. Overton, H. G. Bateman, H. M. Dann, and J. K. Drackley. 2006. Prepartal plane of nutrition, regardless of dietary energy source, affects periparturient metabolism and dry matter intake in Holstein cows. J. Dairy Sci. 89:2141-2157.

Drackley, J. K. Biology of dairy cows during the transition period: the final frontier. 1999. J. Dairy Sci., 82:2259-2273. 
Duffield, T. F., K. D. Lissemore, B. W. McBride, and K. E. Leslie. 2009. Impact of hyperketonemia in early lactation dairy cows on health and production. J. Dairy Sci. 92:571-580.

Duncan, R. E., M. Ahmadian, K. Jaworski, E. Sarkadi-Nagy, and H. S. Sul. 2007. Regulation of lipolysis in adipocytes. Annu. Rev. Nutr. 27:79-101.

Eriksson, H., M. Ridderstrale, E. Degerman, D. Ekholm, C. J. Smith, V. C. Manganiello, P. Belfrage, and H. Tornqvist. 1995. Evidence for the key role of the adipocyte cGMPinhibited cAMP phosphodiesterase in the antilipolytic action of insulin. Biochim. Biophys. Acta. 1266:101-107.

Esposito, G., P. C. Irons, E. C. Webb, A. Chapwanya. 2014. Interactions between negative energy balance, metabolic diseases, uterine health and immune response in transition dairy cows. Anim. Repro. Sci. 144:60-71.

Foretz, M, C. Guichard, P. Ferre, and F. Foufelle. 1999. Sterol regulatory element binding protein-1c is a major mediator of insulin action on the hepatic expression of glucokinase and lipogenesis-related genes. Proc. Natl. Acad. Sci. USA 96:12737-12742.

Funaki, M. 2009. Saturated fatty acids and insulin resistance. J. Med. Invest. 56:88-92.

Garnsworthy, P. C., and G. P. Jones. 1987. The influence of body condition at calving and dietary protein supply on voluntary food intake and performance in dairy cows. Anim. Prod. 44:347-353.

Garnsworthy, P. C., and J. H. Topps. 1982a. The effect of body condition of dairy cows at calving on their food intake and performance when given complete diets. Anim. Prod. 35:113-119. 
Garnsworthy, P. C., and J. H. Topps. 1982b. The effects of body condition at calving, food intake, and performance in early lactation on blood composition of dairy cows given complete diets. Anim. Prod. 35:121-125

Gillard, B. K., R. G. Clement, D. M. Marcus. 1998. Variations among cell lines in the synthesis of sphingolipids de novo and recycling pathways. Glycobiol. 8:885-890.

Gillund, P., O. Reksen, Y. T. Grohn, K. Karlberg. 2001. Body condition related to ketosis and reproductive performance in Norwegian dairy cows. J. Dairy Sci., 84:1390-1396.

Grum, D. E., J. K. Drackley, R. S. Younker, D. W. LaCount, and J. J. Veenhuizen. 1996. Nutrition during the dry period and hepatic lipid metabolism of periparturient dairy cows. J. Dairy Sci. 79:1850-1864.

Hajduch, E., S. Turban, and X. Le Liepvre. 2008. Targeting of PKC $\zeta$ and PKB to caveolinenriched microdomains represents a crucial step underpinning the disruption in PKBdirected signalling by ceramide. Biochem. J. 410:369-379.

Hajduch, E., S. Turban, and X. Le Liepvre. 2008. Targeting of PKC $\zeta$ and PKB to caveolinenriched microdomains represents a crucial step underpinning the disruption in PKBdirected signalling by ceramide. Biochem. J. 410:369-379.

Hannun, Y. A. 1996. Functions of ceramide in coordinating cellular responses to stress. Science. 274:1855-1859.

Hara, A. and N. S. Radin. 1978. Lipid extraction of tissues with a ow-toxicity solvent. Analytical Biochem. 90:420-426. DeFronzo, R. A., J. D. Tobin, and R. Andres. 1979. Glucose clamp technique: a method for quantifying insulin secretion and resistance. Am. J. Phys. 237:G214-G223. 
Hart, I. C. 1983. Endocrine control of nutrient partition in lactating ruminants. Proc. Nutr. Soc. 42: 181-194.

Haughey, N. J, R. G. Cutler, A. Tamara, J. C. McArthur, J. L. Vargas, C. A. Pardo, J. Turchan, A. Nath, and M. P. Mattson. 2004. Perturbation of sphingolipid metabolism and ceramide production in HIV-dementia. Ann. Neurol. 55:257-267.

Haus, J. M., S. R. Kashyap, T. Kasumov, R. Zhang, K. R. Kelly, R. A. DeFronzo, and J. P. Kirwan. 2009. Plasma ceramides are elevated in obese subjects with type 2 diabetes and correlate with the severity of insulin resistance. Diabetes. 58:337-343.

Hedo, J. A. and I. A. Simpson. 1984. Internalization of insulin receptors in the isolated rat adipose cell. Demonstration of the vectorial disposition of receptor subunits. J. Biol. Chem. 259:11083-11089.

Heemskerk, M. M., S. A. van den Berg, A. C. Pronk, J. B. van Klinken, M. R. Boon, L. M. Havekes, P. C. Rensen, K. W. van Dijk, and V. van Harmelen. 2014. Long-term niacin treatment induces insulin resistance and adrenergic responsiveness in adipocytes by adaptive downregulation of phosphodiesterase 3B. Am. J. Physiol. Endocrinol. Metab. 306:E808-813.

Hirabayashi, Y., Y. Igarashi, and A. H. Merrill. 2006. Sphingolipids synthesis, transport and cellular signaling. In Sphingolipid biology, 3-22. Springer Japan.

Hocquette, J., D. Bauchart. 1999. Intestinal absorption, blood transport and hepatic and muscle metabolism of fatty acids in preruminants and ruminant animals. Reprod. Nutr. Dev. 39:27-48. 
Holcomb, C. S., H. H. Van Horn, H. H. Head, M. B. Hall, and C. J. Wilcox. 2001. Effects of prepartum dry matter intake and forage percentage on postpartum performance of lactating dairy cows. J. Dairy Sci. 84:2051-2058.

Holland, W. L. and S. A. Summers. 2008. Sphingolipids, insulin resistance, and metabolic disease: New insights from in vivo manipulation of sphingolipid metabolism. Endocr. Rev. 29:381-402.

Holland, W. L. and S. A. Summers. 2008. Sphingolipids, insulin resistance, and metabolic disease: New insights from in vivo manipulation of sphingolipid metabolism. Endocr. Rev. 29:381-402.

Holland, W. L., J. T. Brozinick, L. -P. Wang, E. D. Hawkins, K. M. Sargent, Y. L., K. Narra, K. L. Hoehn, T. A. Knotts, A. Siesky, and D. H. Nelson. 2007. Inhibition of ceramide synthesis ameliorates glucocorticoid-, saturated-fat-, and obesity-induced insulin resistance. Cell Metab. 5:167-179.

Holm, C. 2003. Molecular mechanisms regulating hormone-sensitive lipase and lipolysis. Biochem. Soc. Transact. 31:1120-1124.

Holtenius, K., S. Agenas, C. Delavaud, and Y. Chilliard. 2003. Effects of feeding intensity during the dry period. 2. Metabolic and hormonal responses. J. Dairy Sci. 86:883-891.

Holtenius, K., S. Agenäs, C. Delavaud, and Y. Chilliard. 2003. Effects of feeding intensity during the dry period. 2. metabolic and hormonal responses. J. Dairy Sci. 86:883-891. Holtenius, P., K. Holtenius. 2007. A model to estimate insulin sensitivity in dairy cow. Acta Vet. Scand. 49:29.

Hughes, J. P. 1962. A simplified instrument for obtaining liver biopsies in cattle. Am. J. Vet. Res. 23:1111-1113. 
Ingvartsen, K. L. 2006. Feeding- and management-related diseases in the transition cow: Physiological adaptations around calving and strategies to reduce feeding-related diseases. Anim. Feed Sci. and Tech. 126:175-213.

Ingvartsen, K. L., Dewhurst, R. J., Friggens, N. C., 2003. On the relationship between lactational performance and health: is it yield or metabolic imbalance that cause production diseases in dairy cattle? A position paper. Livestock Production Science 83, 277-308.

Janovick, N. A., Y. R. Boisclair, and J. K. Drackley. 2011. Prepartum dietary energy intake affects metabolism and health during the periparturient period in primiparous and multiparous Holstein cows. J. Dairy Sci. 94:1385-1400.

Karlsson, H. K. R., J. R. Zierath, S. Kane, A. Krook, G. E. Lienhard, and H. WallbergHenriksson. 2005. Insulin-stimulated phosphorylation of the Akt substrate AS160 is impaired in skeletal muscle of type 2 diabetes subjects. Diabetes 54:1692-1697.

Kasuga, M., Karlsson, F. A. and C. R. Kahn. 1982. Insulin stimulates the phosphorylation of the 95,000-dalton subunit of its own receptor. Science 215, 4529:185-187.

Kehoe, S. I., B. M. Jayarao, and A. J. Heinrichs. 2007. A survey of bovine colostrum composition and colostrum management practices on Pennsylvania dairy farms. J. Dairy Sci. 90:4108-4116.

Kerestes, M., V. F. Faigl, M. Kulcsára, O. Balogha, J. Földi, H. Fébelc, Y. Chilliardd, and G. Huszenicza. 2009. Periparturient insulin secretion and whole -body insulin responsiveness in dairy cows showing various forms of ketone pattern with or without puerperal metritis. Dom. Anim. Endocrin. 4:250-261. 
Kessler, E. C., J. J. Gross, R. M. Bruckmaier, and C. Albrecht. 2014. Cholesterol metabolism, transport, and hepatic regulation in dairy cows during transition and early lactation. J. Dairy Sci. 97:5481-5490.

Kim, J. K. 2009. Hyperinsulinemic-euglycemic clamp to assess insulin sensitivity in vivo. Methods Mol. Biol. 560:221-238.

Kitamura, T., Y. Kitamura, S. Kuroda, Y. Hino, M. Ando, K. Kotani, H. Konishi, H. Matsuzaki, U. Kikkawa, W. Ogawa, and M. Kasuga. 1999. Insulin-induced phosphorylation and activation of cyclic nucleotide phosphodiesterase 3B by the serine threonine kinase Akt. Mol. Cell. Biol. 19:6286-6296.

Kitatani, K., J. Idkowiak-Baldys, and Y. A. Hannun. 2008. The sphingolipid salvage pathway in ceramide metabolism and signaling. Cell. Signal. 20:1010-1018.

Kokkonen, T., J. Taponen, T. Anttila, L. Syrjälä-Qvist, C. Delavaud, Y. Chilliard, M. Tuori, and A. T. Tesfa. 2005. Effect of body batness and glucogenic supplement on lipid and protein mobilization and plasma leptin in dairy cows. J. Dairy Sci. 88:1127-1141.

Konishi, H., S. Kuroda, and U. Kikkawa. 1994. The pleckstriin homology domain of RAC protein kinase associates with the regulatory domain of protein kinase $\mathrm{C} \zeta$. Biochem. and Biophys. Res. Commun. 205:1770-1775.

L.R. McDowell, L. R. 2000. Vitamins in animal and human nutrition (2nd ed.) University Press, Ames, IA.

Lacetera, N., D. Scalia, U. Bernabucci, B. Ronchi, D. Pirazzi, and A. Nardone. 2005. Lymphocyte functions in overconditioned cows around parturition. J. Dairy Sci. 88:20102016. 
Lahiri, S. and A. H. Futerman. 2005. LASS5 is a bona fide dihydroceramide synthase that selectively utilizes palmitoyl-oA as acyl donor. J. Biol. Chem. 280:33735-33738.

Le Blanc, S.J., Leslie, K.E., Duffield, T.F., 2005a. Metabolic predictors of displaced abomasums in dairy cattle. Journal of Dairy Science 88, 159- 170.

Le Blanc, S.J., Lissemore, K.D., Kelton, D.F., Duffield, T.F., Leslie, K.E., 2005b. Major advances in disease prevention in dairy cattle. Journal of Dairy Science 89, 1267-1279.

Le Marchand-Brustel, Y., P. Gual, T. Gremeaux, T. Conzalez, R. Barrès, and J.-F. Tanti. 2003. Fatty acid-induced insulin resistance: role of insulin receptor substrate 1 serine phosphorylation in the retroregulation of insulin signalling. Biochem. Soc. Transact. 31:1152-1156.

Le Roith, D., C. Bondy, S. Yakar, J.-L. Liu, and A. Butler. 2001. The somatomedin hypothesis: 2001. Endocr. Rev 22:53-74.

Lean, I. J., M. L. Bruss, H. F. Troutt, J. C. Galland, T. B. Farver, J. Rostami, C. A. Holmberg, and L. D. Weaver. 1994. Bovine ketosis and somatotrophin: risk factors for ketosis and effects of ketosis on health and production. Res. Vet. Sci. 57:200-209.

Liefers, S. C., R. F. Veerkamp, M. F. W. te Pas, C. Delavaud, Y. Chilliard, and T. van der Lende. 2003. Leptin concentrations in relation to energy balance, milk yield, intake, liveweight, and estrus in dairy cows. J. Dairy Sci. 86:799-807.

Livingstone, C. and C. Mary. 2002. Sex steroids and insulin resistance. Clin. Sci. 102:151-166.

Locher, L. F., N. Meyer, E. -M. Weber, J. Rehage, U. Meyer, S. Dänicke, and K. Huber. 2011. Hormone-sensitive lipase protein expression and extent of phosphorylation in subcutaneous and retroperitoneal adipose tissues in the periparturient dairy cow. J. Dairy Sci. 94:4514-4523. 
Locher, L. F., N. Meyer, E.-M. Weber, J. Rehage, U. Meyer, S. Dänicke, and K. Huber. 2011. Hormone-sensitive lipase protein expression and extent of phosphorylation in subcutaneous and retroperitoneal adipose tissues in the periparturient dairy cow. J. Dairy Sci. 94:4514-4523.

Lomax, M. A. and G. D. Baird. 1983. Blood flow and nutrient exchange across the liver and gut of the dairy cow. Br. J. Nutr. 49:481-496.

Loor, J. J., R. E. Everts, M. Bionaz, H. M. Dann, D. E. Morin, R. Oliveira, S. L. Rodriguez-Zas, J. K. Drackley, and H. A. Lewin. 2007. Nutrition-induced ketosis alters metabolic and signaling gene networks in liver of periparturient dairy cows. Physiol. Genomics 32:105116.

Mallard, B. A., J. C. Dekkers, M. J. Ireland, K. E. Leslie, S. Sharif, C. Lacey Vankampen, L. Wagter, and B. N. Wilkie. 1998. Alteration in immune responsiveness during the peripartum period and its ramification on dairy cow and calf health. J. Dairy Sci. 81:585595

Manganiello, V. C., E. Degerman, M. Taira, T. Kono, P., Belfrage. 1996. Type III cyclic nucleotide phosphodiesterases and insulin action. Curr. Top. Cell. Regul. 34:63-100.

Mann, S., D. V. Nydam, A. Abuelo, F. L. Yepes, T. R. Overton, and J. J. Wakshlag. 2016. Insulin signaling, inflammation, and lipolysis in subcutaneous adipose tissue of transition dairy cows either overfed energy during the prepartum period or fed a controlled-energy diet. J. Dairy Sci. 99:6737-6752.

Mann, S., F. A. Leal Yepes, M. Duplessis, J. J. Wakshlag, T. R. Overton, B. P. Cummings, and D. V. Nydam. 2016. Dry period plane of energy: Effects on glucose tolerance in transition dairy cows. J. Dairy Sci. 99:701-717. 
Mann, S., F. A. Leal Yepes, T. R. Overton, J. J. Wakshlag, A. L. Lock, C. M. Ryan, D. V. Nydam. 2015. Dry period plane of energy: Effects on feed intake, energy balance, milk production, and composition in transition dairy cows. J. Dairy Sci. 98:3366-3382.

Mashek, D. G., and D. K. Beede. 2000. Peripartum responses of dairy cows to partial substitution of corn silage with corn grain in diets fed during the late dry period. J. Dairy Sci. 83:2310-2318.

Mashek, D. G., and D. K. Beede. 2001. Peripartum responses of dairy cows fed energy-dense diets for 3 or 6 weeks prepartum. J. Dairy Sci. 84:115-125.

Mathews, A. T., J. E. Rico, N. T. Sprenkle, A. L. Lock, and J. W. McFadden. 2016. Increasing palmitic acid intake enhances milk production and prevents glucose-stimulated fatty acid disappearance without modifying systemic glucose tolerance in mid-lactation dairy cows. J. Dairy Sci. 99:8802-8816.

Mathews, A. T., J. E. Rico, N. T. Sprenkle, A. L. Lock, and J. W. McFadden. 2016. Increasing palmitic acid intake enhances milk production and prevents glucose-stimulated fatty acid disappearance without modifying systemic glucose tolerance in mid-lactation dairy cows. J. Dairy Sci. 99:8802-8816.

Mattos, R., A. Guzeloglu, L. Badinga, C. R. Staples, and W. W. Thatcher. 2003. Polyunsaturated fatty acids and bovine interferon- $\tau$ modify phorbol ester-induced secretion of prostaglandin $\mathrm{F}_{2 a}$ and expression of prostaglandin endoperoxide synthase- 2 and phospholipase-A2 in bovine endometrial cells. Biol. Repro. 69:780-787.

Mattos, R., C. R. Staples, A. Arteche, M. C. Wiltbank, F. J. Diaz, T. C. Jenkins, and W. W. Thatcher. 2004. The effects of feeding fish oil on uterine secretion of $\mathrm{PGF}_{2 \alpha}$, milk 
composition, and metabolic status of periparturient Holstein cows. J. Dairy Sci. 87:921932.

Mattos, R., C. R. Staples, and W. W. Thatcher. 2000. Effects of dietary fatty acids on reproduction in ruminants. Rev. Repro. 5:38-45.

Mattos, R., C. R. Staples, J. Williams, A. Amorocho, M. A. McGuire, and W. W. Thatcher. 2002. Uterine, ovarian, and production responses of lactating dairy cows to increasing dietary concentrations of menhaden fish meal. J. Dairy Sci. 85:755-764.

McCarthy, S., D. P. Berry, P. Dillon, M. Rath, and B. Horan. 2007.Influence of Holstein-Friesian strain and feed system on bodyweight and body condition score lactation profiles. J. Dairy Sci. 90:1859-1869.

McNamara, J. P. 1991. Regulation of adipose tissue metabolism in support of lactation. J. Dairy Sci. 74:706-719.

Mcnamara, J. P. and J. K. Hillers. 1986. Adaptations in lipid metabolism of bovine adipose tissue in lactogenesis and lactation J. Lipid Res. 27:150-157.

Mei, J., L. S. Holst, T. R. Landström, C. Holm, D. Brindley, V. Manganiello, and E. Degerman. 2002. C2-ceramide influences the expression and insulin-mediated regulation of cyclic nucleotide phosphodiesterase 3B and lipolysis in 3T3-L1 adipocytes. Diabetes. 51:631637.

Meikle, P. J., G. Wong, C. K. Barlow, J. M. Weir, M. A. Greeve, G. L. MacIntosh, L. Almasy, A. G. Comuzzie, M. C. Mahaney, A. Kowalczyk, I. Haviv, N. Grantham, D. J. Magliano, J. B. M. Jowett, P. Zimmet, J. E. Curran, J. Blangero, and J. Shaw. 2013. Plasma lipid profiling shows similar associations with prediabetes and type 2 diabetes. 
Menaldino, D. S., A. Bushnev, A., Sun, D. C. Liotta, H., Symolon, K. Desai, D. L. Dillehay, Q. Peng, E. Wang, J. Allegood, S. Trotman-Pruett. 2003. Sphingoid bases and de novo ceramide synthesis: enzymes involved, pharmacology and mechanisms of action. Pharm. Res. 47:373-381.

Merrill, A. H. 2002. De novo sphingolipid biosynthesis: a necessary but dangerous pathway. J. Biol. Chem. 277:25843-25846.

Merrill, A. H. and E. Wang. 1986. Biosyntheiss of long-chain (sphingoid bases from serine by LM cells. Evidence for introduction of the 4-trans-double bond after de novo biosynthesis of N-acylshinganine(s). J. Biol. Chem. 261:3764-3769.

Minor, D. J., S. L. Trower, B. D. Strang, R. D. Shaver, and R. R. Grummer. 1998. Effects of nonfiber carbohydrate and niacin on periparturien metabolic status and lactation of dairy cows. J. Dairy Sci. 81:189-200.

Mizutani, Y., A. Kihara, A. Kihara, and Y. Igarashi. 2005. Mammalian Lass6 and its related family members regulate synthesis of specific ceramides. Biochem. J. 390:263-271.

Morrow, D. A. 1976. Fat cow syndrome. J. Dairy Sci. 59:1625-1629.

Mulligan, F. J., M. L. Doherty. 2008. Production diseases of the transition cow. Vet. J. 176:3-9.

Muniyappa, R., S. Lee, H. Chen, and M. J. Quon. 2007. Current approaches for assessing insulin sensitivity and resistance in vivo: advantages, limitations, and appropriate usage.

Myers Jr., M.G., J. M. Backer, X. J. Sun, S. Shoelson,, P. Hu, J. Schlessinger, M. Yoakim, B. Schaffhausen, and M.F. White. 1992. IRS-1 activates phosphatidylinositol 30 -kinase by associating with src homology 2 domains of p85. Proc. Natl. Acad. Sci. 89: 1035010354.

Nafikov, R. A. and D. C. Beitz. 2007. Carbohydrate and lipid metabolism in farm animals. J. Nutr. 137:702-705. 
National Research Council. 2001. Nutrient Requirements of Dairy Cattle, 7th rev. edn., National Academy of Sciences, Washington, DC.

Nilsson, Å. 1969. The presence of sphingomyelin- and ceramide-cleaving enzymes in the small intestinal tract. Biochim Biophys Acta. 176: 339-347.

Oikawa, S. and G. R. Oetzel. 2006. Decreased insulin response in dairy cows following a fourday fast to induce hepatic lipidosis. J. Dairy. Sci. 89:2999-3005.

Oltenacu, P.A. and D. M. Broom. 2010. The impact of genetic selection for increased milk yield on the welfare of dairy cows. Anim. Welfare. 19:39-49.

Ospina, P. A., D. V. Nydam, T. Stokol, and T. R. Overton. 2010. Evaluation of nonesterified fatty acids and beta-hydroxybutyrate in transition dairy cattle in the northeastern United States: critical thresholds for prediction of clinical diseases. J. Dairy Sci. 93:546-554.

Overton, T. R. and M. R. Waldron. 2004. Nutritional management of transition dairy cows: strategies to optimize metabolic health. J. Dairy Sci. 87(Suppl.):E105-E119.

Park., J. W., Y. Pewzner-Jung. 2013. Ceramide Synthases: Reexamining longevity. E. Gulbins, I. Petrache (Eds.), Sphingolipids: Basic science and drug development, 215, Springer, Vienna, Italy. 89-107.

Perry, D. K. 2002. Serine palmitoyltransferase: role in apoptotic de novo ceramide synthesis and other stress responses. Biochim. Biophys. Acta. 1585:146-152.

Petersen, K.F. and G.I. Shulman. 2006. Etiology of insulin resistance. Am. J. Med. 119: S10S16.

Petit, H. V., C. Germiquet, and D. Lebel. 2004. Effect of feeding whole, unprocessed sunflower seeds and flaxseed on milk production, milk composition, and prostaglandin secretion in dairy cows. J. Dairy Sci. 87:3889-3898. 
Piepenbrink, M. S., and T. R. Overton. 2003b. Interrelationships of hepatic palmitate and propionate metabolism, liver composition, blood metabolites, and cow performance. J. Dairy Sci. 86(Suppl. 1):148. (Abstr.)

Pires, J. A. and R. R. Grummer R. R. 2007b. The use of nicotinic acid to induce sustained low plasma nonesterified fatty acids in feed-restricted Holstein cows. J. Dairy Sci. 90:37253732.

Pires, J. A. and R. R. Grummer. 2007a. Induction of hyperlipidemia by intravenous infusion of tallow emulsion causes insulin resistance in Holstein cows. J. Dairy Sci. 90:2735-2744.

Pires, J. A., J. B. Pescara, and R. R. Grummer. 2007b. Reduction of plasma NEFA concentration by nicotinic acid enhances the response to insulin in feed-restricted Holstein cows. $\mathbf{J}$ Dairy Sci 90:4635-4642.

Pires, J. A., L. F. Stumpf, I. D. Soutullo, J. B. Pescara, S. E. Stocks, and R. R. Grummer. 2016. Effects of abomasal infusion of nicotinic acid on responses to glucose and $\beta$-agonist challenges in underfed lactating cows. J. Dairy Sci. 99:1-11.

Powell, D. J., E. Hajduch, G. Kular, and H. S. Hundal. 2003. Ceramide disables 3phosphoinositide binding to the pleckstrin omology domain of protein kinase $\mathrm{B}$ (PKB)/Akt by a PKCל-dependent mechanism. Mol. Cell. Biol. 23:7794-7808.

Preynat, A., H. Lapierre, M. C. Thivierge, M. F. Palin, N. Cardinault, J. J. Matte, A. Desrochers, C. L. Girard. 2010. Effects of supplementary folic acid and vitamin $B_{12}$ on hepatic metabolism of dairy cows according to methionine supply. J. Dairy Sci. 93:2130-2142.

Pullen, D. L., D. L. Palmquist, R. S. Emery. 1989. Effect on Days of Lactation and Methionine Hydroxy Analog on Incorporation of Plasma Fatty Acids into Plasma Triglycerides. J. Dairy Sci. 72:49-58. 
Pullen, D. L., J. S. Liesman, and R. S. Emery. 1990. A species comparison of liver slice synthesis and secretion of triacylglycerol from nonesterified fatty acids in media. J. Anim. Sci. 68:1395-1399.

Raichur, S., S. T. Wang, P. W. Chan, Y. Li, J. Ching, B. Chaurasia, S. Dogra, M. K. Öhman, K. Takeda, and S. Sugii. 2014. CerS2 haploinsufficiency inhibits $\beta$-oxidation and confers susceptibility to diet-induced steatohepatitis and insulin resistance. Cell Metab. 20:687695.

Reaven, G. M., C. Hollenbeck, C. -Y. Jeng, M. S. Wu, and Y. -D. I. Chen. 1988. Measurement of plasma glucose, free fatty acid, lactate, and insulin for $24 \mathrm{~h}$ in patients with NIDDM. Diabetes. 37:1020-1024.

Reynolds, C. K., P. C. Aikman, B. Lupoli, D. J. Humphries, and D. E. Beever. 2003. Splanchnic metabolism of dairy cows during the transition from late gestation through early lactation. J. Dairy Sci. 86:1201-1217.

Reynolds, C. P., B. J. Maurer, and R. N. Kolesnick. 2004. Ceramide synthesis and metabolism as a target for cancer therapy. Cancer Letters 206:169-180.

Riboni, L., P. Viani, R. Bassi, A., Prinetti, and G. Tettamanti. 1997. The role of sphingolipids in the process of signal transduction. Prog. Lipid Res. 36:153-195.

Rico, J. E., A. T. Mathews, J. Lovett, N. J. Haughey, J. W. McFadden. 2016. Palmitic acid feeding increases ceramide supply in association with increased milk yield, circulating nonesterified fatty acids, and adipose tissue responsiveness to a glucose challenge. J. Dairy Sci. 99:8817-8830.

Rico, J. E., V. V. Bandaru, J. M. Dorskind, N. J. Haughey, and J. W. McFadden. 2015. Plasma ceramides are elevated in overweight Holstein dairy cows experiencing greater lipolysis 
and insulin resistance during the transition from late pregnancy to early lactation. $\mathrm{J}$. Dairy. Sci. 98:1-14.

Roche, J. R. and D. P. Berry. 2006. Periparturient climatic, animal, and management factors influencing the incidence of milk fever in grazing systems. J. Dairy Sci., 89:2775-2783

Roche, J. R., D. P. Berry, and E. S. Kolver. 2006. Holstein-Friesian strain and feed effects on milk production, body weight, and body condition score profiles in grazing dairy cows. J. Dairy Sci. 89:3532-3543.

Roche, J. R., D. P. Berry, J. M. Lee, K. A. Macdonald, and R. C. Boston. 2007. Describing the body condition score change between successive calvings: A novel strategy generalizable to diverse cohorts. J. Dairy Sci. 90:4378-4396

Roche, J. R., J. K. Kay, N. C. Friggens, J. J. Loor, and D. P. Berry. 2013. Assessing and managing body condition score for the prevention of metabolic disease in dairy cows. Vet. Clin. North. Am. Food Anim. Pract. 29:323-336.

Roche, J. R., N. C. Friggens, J. K. Kay, M. W. Fisher, K. J. Stafford, and D. P. Berry. 2009. Body condition score and its association with dairy cow productivity, health, and welfare. J. Dairy Sci. 92:5769-5801.

Rother, J., G. V. Echten, G., Schwarz, and K., Sandoff. 1992. Biosynthesis of sphingolipids: Dihydroceramide and not sphinganine is desaturated by cultured cells. Biochem. and Biophys. Res. Comm. 189:14-20.

Rukkwamsuk, T., M. J. H. Geelen, T. A. M. Kruip, and T. Wensing. 2000. Interrelation of fatty acid composition in adipose tissue, serum, and liver of dairy cows during the development of fatty liver postpartum. J. Dairy Sci. 83:52-59. 
Rukkwamsuk, T., T. Wensing, and T. A. Kruip. 1999. Relationship between triacylglycerol concentration in the liver and first ovulation in postpartum dairy cows. Theriogenology 51:1133-1142.

Saltiel, A.R., and C.R. Kahn. 2001. Insulin signalling and the regulation of glucose and lipid metabolism. Nature 414:799-806.

Samii, S. S., J. E. Rico, A. T. Mathews, C. L. Orndorff, A. N. Davis, and J. W. McFadden. 2015. Comparison of the RQUICKI estimate of insulin sensitivity with glucose and insulin tolerance in periparturient dairy cows. J. Dairy Sci. 98(E-Suppl. 2):144.

Santos, J. E. P., T. R. Bilby, W. W. Thatcher, C. R. Staples, and F. T. Silvestre. 2008. Long chain fatty acids of diet as factors influencing reproduction in cattle. Repro. Domestic Anim. 43:23-30.

Sävendahl L. and L. E. Underwood. 1999. Fasting increases serum total cholesterol, LDL cholesterol and apolipoprotein B in healthy, nonobese humans. J. Nutr. 129:2005-2008.

Schoenberg, K. M., R. M. Ehrhardt, and T. R. Overton. 2012. Effects of plane of nutrition and feed deprivation on insulin responses in dairy cattle during late gestation. J. Dairy. Sci 95:670-682.

Schoenberg, K. M., R. M. Ehrhardt, and T. R. Overton. 2012. Effects of plane of nutrition and feed deprivation on insulin responses in dairy cattle during late gestation. J. Dairy Sci. 95.2: 670-682.

Seal, C. J., and C. K. Reynolds. 1993. Nutritional implications of gastrointestinal and liver metabolism in ruminants. Nutr. Res. Rev. 6:185-208.

Shaw, L.M. 2011. The insulin receptor substrate (IRS) proteins: At the intersection of metabolism and cancer. Cell Cycle 10: 1750-1756. 
Silva-del- Río, N., P. M. Fricke, and R. R. Grummer. 2010. Effects of twin pregnancy and dry period feeding strategy on milk production, energy balance, and metabolic profiles in dairy cows. Am. Soc. Anim. Sci. 88:1048-1060.

Silvestre, F. T., T. S. M. Carvalho, N. Francisco, J. E. P. Santos, C. R. Staples, T. C. Jenkins, and W. W. Thatcher. 2011. Effects of differential supplementation of fatty acids during the peripartum and breeding periods of Holstein cows: I. Uterine and metabolic responses, reproduction, and lactation. J. Dairy Sci. 94:189-204.

Smith, K. L., M. R. Waldron, J. K. Drackley, M. T. Socha, and T. R. Overton. 2005. Performance of dairy cows as affected by preparum dietary carbohydrate source and supplementation with chromium throughout the transition period. J. Dairy Sci. 88:255263.

Smith, K. L., M. R. Waldron, L. C. Ruzzi, J. K. Drackley, M. T. Socha, and T. R. Overton. 2008. Metabolism of dairy cows as affected by prepartum dietar carbphydrate source and supplementation with chromium throughout the periparturient period. J. Dairy Sci. 91:2011-2020.

Stratford, S., K. L. Hoehn, F. Liu, and S. A. Summers. 2004. Regulation of insulin action by ceramide. J. Biol. Chem. 279:36608-36615.

Summers, S. A. 2006. Ceramides in insulin resistance and lipotoxicity. Prog. Lipid Res. 45:4272.

Summers, S. A., L. A. Garza, H. L. Zhou, and M. J. Birnbaum. 1998. Regulation of insulinstimulated glucose transporter GLUT4 translocation and Akt kinase activity by ceramide. Mol. Cell. Biol. 18:5457-5464. 
Sumner, J. M. and J. P. McNamara. 2007. Expression of lipolytic genes in the adipose tissue of pregnant and lactating Holstein dairy cattle. J. Dairy Sci. 90:5237-5246.

Sun, X. J., D. L. Crimmins, M. G. Myers Jr., M. Miralpeix, and M. F. White. 1993. Pleiotropic insulin signals are engaged by multisite phosphorylation of IRS-1. Mol. Cell. Biol. 13: $7418-7428$.

Tanno O, Y. Ota, N. Kitamura, T. Katsube, and S. Inoue. 2000. Nicotinamide increases biosynthesis of ceramides as well as other stratum corneum lipids to improve the epidermal permeability barrier. Br. J. Dermatol. 143:524-531.

Taylor, V. J., Z. Cheng, P. G. A. Pushpakumara, D. E. Beever, and D. C. Wathes. 2004. Relationships between the plasma concentrations of insulin-like growth factor-I in dairy cows and their fertility and milk yield. Vet. Rec. 155:583-588.

Tettamanti, G. 2003. Ganglioside/glycosphingolipid turnover: New concepts. Glycoconj. J. 20:301-317.

Thévenod, F. 2008. Pathophysiology of diabetes mellitus type 2: Roles of obesity, insulin resistance and $\beta$-Cell dysfunction. Diabetes and Cancer. 19:1-18.

Thissen, J. P., J. M. Ketelslegers, and L. E. Underwood. 1994. Nutritional regulation of the insulin-like growth factors. Endocr. Rev. 15:80-101.

Treacher, R. J., I. M. Reid, and C. J. Roberts. 1986. Effect of body condition at calving on the health and performance of dairy cows. Anim. Prod. 43:1-6.

Turpin, S. M., H. T. Nicholls, D. M. Willmes, A. Mourier, S. Brodesser, C. M. Wunderlich, J. Mauer, E. Xu, and P. Hammerschmidt. 2014. Obesity-induced CerS6-dependent C16:0 ceramide production promotes weight gain and glucose intolerance. Cell Metab. 20:678686. 
Tzivion, G., M. Dobson, G. Ramakrishnan. 2011. FoxO transcription factors; Regulation by AKT and 14-3-3 proteins. Biochim. Biophys. Acta. 1813:1938-1945.

Virkamäki, Antii, K. Ueki, and C. R. Kahn. 1999. Protein-protein interaction in insulin signaling and the molecular mechanisms of insulin resistance. J. Clin. Invest. 103:931-943.

Wadsworth J. M., D. J. Clarke, S. A. McMahon, J. P. Lowther, A. E. Beattie, P. R. R. LangridgeSmith, H. B. Broughton, T. M. Dunn, J. H. Naismith, and D. J. Campopiano. 2013. The chemical basis of serine palmitoyltransferase inhibition by myriocin. J. Am. Chem. Soc. $135: 14276-14285$.

Ward, C. W., and M. C. Lawrence. 2009. Ligand-induced activation of the insulin receptor: a multi-step process involving structural changes in both the ligand and the receptor. Bioessays. 4:422-34.

Wathes, D. C., M. Fenwick, Z. Cheng, N. Bourne, S. Llewellyn, D. G. Morris, D. Kenny, J. Murphy, and R. Fitzpatrick. 2007. Influence of negative energy balance on cyclicity and fertility in the high producing dairy cow. Intl. Conf. on Farm Anim. Repro. 68:S232S241.

Watt, M. J., A. C. Barnett, C. R. Bruce, S. Schenk, J. F. Horowitz, and A. J. Hoy. 2012. Regulation of plasma ceramide levels with fatty acid oversupply: evidence that the liver detects and secretes de novo synthesised ceramide. Diabetologia. 55:2741-2746.

Wildman, E. E., G. M. Jones, P. E. Wagner, and R. L. Bowman. 1982. A dairy cow body condition scoring system and its relationship to selected production characteristics. J Dairy Sci 65:495-501. 
Wilson, L. A., M. C. Barber, M. T. Travers, J. Soar, P. J. Buttery, and R. G. Vernon. 1996. Effect of plane of nutrition and growth hormone treatment on insulin receptor gene expression and kinase activity of sheep muscle and adipose tissue. Biochem. Soc. Transact. 24:222S.

Wu, B. X., V., Rajagopalan, P. L. Roddy, C. J. Clarke, and Y. A. Hannun. 2010. Identification and characterization of murine mitochondria-associated neutral sphingomyelinase (MAnSMase), the mammalian sphingomyelin phosphodiesterase 5. J. Biol. Chem. 285:1799318002.

Xia J. Y., W. L. Holland, C. M. Kusminski, K. Sun, A. X. Sharma, M. J. Pearson, A. J. Sifuented, J. G. McDonald, R. Grodillo, and P. E. Scherer. 2015. Targeted induction of ceramide degradation leads to improved systemic metabolism and improved hepatic steatosis. Cell Metab. 22:266-278.

Zachut, M., H. Honig, S. Striem, Y. Zick, S. Boura-Halfon, and U. Moallem. 2013. Periparturient dairy cows do not exhibit hepatic insulin resistance, yet adipose-specific insulin resistance occurs in cows prone to high weight loss. J. Dairy Sci. 96:5656-5669.

Zhao, F. Q. and A. F. Keating. 2007. Expression and regulation of glucose transporters in the bovine mammary gland. J Dairy Sci 90(Suppl 1):E76-86.

Zhao, F. Q., W. M. Moseley, H. A. Tucker, and J. J. Kennelly. 1996. Regulation of glucose transporter gene expression in mammary gland, muscle, and fat of lactating cows by administration of bovine growth hormone and bovine growth hormone-releasing factor. J. Anim. Sci. 74:183-189. 